\author{
WALDEN \\ UNIVERSITY \\ A higher degree. A higher purpose.
}

Walden University ScholarWorks

Walden Dissertations and Doctoral Studies

2016

\title{
Oral Nutritional Supplement Use in Relation to Length of Stay in Heart Failure Patients at a Regional Medical Center
}

Ellen Burkhardt Babb

Walden University

Follow this and additional works at: https://scholarworks.waldenu.edu/dissertations

Part of the Health and Medical Administration Commons, and the Human and Clinical Nutrition Commons

This Dissertation is brought to you for free and open access by the Walden Dissertations and Doctoral Studies Collection at ScholarWorks. It has been accepted for inclusion in Walden Dissertations and Doctoral Studies by an authorized administrator of ScholarWorks. For more information, please contact ScholarWorks@waldenu.edu. 


\title{
Walden University
}

\author{
College of Health Sciences
}

This is to certify that the doctoral dissertation by

\section{Ellen Babb}

has been found to be complete and satisfactory in all respects, and that any and all revisions required by the review committee have been made.

\section{Review Committee}

Dr. James Rohrer, Committee Chairperson, Public Health Faculty

Dr. Roland Thorpe, Committee Member, Public Health Faculty Dr. Loretta Cain, University Reviewer, Public Health Faculty

Chief Academic Officer

Eric Riedel, Ph.D.

Walden University

2016 


\begin{abstract}
Oral Nutritional Supplement Use in Relation to Length of Stay

in Heart Failure Patients at a Regional Medical Center
\end{abstract}

by

Ellen Burkhardt Babb

MPH, University of Michigan

BS, College of William and Mary

Proposal Submitted in Partial Fulfillment

of the Requirements for the Degree of

Doctor of Philosophy

Public Health

Walden University

February, 2016 


\begin{abstract}
Improving the nutritional status of hospitalized patients has been shown to reduce length of stay (LOS), hospital costs, readmission rates, complication rates, and mortality. Provision of nutrient-rich, liquid, oral nutrition supplements (ONS) is one approach to improving nutritional status. ONS use has been associated with improved outcomes among patients with diagnoses of orthopedic injuries and pressure ulcers, mainly using prospective designs among elderly and/or malnourished patients. Less information is available for other diagnoses, and no analysis of the effects of ONS could be found that considered the epidemiological triad of person, place, and time. This study used a quantitative, retrospective design to examine whether routine ONS use was associated with hospital length of stay (LOS) among 570 adult inpatients at a regional medical center diagnosed with heart failure, adjusting for significant personal, locational, and time variables. It was unique in the inclusion of epidemiological triad variables. Using multiple logistic regression to control for covariates, ONS use was associated with higher LOS in this sample (odds ratio=2.43). High LOS was also associated with higher Charlson Comorbidity Index (CCI) values, discharge destination, White ethnicity, female gender, and hospital room location. This study is expected to contribute to positive social change by helping inform hospital staff on factors affecting patient outcomes and LOS, and highlighting the need for continued research on interventions to improve care in hospitals.
\end{abstract}


Oral Nutritional Supplement Use in Relation to Length of Stay

in Heart Failure Patients at a Regional Medical Center

by

Ellen Burkhardt Babb

MPH, University of Michigan

BS, College of William and Mary

Proposal Submitted in Partial Fulfillment

of the Requirements for the Degree of

Doctor of Philosophy

Public Health

Walden University

February 2016 


\section{Dedication}

This dissertation is dedicated to my husband, Jon Babb, for putting up with my busy schedule and taking on extra work around the house while I was so busy with schoolwork; and my sister, Elizabeth Burkhardt, for her support and encouragement throughout this long process. 


\section{Acknowledgments}

I must first acknowledge my doctoral committee chair, James Rohrer for all his guidance, help, encouragement, and quick responses to my numerous questions and concerns. Thank you, Dr. Rohrer, for being exceptionally helpful and available to respond to my queries and review my work with quick turnarounds throughout the whole process. Thank you also to Dr. Roland Thorpe for serving on my committee and reviewing my dissertation documents through the various stages.

I would also like to extend a special thank you to Joan Coleman for helping me with information on the hospital population; to Jennifer Plassmeyer for giving me the idea for the study and for information on hospital supplement use; to Tony Derrick for helping me get the whole thing started, and to Shari Donley, Rekha Rawalpally, and Amanda Butler for their assistance in providing needed information and special assistance for this project. I especially appreciate the numerous hours Rekha put in to help me get the information I needed. 


\section{Table of Contents}

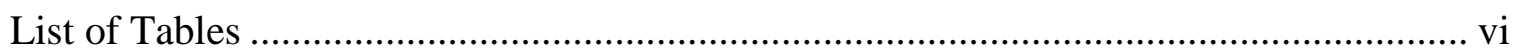

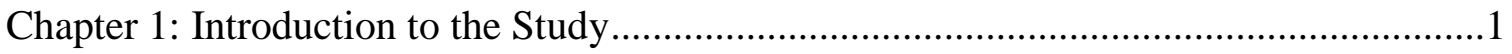

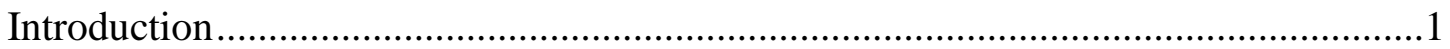

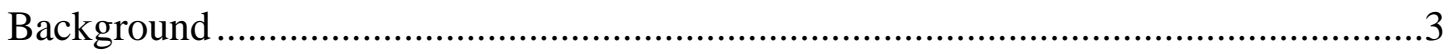

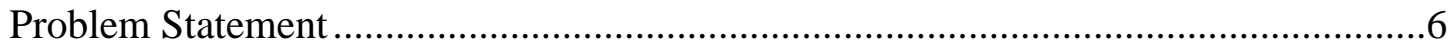

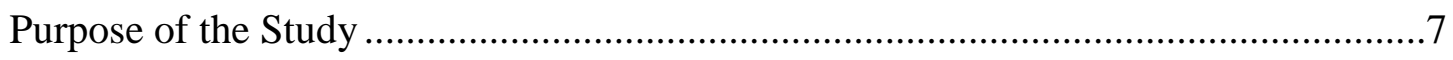

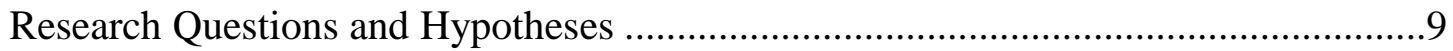

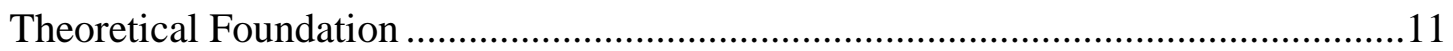

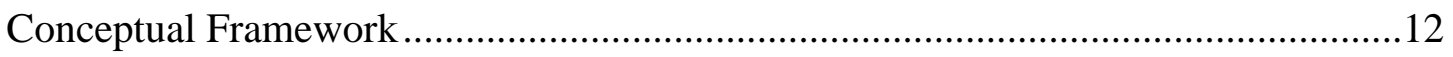

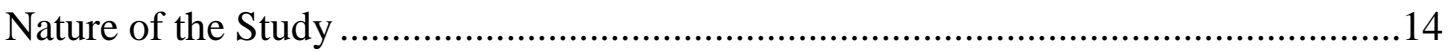

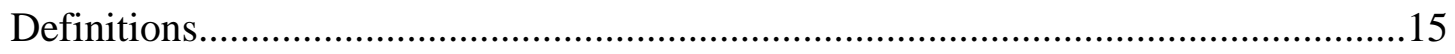

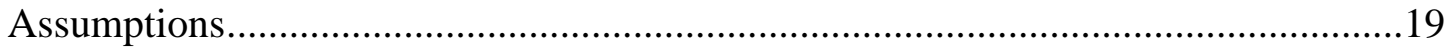

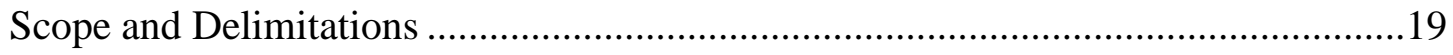

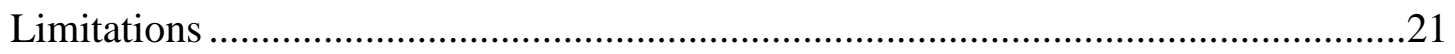

Design and/or Methodological Weaknesses .................................................. 22

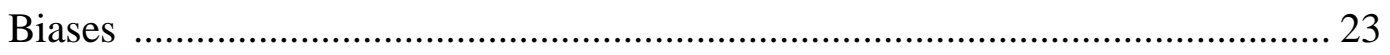


Significance

Summary

Chapter 2: Literature Review .26

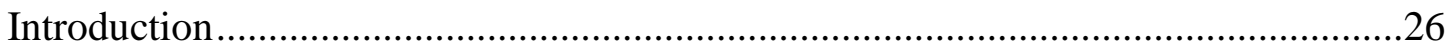

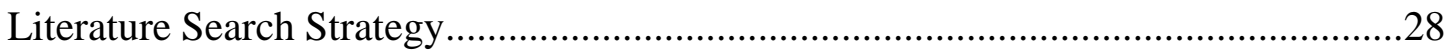

Theoretical Foundation: The Epidemiological Triad..................................................29

Applications of this Model in Ways Similar to this Study ................................... 30

Rationale for Choice of this Theory ................................................................... 31

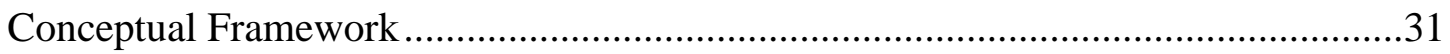

Literature Review Related to Key Variables and Concepts...........................................33

Review of Studies Related to Key Concept: Malnutrition...................................... 33

Review of Studies Related to Key Variables....................................................... 36

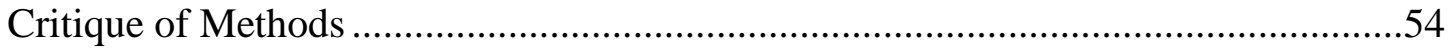

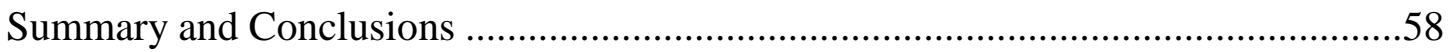

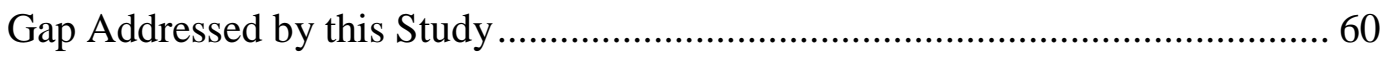

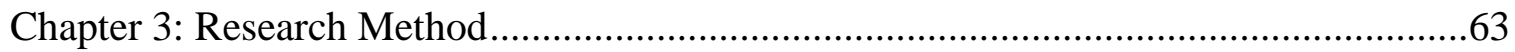

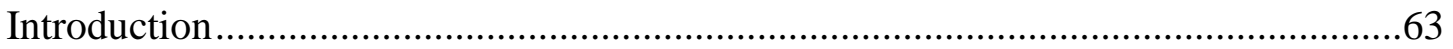




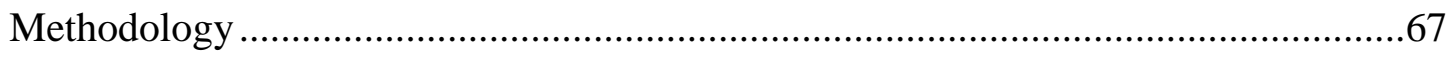

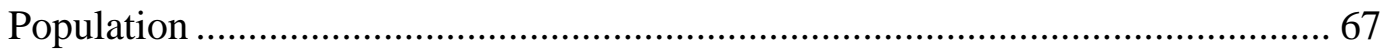

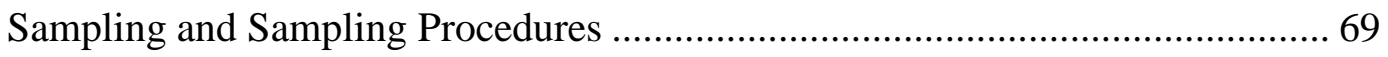

Procedures for Data Collection .............................................................. 72

Instrumentation and Operationalization of Constructs ..................................... 74

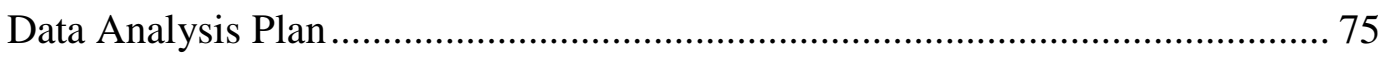

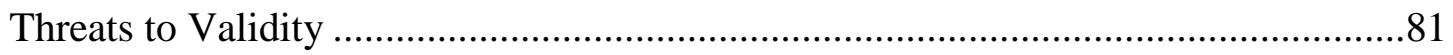

Threats to External Validity .................................................................. 81

Threats to Internal Validity ................................................................. 82

Threats to Construct or Statistical Conclusion Validity …............................... 82

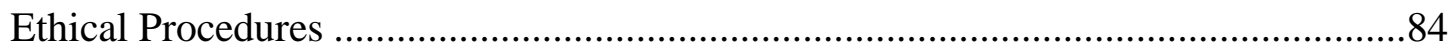

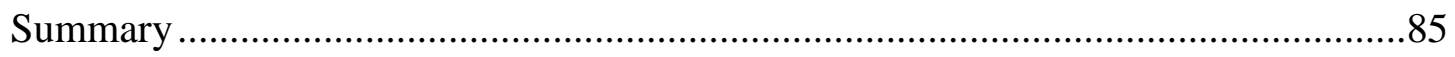

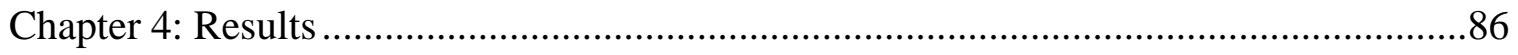

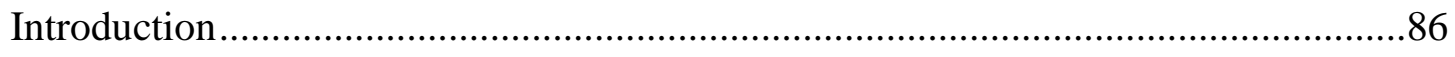

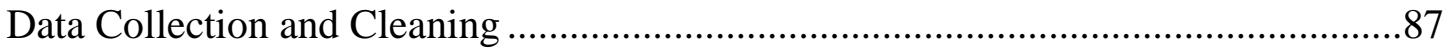

Selection of ONS Cases ........................................................................ 88 


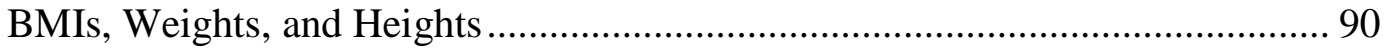

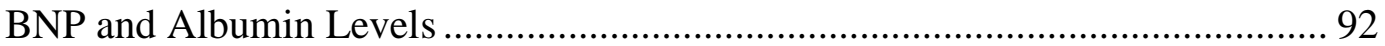

Patient Location in Hospital.......................................................................... 92

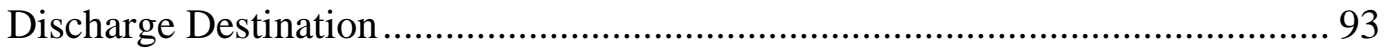

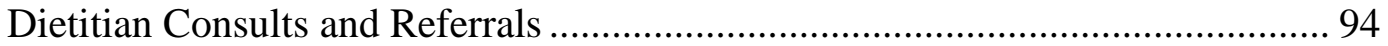

Diagnosis of Malnutrition ....................................................................... 94

Charlson Comorbidity Index (CCI) Scoring ..................................................... 95

Data Accuracy for Spreadsheet Entries ...................................................... 95

Initial Data Review: Variable Inclusions and Exclusions.................................. 96

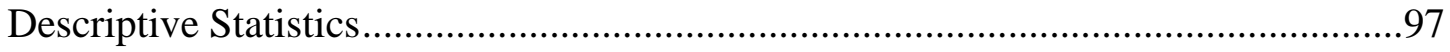

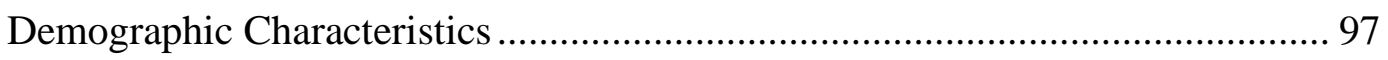

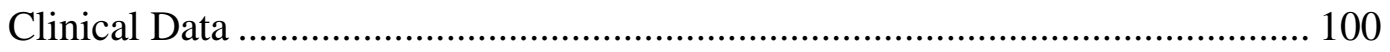

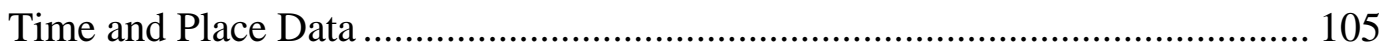

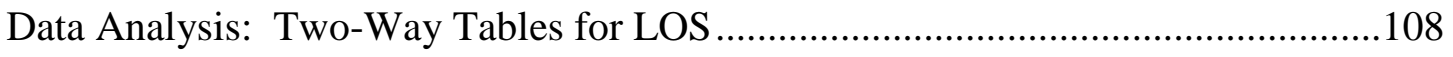

Demographic Characteristics and LOS ..................................................... 108

Clinical Information and LOS ............................................................ 110 
Summary of Two-Way Table Results for LOS .............................................. 114

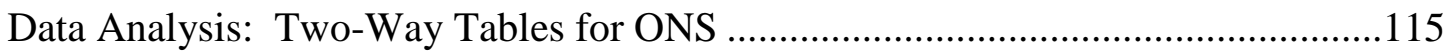

Data Analysis: Logistic Regression Results .........................................................121

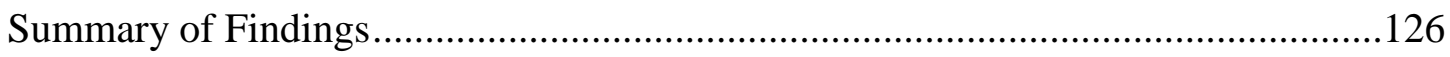

Chapter 5: Discussion, Conclusions, and Recommendations ...........................................128

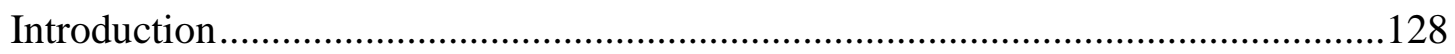

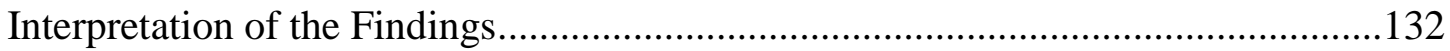

Limitations of the Study ...................................................................................135

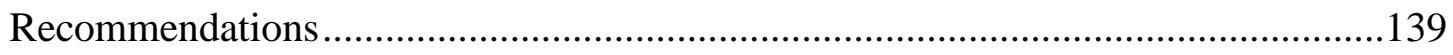

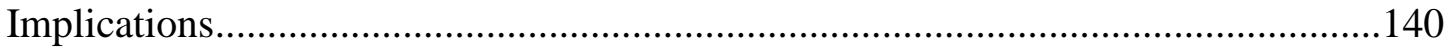

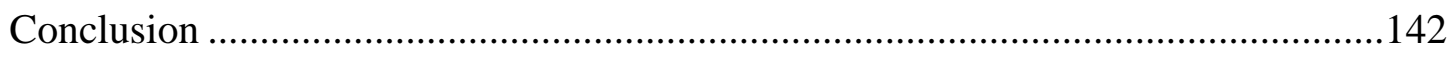

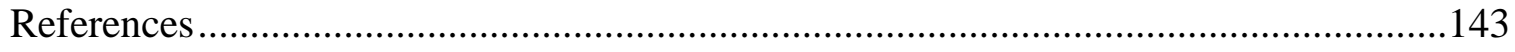




\section{List of Tables}

Table 1 Summary of the Literature on Nutrition Interventions, ONS Use, Malnutrition,

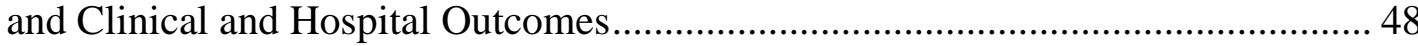

Table 2 Estimated Available ONS Cases and Comparison (July 2012 - December 2014)

Table 3 Demographic Characteristics on Admission 99

Table 4 Descriptive Statistics - Clinical Information ............................................... 104

Table 5 Descriptive Statistics - Time and Place Variables ......................................... 107

Table 6 Two-Way Table Results - High LOS and Demographic Information .............. 109

Table 7 Two-Way Table Results for High LOS -- Clinical Information........................ 111

Table 8 Two-Way Table Results for High LOS -- Time and Place Information ........... 114

Table 9 Two-Way Table Results for ONS- Demographic Information........................ 117

Table 10 Two-Way Table Results for ONS - Clinical Information ............................ 118

Table 11 Two-Way Table Results for ONS - Time and Place Information.................. 120

Table 12 Results of Multiple Logistic Regression for High LOS Outcome.................. 124 


\section{Chapter 1: Introduction to the Study}

\section{Introduction}

Nutrition intervention in acute care hospitals has been shown to be associated with improved medical status and outcomes for patients, leading to reduced length of stay (LOS) and reduced readmission rates in hospitals (Gariballa S, Forster S, Walters S, Powers, 2007; Hoekstra, Goosen, de Wolf, \& Verheyen, 2011; Lawson, Dishi, Barton, \& Cobden, 2003; Somanchi, Tao, \& Mullin, 2011). Nutrition intervention often includes consultation of registered dietitians (RDs), who determine best approaches to address patients' nutritional problems. One common approach used by dietitians and medical providers is commercial, nutrient-rich, liquid ONS. Improved outcomes among patients receiving ONS have previously been demonstrated among patients with orthopedic injuries or pressure ulcers (Botella-Carretero et al., 2008, 2010; Bourdel-Marchasson et al., 2000; Lawson et al., 2003; Miller, Crotty, Whitehead, Bannerman, \& Daniels, 2006). Much of the evidence for improved outcomes has involved elderly patients (ArnaudBattandier et al., 2004; Bourdel-Marchasson et al., 2000; Gariballa et al., 2007; Hoekstra et al., 2011; Neelemaat, Bosmans, Thijs, Seidell, \& van Bokhorst-de van der Schueren, 2012) or elderly malnourished patients (Arnaud-Battandier et al., 2004; Neelemaat et al., 2012). 
This study examined patient and hospital outcomes among patients aged 18 and over receiving ONS compared to patients not receiving this intervention at a regional medical center in the southeastern United States. The study was limited to patients with a diagnosis of heart failure (HF). I originally planned to examine one hospital outcome (LOS) and two patient outcomes (changes in albumin levels and weight changes). In the final analysis, I was only able to examine the LOS outcome. While investigating outcomes, I controlled for and evaluated the confounding effects of body mass index (BMI), age, gender, initial albumin levels, B-type natriuretic peptide (BNP) levels, Charlson Comorbidity Index (CCI), diagnosis of malnutrition, location in the hospital, and time of year of admission.

This study has the potential to promote positive social change by examining aspects of patient care in hospitals that can improve patient health and quality of life, while evaluating potentially more efficient ways to use patient, hospital, and community resources. Use of ONS and other nutrition interventions, such as dietitian consultations, have been shown in other studies to improve the healing process, prevent complications, and reduce the time patients spend in the hospital. This study helps clarify the role of ONS use and RD consultations in normal hospital care, and how these are related to LOS. Shortened LOS can benefit patients, their families, and hospitals. It can reduce costs of hospital care. 
This chapter includes an overview of the study topic, background of the study, and a summary of the relevant literature. A more detailed literature review is presented in Chapter 2. The research problem, independent and dependent variables, research questions, and hypotheses are reviewed. In addition, the theoretical foundation and conceptual framework are introduced, with a more detailed description in Chapter 2. Definitions of key variables are provided, followed by a discussion of the assumptions, scope, limitations, delimitations, and significance of the problem.

\section{Background}

Malnutrition among hospitalized patients has been shown to adversely affect individual health outcomes and has been associated with increased hospital LOS and readmissions (Correia \& Waitzberg, 2003; Lim et al., 2012; Agarwal et al., 2013). It has been estimated that malnutrition in acute care hospital patients affects from $30-55 \%$ of hospital patients worldwide (Agarwal et al., 2012; Barker, Gout, \& Crowe, 2011; Somanchi et al, 2011), with some studies finding malnutrition rates of up to $69 \%$ in hospitals (Singh, Watt, Veitch, Cantor, \& Duerksen, 2006; Young, Kidston, Banks, Mudge, \& Isenring, 2013). Research has demonstrated that the prevention and treatment of malnutrition in hospital patients reduces cost of care, LOS, readmission rates, mortality, and complication rates among patients (Correia \& Waitzberg, 2003; Somanchi et al., 2011; Rasheed \& Woods, 2013, Tappenden et al., 2013). Aziz et al. (2011) found a 
significant association between LOS and lower nutrition risk scores among HF patients, using a risk score derived from albumin levels and weight changes.

Several types of interventions have been demonstrated to improve the nutritional or clinical status of patients, or to reduce rates of malnutrition in hospitals. One approach that has shown success in improving clinical outcomes is nutrition intervention by clinical nutrition staff (Hoekstra et al., 2011; Neelemaat et al., 2012; Somanchi et al., 2011). Another approach, often combined with clinical staff intervention, is the provision of nutrient-rich ONS).

A number of researchers in recent years have looked at the use of ONS to improve nutrition-related outcomes in a variety of settings. Arnaud-Battandier et al. (2003) found that ONS improved the nutritional status of elderly patients in a community setting, leading to reduced health care costs. Significantly reduced costs for additional treatments were demonstrated through administration of ONS to all postoperative orthopedic patients in another study (Lawson et al., 2003). Miller et al. (2006) found that ONS appeared to be beneficial in preventing weight loss following lower limb fractures; Botella-Carretero et al. (2010) found improved postoperative recovery and smaller drops in serum albumin among hip fracture patients receiving supplements, and Lawson et al. (2003) found fewer complications among orthopedic patients using supplements compared to a control group. Bourdel-Marchasson et al. (2000) found lower risk of pressure ulcer development among patients using ONS. Gariballa, Forster, Walters, and 
Powers (2006) showed shorter LOS among elderly hospitalized patients receiving ONS, as well as lower risk of mortality and hospital readmission, and improved nutritional status. Neelemaat et al. (2012) showed smaller decreases in functional limitations of hospitalized patients getting ONS. Stratton and Elia (2007) performed a meta-analysis to demonstrate consistent clinical benefits - such as improved nutritional status and reductions in complications - associated with the use of ONS in hospital and community settings.

With recent changes in the American health care system and the Affordable Care Act, hospitals are increasingly seeking ways to reduce health care costs. Hospitals also continue to strive to improve patient clinical outcomes. Nutrition interventions have been shown to reduce health care costs by improving clinical outcomes, complications, and LOS; however, there are few studies on clinical interventions and ONS use in relation to LOS and clinical outcomes. Among the studies of benefits of ONS, only one of the above studies involved the effect of ONS on hospital LOS (Gariballa et al., 2006); and only one involved clinical nutrition staff interventions in relation to LOS (Somanchi et al., 2011). In addition, none of the reviewed studies evaluated the variables in terms of the epidemiological triad of person, place, and time - factors that could shed further light on how to maximize any benefits of ONS and other nutrition interventions. Therefore, more research is needed on whether ONS use and/or clinical nutrition interventions are related 
to clinical and hospital outcomes, and whether there are personal factors, timing issues, or location factors that influence these relationships.

\section{Problem Statement}

While there is abundant evidence that malnutrition, inadequate nutrition, or poor nutritional status, have adverse consequences for hospitalized patients, less is known about best strategies to improve nutritional status and outcomes for patients. In addition, because hospitals have only a limited time period in which to address poor nutrition among inpatients, there is a need for quick and efficient interventions.

Nutrition intervention by clinical staff has been shown in two studies to be an effective approach to reduce malnutrition rates and improve patient and hospital outcomes (Somanchi et al., 2011; Hoekstra, et al., 2011). Liquid ONS that contain significant amounts of kilocalories (kcal), protein, and multiple nutrients, are often provided as one component of such nutrition interventions because they are a simple and efficient intervention to address the problem of inadequate intake and its adverse outcomes.

The most available evidence in recent years showing improved outcomes related to ONS use is among selected populations. This includes elderly patients (ArnaudBattandier et al., 2004; Botella-Carretero et al., 2010; Bourdel-Marchasson et al., 2000; Neelemaat et al., 2012), orthopedic patients (Lawson et al., 2003) — especially those with hip fractures (Botella-Carretero et al., 2010; Hoekstra et al., 2011), and pressure ulcers 
(Houwing, 2003). Evidence is limited, however, for other specific diagnostic categories, such as acute myocardial infarction (AMI), heart failure (HF), chronic obstructive pulmonary disease (COPD), and pneumonia. There is also evidence that interventions are more pronounced among patients with poor nutritional status, as indicated by selected nutritional indicators or tools (Philipson, Snider, Lakdawalla, Stryckman, \& Goldman, 2013; Somanchi et al., 2011). Therefore, additional studies are needed to evaluate the relationship between ONS use, patient and hospital outcomes, and factors that may be influencing this relationship in hospitalized patients with HF.

\section{Purpose of the Study}

This study was intended to provide further insight into whether intervention with ONS is related to improved outcomes in hospitalized patients with HF. Only one dependent variable could ultimately be analyzed — LOS. Quantitative statistical analysis was used to compare this outcome for patients who received ONS during the hospital stay compared to patients who did not receive supplements, while controlling for and evaluating effects of covariates known to affect nutritional status and LOS.

A manufacturer of a common ONS in the United States has recommended routine ONS use for patients who meet certain criteria in hospitals, citing evidence that the use of ONS in hospitals may be an effective and efficient way to improve patient and hospital outcomes, reduce hospital LOS, and reduce readmission rates (Alliance to Advance Patient Nutrition, 2013; Abbott Laboratories, 2014). One major study cited by the ONS 
manufacturer was a large 10-year retrospective study on ONS use and hospital outcomes using data from the Premier Perspectives Database, in which the authors looked at hospital outcomes in relation to 724,027 episodes of ONS use in the database of 44.0 million inpatient episodes (Philipson et al., 2013). This study was limited by the fact that it was an administrative database; therefore, clinical data were unavailable. Gariballa et al. (2006) found shorter LOS—9.4 versus 10.1 days, among acutely ill elderly patients who received ONS compared to those who did not receive supplements. In another clinical study, routine ONS provision for post-operative orthopedic patients was found to be associated with a significantly lower rate of major complications, transferrin levels, hemoglobin levels, and cost of additional treatments (Lawson et al., 2003).

My study is unique in its focus on the effectiveness of nutrition intervention using ONS in a setting within the southeastern United States, with LOS, albumin, and weight change as outcomes and/or indicators of clinical status. It focused on patients with HF, a diagnosis that has not been adequately addressed in ONS intervention trials. The retrospective quantitative design allowed for evaluation of the effectiveness of ONS use in a setting that reflects day-to-day operations of an acute care hospital. The epidemiological design included an examination of personal characteristics, location in the hospital by hospital unit, and timing of the nutrition interventions in relation to date of admission, time of year, and timing during the day. 


\section{Research Questions and Hypotheses}

For the following research questions and hypotheses, all participants were hospitalized patients at the study facility, and all nutrition interventions were in relation to this population.

Research Question 1: How is the provision of ONS related to changes in albumin levels in participants over the course of hospitalization?

$H_{0} 1$ : Changes in patients' serum albumin levels will not be significantly different between patients receiving ONS and those not receiving ONS during the course of hospitalization after adjusting for baseline level of body mass index, age, race, gender, BNP levels, season of the year, location in the hospital, weight changes, initial albumin level, CCI, RD consultation, and diagnosis of malnutrition.

$H_{\mathrm{a}} 1$ : Changes in patients' serum albumin levels will be significantly different between patients receiving ONS and those not receiving ONS during the course of hospitalization after adjusting for baseline level of body mass index, age, race, gender, BNP levels, season of the year, location in the hospital, weight changes, initial albumin level, $\mathrm{CCI}$, nutrition risk screening score, RD consultation, and diagnosis of malnutrition.

Method of measurement: $t$-test derived from multiple linear regression analysis to compare mean changes in albumin levels in patients receiving ONS with those not receiving ONS. 
Research Question 2: How is the provision of ONS related to patient weight changes during the course of hospitalization?

$H_{0} 2$ : Changes in patients' weights will not be significantly different between patients receiving ONS and the those not receiving ONS after adjusting for baseline level of body mass index, age, race, gender, BNP levels, season of the year, location in the hospital, initial albumin level, CCI, RD consultation, and diagnosis of malnutrition.

$H_{\mathrm{a}} 2$ : Changes in patients' weights will be significantly different between patients receiving ONS and the those not receiving ONS during the course of hospitalization after adjusting for baseline level of body mass index, age, race, gender, BNP levels, season of the year, location in the hospital, weight changes, initial albumin level, CCI, RD consultation, and diagnosis of malnutrition.

Method of measurement: $t$-test derived from multiple linear regression analysis to compare mean weight change for patients receiving ONS with those not receiving ONS.

Research Question 3: How is the provision of ONS related to patient LOS in the hospital?

$H_{0} 3$ : There will be no statistically significant difference in the odds of high LOS between patients receiving ONS and those not receiving ONS after adjusting for baseline level of body mass index, age, race, gender, BNP levels, season of the year, location in 
the hospital, weight changes, initial albumin level, CCI, RD consultation, and diagnosis of malnutrition.

$H_{\mathrm{a}} 3$ : There will be a statistically significant difference in the odds of high LOS between patients receiving ONS and those not receiving ONS after adjusting for baseline level of body mass index, age, race, gender, BNP levels, season of the year, location in the hospital, weight changes, initial albumin level, CCI, RD consultation, and diagnosis of malnutrition.

Method of Measurement: Odds ratios determined from multiple logistic regression analysis with ONS as the main predictor, controlling for covariates above shown to be associated with LOS through two-way tables.

\section{Theoretical Foundation}

The theoretical framework for this paper was the epidemiological triad of person, place, and time. Examination of the frequency of health-related events, along with person, place, and time factors, provides the basis for descriptive epidemiology (Johns Hopkins Bloomberg School of Public Health, 2008). Epidemiology is "the study of the occurrence and distribution of health-related events, states, and processes in specified populations, including the study of the determinants influencing such processes, and the application of this knowledge to control relevant health problems" (Porta, 2014). In order to evaluate patterns of health -related states in populations, an examination of how health 
events vary according to person, place, and time is required (Centers for Disease Control and Prevention [CDC], 2012).).

This model was used by John Snow, a pioneer of modern epidemiological methods, who investigated a cholera outbreak in London in 1853-54 (time) by evaluating the geographic distribution of the outbreak (place), and found that only those people using a particular water pump (place) developed cholera, regardless of sex, age, social standing, occupation, or income status (person; Schneider, 2006). A more detailed explanation and history of this theory, with further examples, may be found in Chapter 2.

In my study this theory provides a framework for a thorough investigation that may uncover issues related to person place, and time that were not previously appreciated. Covariates include person, place, and time factors. Personal factors include age, body-mass index (BMI), and other health indicators; the place-related factor is location in the hospital; and time-related factor involves an evaluation of the time of year (by quarters) in which patients were admitted, and timing of nutrition intervention during hospitalization.

\section{Conceptual Framework}

A key concept in this study is malnutrition, and its relationship to patient and hospital outcomes. Malnutrition can be described as "the condition that develops when the body does not get the right amount of the vitamins, minerals, and other nutrients it needs to maintain healthy tissues and organ function" (Farlex, 2014). Malnutrition often 
has not been adequately recognized or addressed in hospitals (Tappenden et al., 2013); nor has it been clearly or consistently defined in the hospital setting (Jensen, Bistrian, Roubenoff, \& Heimburger, 2009; White, Guenter, Jensen, Malone, \& Schofield, 2012). However, the value of recognizing and treating nutritionally compromised patients has been recognized by The Joint Commission, whose standards require hospital patients to be screened for high-risk nutritional status within 24 hours of admission (The Joint Commission, 2012).

\section{Definitions of Malnutrition}

Malnutrition has been defined by several methods in previous studies on nutritional status and nutritional interventions in hospitals. Some studies use predefined tools, and others use only certain factors such as body mass index (BMI) and weight changes (Neelemaat et al., 2012). One common tool is the Subjective Global Assessment (SGA; Detsky et al., 1987). Factors included in the SGA include changes in weight, dietary intake, gastrointestinal symptoms, functional capacity, disease, and subjective rating by physical exam (Detsky et al., 1987). Another validated tool that is a very abbreviated form of screening for malnutrition is the Malnutrition Screening Tool (MST), developed by Ferguson, Capra, Bauer, and Banks (1999). It is based on patients' perceptions of food intake in relation to appetite, and patient report of unplanned weight loss (Ferguson et al., 1999). More detail on definitions of malnutrition in relation to studies of ONS and RD interventions can be found in Chapter 2. Aziz et al. (2011) used 
the Nutrition Risk Score (NRS), which is calculated from serum albumin level and ratio of actual to usual weight. A medical diagnosis of malnutrition is designated by ICD-9 codes 263.9 (Unspecified protein-calorie malnutrition), or 269.9 (Unspecified nutritional deficiency).

\section{Malnutrition and Patient and Hospital Outcomes}

A number of studies have shown that malnutrition adversely affects individual health outcomes and hospital outcomes (Correia \& Waitzberg, 2003; Lim et al., 2012; Agarwal et al., 2013, Chima et al., 1997). Outcomes related to malnutrition include cost

of hospitalization, hospital mortality, and LOS (Agarwal et al., 2013; Chima et al., 1997; Correia \& Waitzberg, 2003). In addition, several studies have also indicated that the use of ONS and other nutrition interventions among hospitalized patients appear to have a greater effect among sicker or more malnourished patients in comparison to wellnourished or healthier patients (Philipson et al., 2013; Somanchi et al., 2011).

\section{Nature of the Study}

A retrospective observational study design was used. This study was designed as an epidemiological study rather than a clinical trial. The independent variable (IV) in this study was nutrition intervention using ONS. Dependent variables included two clinical outcomes (albumin and weight changes); and one hospital outcome (LOS). Covariates included BMI, age, race, gender, BNP levels, season of the year, location in the hospital, payer, CCI, RD consultation, diagnosis of malnutrition, and planned discharge 
destination. These covariates included the three aspects of the epidemiological triad: person, place, and time.

Data were extracted by hospital information services staff from the electronic medical records/healthcare information system at the hospital. Quantitative methods of analysis were used to compare outcomes for hospital patients who received ONS with a comparison group that did not receive supplements over a 2-1/2-year period. The observational, retrospective, design allowed for evaluation of the effectiveness of dietitian interventions and ONS use in a real-world setting that reflected day-to-day operations in an acute care setting.

\section{Definitions}

Albumin: Albumin is the major protein found in the blood plasma (Serum albumin test, n.d.). It has been associated with poor nutritional status and presence of disease. It may be low when there is inadequate intake or absorption of nutrients, especially protein (Serum albumin test, n.d.).

B-type natriuretic peptide: This is a cardiac hormone secreted from the heart in response to volume and pressure overload (Faggiano et al., 2010; Mair, 2011). It is used to diagnose or to rule out heart failure, as well as to indicate severity of HF (Faggiano et al., 2010; Mair, 2011). A reduction in BNP has been associated with improved outcomes and reduced risk of future adverse events (Dhaliwal et al., 2009; Di Somma et al., 2010; Mair, 2011; Yancy et al., 2013). 
Body mass index: The BMI is a common general indicator of body fatness. It is used as a screening tool to determine whether a person is underweight or overweight. It is an indirect measure of body fat, so is not as reliable as direct measures such as underwater weighing or skinfold thickness measurement; however, it is the easiest method and based on readily available information — height and weight. The following table from the CDC (2014) shows the ranges of BMI and how they are interpreted:

\begin{tabular}{|c|c|}
\hline Below 18.5 & Underweight \\
\hline $18.5-24.9$ & Normal \\
\hline $25.0-29.9$ & Overweight \\
\hline 30.0 and Above & Obese \\
\hline
\end{tabular}

Charlson Comorbidity Index: This is a comorbidity index with 17 items, weighted according to association with mortality (Charlson, Pompei, Ales, \& MacKenzie, 1987; Degroot, Beckerman, Lankhorst, \& Bouter, 2003; Farley, Harley, \& Devine, 2006). A modified form with 19 items is also available (Rohrer, Adamson, Barnes, \& Herman, 2008). Several studies have validated an adaption of the CCI using ICD-9 codes (Deyo, Cherkin, \& Ciol, 1992; Quan et al., 2005; Sundararajan et al., 2004). The study by Quan et al. (2005) includes expanded ICD-9 codes to address inconsistencies in interpreting CCI with ICD-9 codes, and to better align with the more detailed ICD-10 coding. 
Because of the availability of ICD-9 codes for all diagnoses on patients at the study hospital and current transition to ICD-10 codes (October 2015), I used the CCI adaptation by Quan et al. to control for severity of illness in this study.

The relationship between the index and ONS use was demonstrated by Philipson et al. (2013) in their large retrospective study that used billing and diagnostic data from the Premier Perspectives Database to show the impact of ONS use on hospital outcomes. They found a significantly higher $(\mathrm{p}<.0001)$ mean CCI score of 3.4 for patients using ONS (724,027 episodes), compared to a score of 2.1 for all hospitalization episodes $(\mathrm{N}=$ $43,244,540)$.

Length of Stay: This refers to the length of time in days that a person is hospitalized. For this study, exact LOS was calculated using date and time of admission and discharge.

Malnutrition: This term is defined in detail under the Conceptual Framework section (above).

Nutritional Risk Screening Tool: At the time of this study, a nutritional risk screening tool used at MRMC used to determine which patients are at high-risk nutritionally and in need of dietitian consultations. Further information on this tool may be found under Instrumentation and Operationalization of Constructs in Chapter 3. 
The tool contained criteria used by nurses to screen patients for nutritional risk within 12 hours of admission and during shift assessments every 12 hours. It included the following items: head/neck cancer with chemotherapy/radiation therapy; diagnosis of malnutrition/failure to thrive; hyperemesis gravidarium; LOS >11 days; NPO (nil per os, or nothing by mouth) or clear liquids diet $>5$ days; poor oral intake of 3 or more days; stage 2-4 pressure sore, non-healing wound, or deep tissue injury; and unplanned weight loss of $>10$ pounds in the past 3 months.

If a nurse checked off any one of these items during the initial nursing assessment or 12-hour shift assessment for a patient at any time during the hospital stay, an automatic referral was triggered for a registered dietitian consultation (see definition below). See Appendix for a screenshot of the tool used by the nurses for nutrition screening.

ONS: Commercial oral liquid high-protein, high-calorie oral nutrition supplements. For this study, I included only ONS ordered at least twice daily, with at least $220 \mathrm{kcal}$ per 8 -ounce serving, at least $40 \%$ of calories from carbohydrate, at least $10 \%$ of calories from protein, and at least $20 \%$ of calories from fat; or one supplement daily providing the same nutrients (and at least $440 \mathrm{kcal}$ ) in one serving.

Registered Dietitian (RD) Consultation: This refers to a request for the services of a registered dietitian (RD), initiated by a physician order or nutritional screening (defined above) trigger by a nurse. 


\section{Assumptions}

Supplement data were not consistently recorded in the electronic medical record (EMR) from which the data was abstracted. Because the EMR did not have reliable data on how much of the supplements were being consumed by patients, it was necessary to assume that patients were consuming the supplements provided, which may not always have been the case. However, staff at this facility have historically discontinued orders for supplements if they were not being consumed.

It was assumed that LOS reflected duration of illness and severity of condition while in the hospital, so an intervention that supported improved health outcomes would be associated with shorter LOS. Patients who are sicker tend to have poorer oral intake and may be more likely to be prescribed ONS (Philipson et al., 2013). However, an attempt was made to minimize this bias by controlling for covariates known to influence LOS.

\section{Scope and Delimitations}

This study focused on the adult (age 18 or over) inpatient population at a regional acute care medical center with a diagnosis of heart failure (HF). This one diagnosis was chosen after analysis of sample size showed that there may be inadequate data available to analyze or control for other proposed diagnoses, including AMI, COPD, and pneumonia. 
The use of ONS was selected because it has the potential to be a convenient, costeffective nutrition intervention to address inadequate nutrition in inpatient settings, in light of the previously demonstrated importance of nutrition on patient and hospital outcomes. Nutrition is a preventive factor that can be relatively easily addressed in the hospital, and is a cost-effective way to improve outcomes (Neelemaat et al., 2012; Philipson et al., 2013; Somanchi et al., 2011). While there is previous evidence of the effectiveness of nutrition outcomes for wound outcomes and orthopedic injuries (BotellaCarretero et al., 2010; Hoekstra et al., 2011; Lawson et al., 2003; Miller et al., 2006; Houwing, 2003), information is lacking on how nutrition interventions specifically affect HF patient outcomes. In addition, HF is one of the diagnoses chosen by Medicare as high-risk outcomes with frequent readmissions (Kociol et al., 2013); readmission rates have also been demonstrated to be higher with diagnosis of HF (Aziz et al., 2011; Kociol et al., 2013). Therefore, this study was limited to patients with this diagnosis.

Many studies have focused only on elderly patients, but because patients at any age may need nutritional intervention, this study included all adults aged 18 and over. Only patients exclusively on oral diets were considered, because of the confounding effects of tube feedings or total parenteral nutrition. Patients on clear liquids were excluded because of the baseline inadequacy of such diets. While there are potential benefits to outpatients or patients living in the community (Arnaud-Battandier et al., 2004), it was not practical for this dissertation study to include that population. 
It was expected that the results of this study could be generalizable to future HF inpatients at the same hospital, as well as inpatients at other hospitals with the same diagnoses. However, results could vary from hospital to hospital according to severity of conditions in the facility, supplement protocols, demographic profiles of the patient population, and other factors identified as covariates by the outcomes of this study.

\section{Limitations}

Based on my personal experience at this hospital, nutritional interventions were addressed by one of several dietitians working in the facility, and different clinicians may provide different intervention approaches; some may be more likely to order ONS than others. However, it is expected that the mix of intervention approaches at this facility will generally reflect the nutrition intervention approaches in other acute care facilities, unless a specific policy is in place regarding the prescribing of ONS.

I attempted to control for any major known confounding variables, but not all confounding factors can be identified because of the numerous factors affecting clinical and hospital outcomes. For example, the lack of availability of an appropriate and safe discharge facility may significantly delay discharge from the hospital. For this reason, the study controlled for discharge destination (home, rehabilitation, or long-term care, or death). Additionally, LOS is often a skewed (non-linear) variable (J. Rohrer, personal communication, September 22, 2014), and this was true for this study. Therefore, highlow categories were used for this outcome, and logistic regression was used instead of 
linear regression to analyze the LOS outcome. Data from previous studies were used to determine those other factors most likely to affect LOS.

\section{Design and/or Methodological Weaknesses}

Since this was a retrospective observational study, it did not have the strong internal validity of a randomly controlled trial (RCT). However, observational studies such as this one have an advantage over an RCT in that they can capture the results of patterns of practice of the clinicians who normally provide these interventions in the acute care setting (Hannan, 2008). This study may better reflect the realities and limits of normal hospital operations, such as variation in patient loads and limited time to identify and assess high-risk patients. RCTs also have weaker external validity than observational studies; that is, they may not be as generalizable to populations outside of the sample population (Hannan, 2008). This study sought to produce results that could apply to other hospital settings and potentially other diagnoses.

Patients for whom supplements are ordered in the hospital are generally eating more poorly and/or are sicker than patients for whom they are not prescribed (Philipson et al., 2013). This potential weakness was addressed by controlling for factors known to affect nutrition status and supplement use.

Patients with heart failure may have large amounts of fluid retention, so weights may vary and some weight loss (sometimes quite large amounts) may be associated with improvement in condition. 


\section{Biases}

The biggest potential bias may be that of selection bias; that is, patients who are found to have received ONS or nutrition consultation would be those patients who were considered at higher risk nutritionally by medical or nursing staff, or through initial nursing assessment nutrition screening. Nutritional screening of patients in hospitals within 24 hours is a national standard of The Joint Commission (TJC; Somanchi et al., 2011). I sought to overcome this bias by adjusting for nutritional risk, as well as other factors affecting supplement use--age, sex, BMI, diagnosis of malnutrition, and cormorbidity score--through linear regression analysis.

I was a PRN (pro re nata, or "as needed") registered dietitian at the hospital during the initial planning stages of the study proposal, which provided better knowledge of what factors may influence nutritional interventions, what type of data are collected in the EMS, and how the study could be designed to provide the data of interest. I am no longer employed by the hospital and thus believe I am free of bias in evaluating the results.

\section{Significance}

It is expected that this study will contribute to the body of evidence on the use of ONS in relation to patient and hospital outcomes, specifically for the diagnosis of HF. It provides another perspective on whether this approach to nutritional care contributes to potential benefits for patients and hospitals, and whether routine use of supplements may 
be beneficial for the regional medical center under study and other similar acute care facilities. In practice, it may help provide guidance to hospitals, physicians, other providers, dietitians, and nurses in the use of ONS. This type of information can help hospital administrators and payers know whether more routine use of ONS is worth supporting.

This study is expected to promote positive social change by examining aspects of patient care in hospitals that can improve patient health and quality of life, and also promote more efficient ways to use patient, hospital, and community resources. Use of ONS and other nutrition interventions, such as consulting staff dietitians to determine individualized plans of care, have the potential to improve the healing process, prevent complications, and reduce the time patients spend in the hospital. This can mean improved quality of life for patients and those close to them. It can also save valuable resources for use in other needed areas, providing positive social benefit to the community or general population, as well as individuals receiving hospital care.

\section{Summary}

This chapter has outlined the problem of malnutrition and the importance of nutrition intervention for preventing and treating malnutrition. The role of nutrition intervention in improving outcomes for hospitalized patients was reviewed. Research has been reviewed on the effectiveness of nutritional supplements for older patients in hospital and community settings, for orthopedic patients in the hospital, for postoperative 
patients, and those with pressure sores. Improved outcomes included reduced health care costs in the community and the hospital (Arnaud-Battandier et al., 2004; Lawson et al., 2003), smaller drops in albumin levels and better recovery among hip fracture patients (Botella-Carretero et al., 2008), fewer complications and less weight loss in orthopedic patients (Lawson et al., 2003; Miller et al., 2006), lower risk of pressure ulcer development (Bourdel-Marchasson et al., 2000), and shorter LOS, improved nutritional status, lower mortality risk, and reduced hospital readmission rates among acutely ill older patients (Gariballa et al., 2007). Decreases in functional limitations were also demonstrated in malnourished elderly patients (Neelemaat et al., 2012) .

The need for further study in other populations such as the general population, other diagnoses, and the potential for routine supplementation was presented. The research questions and hypotheses for this study were then provided. This study focused on ONS use to improve outcomes for patients with a diagnosis of HF, a common diagnosis with high rates of complications, high hospitalization costs, and high 30-day readmission rates (Aziz et al., 2011; Kociol et al., 2013). The theoretical foundation of the epidemiological triad was described, and the conceptual foundation was outlined to describe the problem of malnutrition in hospitalized patients.

A literature review that presents further detail on the research described above will follow in Chapter 2. In addition, further research background on the theoretical foundation and conceptual framework will be presented. 


\section{Chapter 2: Literature Review}

\section{Introduction}

Malnutrition in acute hospital patients has been estimated to affect from 30-55\% of hospital patients worldwide (Agarwal et al., 2012; Barker et al., 2011; Somanchi et al., 2011), with some studies finding malnutrition rates of up to $69 \%$ in hospitals (Singh et al., 2006; Young et al., 2013). Research has demonstrated that the prevention and treatment of malnutrition in hospital patients reduces cost of care, LOS, readmission rates, mortality, and complication rates among patients (Correia \& Waitzberg, 2003; Somanchi, et al., 2011; Rasheed \& Woods, 2013, Tappenden et al., 2013).

Malnutrition is costly not only to those who suffer from it, but to the health care system as a whole. Correia and Waitzberg (2003) found that the overall costs for hospitalized malnourished patients were $308.9 \%$ higher than for well-nourished patients from 25 Brazilian hospitals. Significantly greater LOS, readmission rates, and mortality rates have also been demonstrated among hospitalized patients who are malnourished compared to those who are well-nourished (Aziz et al., 2011; Lim et al., 2012).

Factors contributing to malnutrition in the hospital include changes in metabolism, altered nutrient absorption, anorexia, inability to chew or swallow, dietary restrictions related to illness or tests, increased nutritional needs caused by disease or infections; and inadequate food and beverage intake because of dislike of hospital foods or special diets. Inadequate food and beverage intake to meet nutritional needs during 
hospitalization is one major cause of malnutrition, and research has shown that inadequate intake is common among acute care patients (Agarwal et al., 2012; Hiesmayr et al., 2009).

ONS that contain significant amounts of kilocalories (kcal), protein, and multiple nutrients, are often provided as a convenient intervention to address the problem of inadequate intake and help to prevent and treat malnutrition in hospitals. The effectiveness of this approach has been demonstrated in a variety of research settings. A multicenter trial in France found a reduced risk of pressure ulcer development among elderly hospitalized patients who received two high-protein, high-calorie supplements daily (Bourdel-Marchasson et al., 2000). Arnaud-Battandier et al. (2003) found that ONS improved the nutritional status of elderly patients in a community setting, leading to reduced health care costs. Miller et al. (2006) demonstrated that ONS were beneficial in preventing the weight loss that commonly occurs among older adults at nutritional risk following lower limb fractures. A meta-analysis by Stratton and Elia (2007) also showed consistent clinical benefits— such as improved nutritional status and reductions in complications - associated with the use of ONS in hospital and community settings. A review of 55 studies by Milne, Avenell, and Potter (2006) concluded that the provision of ONS in elderly hospital patients appeared to benefit individuals who were undernourished at baseline. Patients using the supplements had fewer complications and lower mortality rates compared to controls. 
The remainder of this chapter will provide a detailed review of major literature related to nutrition issues in hospitals, especially malnutrition, and the role of ONS and other clinical nutrition interventions to help improve nutritional status of hospitalized patients and improve hospital outcomes. I will start by summarizing the literature search strategy I used, followed by a theoretical foundation for my study. This will include a review of how malnutrition is defined, the tools used to identify it, and interventions that have proven effective to help prevent or reduce the incidence of malnutrition in the hospital setting. I will focus the review on studies related to the major variables in my study.

Significant articles reviewed are summarized in the literature matrix in Table 1. Next, I discuss the rationale for selection of the key variables in this study, previous research related to these variables, limitations of previous research, and where there remain gaps in the literature. I will then review and summarize studies related to my particular research questions.

\section{Literature Search Strategy}

The main databases I used for my literature search were CINAHL, MEDLINE, Cochrane Database of Systematic Reviews, and the ProQuest Dissertations Database. I searched for articles using the Walden University Library, Google Scholar, the Google Scholar link to the Walden Library via SFX by ExLibris, and related articles suggested 
by Science Direct and Google Scholar. I also accessed relevant articles referenced in other journal articles, and the "cited by" feature of Google Scholar and Pub Med. The following search terms were used in reviewing the literature: oral nutrition supplement, nutrition supplements, LOS, nutrition, malnutrition, supplement, and hospital outcomes. I focused on articles published in the past 5 years, but also reviewed seminal research articles for earlier years.

\section{Theoretical Foundation: The Epidemiological Triad}

The theoretical framework for this paper is the epidemiological triad of person, place and time. This triad is a key concept in descriptive epidemiology (Johns Hopkins Bloomberg SPH, 2008). I applied the epidemiological triad in this study as I examined patterns of health-related outcomes not only in relation to clinical factors, but according to person, place, and time factors.

Schneider (2006) described how the epidemiological triad model was used by

John Snow, considered the "father of modern epidemiology," who investigated a cholera outbreak in London in 1853-54 (time) by evaluating the geographic distribution of the outbreak (place), and found that only those people using a particular water pump (place) developed cholera, regardless of sex, age, "rank or occupation," or income status (person). Snow removed the handle of the suspected pump, and the outbreak stopped. Upon investigating the source of the water supplying the pumps, it was learned that the water company supplying individuals who did not develop cholera had changed its water 
source between 1849 and1854 (time), from a part of the Thames River receiving heavy contamination from the city's sewer systems to an area of the river without the contamination (Schneider, 2006). The other water company continued to use the polluted water as the water source for its customers. The use of person, place, and time has continued to serve as the basis for epidemiological investigations in subsequent years.

\section{Applications of this Model in Ways Similar to this Study}

Agarwal et al. (2012) used person, place, and time in a study of nutritional status and oral dietary intake of 3122 participants in 56 hospitals in Australia and New Zealand. Personal characteristics of participants included in the analysis included age, gender, and ethnicity; they found that nutritional status of males and females was not significantly different, but mean age was significantly different between well-nourished and poorlynourished patients. Timing involved a 24-hour data collection period, with comparison of intake at different times of day (breakfast, lunch, and dinner meals); heaviest intake was at the morning meal. Place involved hospital ward, with the largest percentage of malnourished patients on the oncology wards (48\%), followed by gastroenterology wards (44\%). The wards with the lowest percentages of malnourished patients were the neurology wards (22\%) and cardiology/respiratory wards (24\%). A follow-up part of this study (Agarwal et al., 2013) looked at outcomes data after 90 days (time) to show hospital LOS, readmissions, and in-hospital mortality in this time period. However, these 
studies did not concern supplement use. No studies using the epidemiological triad could be found involving nutrition interventions or supplement use and clinical or hospital outcomes.

\section{Rationale for Choice of this Theory}

This study is an epidemiological study rather than a clinical trial. The study is a retrospective, non-randomized observational study. My covariates cover the three aspects of the epidemiological triad: person, place, and time. To investigate personal characteristics related to use of ONS, I evaluated age, gender, ethnicity, height, weight, and BMI in relation to supplement use and patient and hospital outcomes. For the place variables, I chose to perform the study in a hospital setting, and compared supplement use in relation to outcomes in various units at the hospital--an aspect that has been shown previously to have a possible effect on my chosen outcomes (Agarwald et al., 2012). Time aspects of my study included an evaluation of the time of year (by quarters) in which patients were admitted, time patterns of supplement provision-such as whether it was started on admission or later during the hospital stay--and whether the impact of supplement use on patient and hospital outcomes was affected by such timing factors.

\section{Conceptual Framework}

Malnutrition leads to increased inflammation in the body which reduces the ability of tissues to heal or to fight infection. Malnutrition impedes healing and recovery of hospitalized patients, and treatment of or prevention of malnutrition has been shown to 
improve outcomes for hospitals, as well as for individual in medical facilities or at home (Agarwal, 2013; Arnaud-Battandier et al., 2004). As mentioned earlier, malnutrition has been estimated to affect from 30-55\% of hospital patients worldwide (Agarwal et al., 2012; Barker et al., 2011; Somanchi et al., 2011).

One cause of malnutrition is poor intake of food and beverages. Poor food intake (less than $50 \%$ of food offered) is common in hospitals, among well-nourished patients as well as malnourished patients; one study of 3122 patients in 56 hospitals in Australia and New Zealand found poor intake in 55\% of malnourished participants, and 35\% of wellnourished participants (Agarwal et al., 2012). Thirty-two percent of the participants overall in that study were found to be malnourished, using the Subjective Global Assessment (SGA) tool.

A common reason for poor intake is "not hungry" (Agarwal et al., 2012, abstract). However, patients may be able to consume a liquid nutritional supplement even when their appetites are poor. ONS supplements have been shown to improve nutritional intake Bourdel-Marchasson et al. (2000) found improved calorie and protein intakes and lower rates of pressure ulcers in an intervention group receiving two nutritional supplement beverages daily for 15 days.

For this reason, one traditional approach to prevent and/or treat malnutrition has been through the use of high-calorie, high-protein nutrition supplements. I tested whether the use of these supplements in hospitals might have a sufficient effect to reduce LOS. 


\section{Literature Review Related to Key Variables and Concepts}

A key concept in this study is malnutrition, and its relationship to patient and

hospital outcomes. Key variables in this study include the following: albumin levels;

prealbumin levels; use of high protein, high-calorie dietary supplements; nutrition

intervention through registered dietitian consultations; in-hospital weight changes; body-

mass index; patient location in hospital; time of year of admission; patient characteristics (age, gender, and ethnicity); diagnosis; and LOS.

\section{Review of Studies Related to Key Concept: Malnutrition}

Malnutrition can be described as "the condition that develops when the body does not get the right amount of the vitamins, minerals, and other nutrients it needs to maintain healthy tissues and organ function" (Farlex, 2014). Malnutrition often has not been recognized in hospitals (Tappenden et al., 2013) and has not been easy to clearly recognize or define in the hospital setting (Jensen, Bistrian, Roubenoff, \& Heimburger, 2009; White, Guenter, Jensen, Malone, \& Schofield, 2012). However, recognizing the value of identifying and treating patients at high-risk nutritionally (whether or not they are officially diagnosed with malnutrition), the Joint Commission (2012) standards require hospital patients to receive nutritional screening within 24 hours of admission.

Definitions of malnutrition. Malnutrition has been defined by several methods in the studies reviewed. One common method is the Subjective Global Assessment (SGA) (Detsky et al, 1987). Factors included in the SGA include recent weight loss (amount and 
pattern); changes in oral intake; adverse gastrointestinal symptoms that may affect food intake such as nausea, vomiting, or diarrhea; presence of disease, physical assessment of muscle wasting or edema; and subjective rating by physical exam. This tool been used by a number of studies reviewed for this paper, and is often the tool used as a gold standard for comparison and validation of other less burdensome tools.

The ICD-10-AM code for malnutrition in Australia defines malnutrition as a BMI less than $18.5 \mathrm{~kg} / \mathrm{m}^{2}$ combined with SGA ratings of moderately malnourished or severely malnourished (ICD-10-AM, as cited by Agarwal et al., 2013).

Another tool that is a very abbreviated form of screening for malnutrition is the Malnutrition Screening Tool (MST), developed by Ferguson, Capra, Bauer, and Banks (1999). It consists simply of the following two questions: "Have you been eating poorly because of a decreased appetite?" and "Have you lost weight recently without trying?" (Ferguson et al., 1999, p. 460). These two questions were validated by Ferguson et al., and showed high sensitivity and specificity compared to the Subjective Global Assessment. It was used along with the SGA by Agarwal et al. (2012), Agarwal et al. (2014), and others.

Not all studies used a pre-designed tool. In a study on the benefits of a nutrition intervention among malnourished elderly patients in the Netherlands, Neelemaat et al. (2012) used the following criteria to identify malnourished patients:

- Body Mass Index $\left(\mathrm{BMI}\right.$ in $\left.\mathrm{kg} / \mathrm{m}^{2}\right) \leq 20$ and/or 
- $5 \%$ unintentional weight loss in the previous month and/or

- $10 \%$ unintentional weight loss in the previous six months (p. 184).

Malnutrition and patient and hospital outcomes. A number of studies have shown that malnutrition adversely affects individual health outcomes and hospital outcomes (Correia \& Waitzberg, 2003; Lim et al., 2012; Agarwal et al., 2013). Cost of hospitalization and LOS were higher in inpatient medical units in a tertiary-care hospital in the Midwest among patients at risk for malnutrition compared to patients not at risk. (Chima et al., 1997). In a study of 3122 patients from 56 hospitals in Australia and New Zealand, median LOS for malnourished participants was 15 days compared to 10 days in well-nourished participants $(p<.0001)$ (Agarwal et al., 2013). In the same study, participants consuming less than $25 \%$ of food offered also had significantly greater LOS, with median LOS of 13 days compared to 11 days for those consuming at least 50\% ( $p<$ .0001). Correia and Waitzberg (2003) found reduced LOS (OR 0.7, CI [0.59, 0.83]), increased complications ( OR 1.60, CI [1.09, 2.35]), increased hospital mortality, and higher overall hospital costs (by 309\%) among 709 hospitalized patients over 18 years of age, chosen randomly from 25 Brazilian hospitals. Agarwal et al. (2013) also found a significant association between malnutrition and age 65 or greater, and emergency admission to a hospital.

Nutrition interventions and malnutrition. Several studies have indicated that the use of ONS and other nutrition interventions among hospitalized patients appear to 
have a greater effect among sicker or more malnourished patients in comparison to wellnourished or healthier patients. Philipson et al. (2013), in a 10-year retrospective study on ONS use and hospital outcomes in patients in the Premier Perspectives Database, looked at hospital outcomes in relation to ONS use. In this large database, they found 724,027 episodes of ONS use in the database of 44.0 million inpatient episodes. They used propensity score matching to produce a comparison group of 1,160,088 non-ONS episodes. Analysis of the data showed that, overall, those using the ONS were older, sicker, and more likely to have had another recent hospital admission. But when the ONS group was compared to a group of matched patients, LOS was reduced $21 \%$, or 2.3 days (95\% CI [-2.4, -2.2]). In a prospective nutrition intervention study of 400 patients in two medical wards at Johns Hopkins Hospital, Somanchi et al. (2011) identified malnutrition in 53\% of the study population. Those patients who received the nutrition intervention received a clinical nutrition screening, dietary department consultation, and assessment. LOS was reduced by an average of 1.93 days (CI $[-3.19,0.661])$ in the nutrition intervention cohort, and 3.2 days (95\% CI [-6.43, 0.028]) in a those found to be severely malnourished.

\section{Review of Studies Related to Key Variables}

Albumin level. Several studies reviewed for this paper used albumin levels as an indicator for nutritional status, although there is some disagreement regarding the validity of these lab values as indicators of nutritional status because of their high association 
with the inflammatory process - a common issue among hospitalized patients (Tappenden et al., 2013). Low serum albumin is an established risk factor for pressure ulcer development, as demonstrated in previous research, and used by BourdelMarchasson et al. (2000), in a prospective multi-center study evaluating the relationship between provision of nutritional supplements, oral intake, and pressure ulcer development among critically ill elderly hospital patients. They found that decreased serum albumin was an independent risk factor for the development of pressure ulcers, with an increase in risk by 1.05 for each $1 \mathrm{~g} / \mathrm{L}$ decrease in serum albumin (95\% CI [1.02, 1.07], $p<.001)$. In a randomized, controlled clinical trial, Botella-Carretero et al. (2010) administered two supplements daily for an average of 5.8 days to pre-hip fracture patients, and found greater decreases in serum albumin and prealbumin levels in the control group compared to the intervention group, as well as poorer recovery postoperative in this group compared with the intervention group.

Weight changes. Lawson et al. (2003) measured weight changes, but reported results in BMI changes. They found no significant change in BMI values over a 7-day period. Potter, Langhorne, \& Roberts (1996) reviewed 32 randomized controlled trials of patients receiving oral or enteral protein-energy supplementation. Of these, 20 involved oral supplementation. They found a 3.11\% (CI [2.03, 4.20]) benefit in weight from supplementation, using an alternative random effects model to account for differences in whether supplemented patients showed greater weight gains, or smaller weight losses 
compared to controls. Milne et al. (2006), in a review of 14 trials, found a pooled weighted mean weight change of $1.75 \%[1.12,2.30]$. However, Neelemaat et al. (2012) did not find significant weight changes over a 3-month period among malnourished hospitalized elderly patients who received ONS. Potter, Roberts, McColl, and Reilly (2001), in a study of ONS in hospitalized elderly patients, found the difference in weight change between the treatment group and control group was $2.8 \%$ weight improvement: An increase of $2.0 \%$ (SD $4.5 ; n=113$ ) in the treatment group, compared to - $0.8 \%$ (SD $5.3 ; n=121)$ in the control group.

High- protein, high-calorie dietary supplement use. In this study, ONS refers to supplements containing at least $15 \%$ of kcal as protein, at least $200 \mathrm{kcal}$ per serving, and at least $20 \%$ of daily requirements for vitamins and minerals. Most of the ONS used in the studies referenced contained at least $20 \%$ of kcal as protein. The importance of protein for maintaining nutritional status, preventing malnutrition, and promoting healing has been clearly established in the nutrition literature, as well as national and international references (National Institutes of Health, 2014).

ONS have been shown to be related to improved patient outcomes in several studies. In a randomized, controlled study of 445 hospitalized elderly patients, Gariballa et al. (2006) found improvements in nutritional status indicators and a significant reduction in non-elective hospital readmission rates among participants receiving ONS compared to those receiving placebo drinks. Albumin levels were significantly higher at 
six-month follow-up among those receiving supplements, compared to those in the placebo group, with values of 42.0 and 40.5 , respectively $(\mathrm{P}=.04)$. This trial was limited to people 65 to 92 years of age. Supplements were provided for six weeks, along with "the standard hospital diet", indicating that participants consumed supplements even after hospital discharge, since mean hospital LOS was reported as 9.4 days in the supplement group and 10.1 days for the placebo group. For comparison, the average hospital LOS among approximately 33 member countries of the Organisation for Economic Cooperation and Development [OECD] was 8.2 days in 2000, 7.2 days in 2009, and 7.0 days in 2011 (OECD, n.d). Mortality at six months was 14\% for the supplement group, and $9 \%$ for the placebo group. Adherence to supplements varied; graphs of percentage consumed showed only about $14 \%$ of patients taking $75-100 \%$ of the supplement, $22 \%$ of patients consuming $50-75 \%, 6 \%$ consuming $25-50 \%$, and $58 \%$ of patients taking $0-25 \%$ of supplements offered. Since the supplements contained 995 kilocalories (kcal) daily, even 50\% intake provided a substantial increase in daily kcal consumption for patients (Gariballa et al., 2006, Figure 2).

Philipson et al. (2013), in a study of 724,027 episodes of ONS use out of 44,000,000 hospitalization episodes, found that use of ONS use was related to decreased LOS, decreased 30-day readmission rates, and reduced episode cost, compared to the matched comparison group. The variable ONS use is based on "the fraction of episodes involving any ONS use in a given hospital in a given quarter" (p. 122), so the quantity of 
actual supplement consumed was not available. Because the data involved data from 460 sites, there would have been a variety of methods of supplement provision: In some cases, supplement may be administered by nursing staff; at other sites the supplement may have been available only at med pass. At some sites, supplement may be sent on patient trays, while it may be offered between meals at other hospitals. Additionally, at some hospitals supplements may be sent automatically, whether patients want it or not; while other hospitals may not send supplements unless the staff has determined that the patient has some interest in drinking it. Further information on rates of supplement consumption or compliance is under the section Consumption of ONS Offered below. While the database included billing information, which was useful in determining supplement use, it was limited in that it did not contain health information for patient hospitalization episodes analyzed.

In a study of ONS use among long-term care residents, Heyman, Van De Louverbosch, Meijer, and Schols (2008) found significant healing of pressure ulcers among elderly residents receiving the supplements. Average intake was $2.3 \pm 0.56$ servings of a $200 \mathrm{ml}$ supplement providing a total daily average of $575 \mathrm{kcal}$, and $46 \mathrm{~g}$ protein, as well as other supplemental nutrients demonstrated in previous studies to help promote healing (these included arginine, vitamin $\mathrm{C}$, vitamin $\mathrm{E}$, and zinc). Measurements after three weeks of supplementation revealed an average decrease in pressure ulcer area from $1580 \pm 3743 \mathrm{~mm}^{2}$ to $1103 \pm 2999 \mathrm{~mm}^{2}(\mathrm{p}<.0001)$ after three weeks; after nine 
weeks, average size was $743+1809 \mathrm{~mm} 2(\mathrm{p}<.0001)$. Exudate levels were also reported to have decreased significantly during the supplementation period. While there were significant improvements in the pressure ulcers over the 9-week supplementation period of this study, there were no comparison groups or placebo groups with which to compare results. This was done to provide a larger sample size, as well as because of ethical concerns of providing placebos to this malnourished population (Heyman et al., 2008). Therefore, one cannot know how much healing normally takes place without the use of such supplements over this period of time, and how much of the improvement can be attributed to the use of the supplements. Additionally, there was potential bias in this study because it was supported by Nutricia Belgium, the company that produces the supplement.

I did not find any studies specifically on the use of ONS among hospitalized HF patients. However, Rozentryt et al. (2010) performed a small pilot study ( $n=29)$ of ONS in an outpatient clinic for patients with heart failure in Poland. In this prospective,

randomized, placebo-controlled study, Rozentyrt et al. found significant improvement in quality of life and weight gain over the 18 weeks of the study, with an average weight gain of $3.6 \pm 4.7 \%(p=.007)$ among the 19 patients who completed the treatment arm of the study.

\section{Nutrition intervention through dietary department or registered dietitian}

consultations. In a prospective cohort intervention study of 400 patients in two medical 
wards at Johns Hopkins Hospital, LOS was 1.93 days lower (CI [-3.19, 0.661]) among patients who received s nutrition intervention compared those without the intervention (Somanchi et al., 2011). The intervention consisted of a nutrition assessment form filled out by a nurse, followed by consultation of the clinical nutrition department and monitoring of the consultation. Among a subset of patients with severe malnutrition in this same study, LOS was reduced by an average of 3.2 days (95\% CI [-6.43, 0.028]). Somanchi et al. (2011), in a prospective intervention cohort study of 400 patients in two medical wards at Johns Hopkins Hospital, identified malnutrition in 53\% of the study population. Those patients who received the nutrition intervention received a clinical nutrition screening, dietary department consultation, and assessment. LOS was reduced by an average of 1.93 days in nutrition intervention cohort, and 3.2 days in the severely malnourished group. Neelemaat et al. (2012) also evaluated the effect of an intervention that included telephone counseling by a dietitian after hospital discharge, in addition to an enhanced diet, ONS, and supplementation of vitamin D3 and calcium. As with the previously mentioned study, the effects of dietary intervention via dietitian were not separated from use of supplementary nutrition products alone.

Hospital length of stay (LOS). Correia and Waitzberg (2003) looked at LOS, mortality, morbidity, and costs in a retrospective cohort study that included 709 patients from 25 hospitals in Brazil. All participants were over 18 years of age. They used the SGA tool to classify patients as well-nourished or malnourished, and found an average 
difference in LOS for well-nourished patients and malnourished patients to be $10.1 \pm$ 11.7 days. Milne et al (2006) found no significant difference in LOS in patients who were supplemented, but noted that patients who were undernourished and received supplements did have a shorter LOS of 3.30 fewer days compared to 0.84 fewer days for patients not undernourished.

Joshi, D'Souza, and Madhavanevision (2004) examined factors related to differences in LOS in congestive heart failure patients from the National Inpatient Sample, part of a project sponsored by the Agency for Healthcare Research and Quality. Significant differences were found by race, age, gender, and primary payer as Private/HMO (other payers considered were Medicare, Medicaid, and self-pay). Therefore, these factors have been included as covariates in my study.

High or low BMI. BMI, defined as 10,000 times weight in kg divided by height in meters ${ }^{2}$, is used as a measure of nutritional status, with different values associated with various levels of weight status. According to the Centers for Disease Control and Prevention, a BMI of less than 18.5 is considered below normal in the United States (CDC, 2014) and is associated with poor nutritional status. Agarwal et al. (2013) used this same value of BMI as one criteria for malnutrition, based on the Australian version of ICD-10 coding that includes this as a definition of malnutrition (as cited by Agarwal et al., 2013). Lawson et al. (2003) also used BMI values as part of their determination of nutritional status of participants receiving post-operative ONS in the UK, but did not 
classify patients as well-nourished or malnourished based on BMI values. Neelemaat et al. (2012) used BMI $<20$ as an indicator of malnutrition in their study of the effects of nutritional support on functional limitations of malnourished hospital patients over aged 60 or older in the Netherlands. It can be seen that BMI values varied somewhat according to study, which may be related to different criteria for malnutrition according to country of origin of the study.

Because of the relationship of BMI to nutritional status, it will be used as a covariate in my study.

Patient demographics. The rate of malnutrition is generally higher among patients 65 years of age and above. Agarwal et al. (2013) found a significant association between older age (65 years and over), and malnutrition among 3,122 hospitalized patients. They did not find any significant difference in percentage of malnourished patients between males and females. In regard to the relationship between ONS and patient characteristics, very little information was available in the literature examined, other than the finding that supplements were associated with greater improvements among those who were malnourished compared to well-nourished patients. This information suggests a gap in recent literature regarding ONS effectiveness and demographic information that my study will address. It also shows a relationship between malnutrition and age which will need to be adjusted for in my study to prevent confounding. 
In regard to demographic factors affecting the outcome of LOS, Joshi et al. (2004) found significant differences in LOS among HF patients according to race, age, gender, and payer in their examination of factors affecting LOS among HF patients in the National Inpatient Sample.

Timing of nutrition intervention or supplement use. Studies involving timing of supplement use as a variable were not available, although one group of authors (Botella-Carretero et al., 2010) addressed the potential for differences in outcomes depending on timing of supplementation by comparing results of perioperative administration of ONS to hip fracture patients to results of an earlier study they performed on post-operative provision of ONS (Botella-Carretero et al, 2008). Both studies examined the same outcomes, and found beneficial results from supplementation in both cases. The dearth of information in this area, especially in regard to season of the year, indicate a gap and suggest that further studies may be appropriate.

Patient Location in Hospital and Season of Year. No study was available that considered differences in nutrition interventions or ONS provision according to patient location or season of the year. Park, Andrade, Mastey, Sun, and Hicks (2014), in an examination of facility-related factors in relation to 30-day hospital readmissions for congestive heart failure, pneumonia, and chronic obstructive pulmonary disease at a community hospital in Massachusetts, found some variation by patient location in hospital in relation to readmission rates. They found fewer readmissions for patients 
discharged from the cardiac floor vs. medical/oncology floors $(\mathrm{OR}=0.85, \mathrm{p}=.08)$, and that readmissions were significantly more likely in winter than summer $(\mathrm{OR}=1.54 ; \mathrm{p}=$ .0008). These results indicate a need for further study in this area.

Consumption of ONS offered. One issue noted in this literature search was the question of whether those who receive nutritional supplements are actually consuming them. There have been studies questioning whether supplements provided are actually consumed (Gosney, 2003). A multi-center study by Bourdel-Marchasson et al. (2000), evaluating the relationship between provision of nutritional supplements, oral intake, and pressure ulcer development among critically ill elderly hospital patients, found an intake of $60 \%$ of the two high-protein, high-calorie supplements provided daily in week one, with an increase to $99 \%$ the second week. Additionally, a recent review of 46 studies, covering 2282 persons on ONS, found a $78 \%$ overall rate of supplement consumption in all settings, and 67\% in hospital settings (Hubbard, Elia, Holdoway, \& Stratton, 2012). Botella-Carretero et al. (2010) found an average intake of $52.2+12.1 \%$ of the two daily supplements provided in their study of geriatric hip fracture surgery patients. Gariballa et al. (2006) found an average of $23-48 \%$ consumption of supplements over a six-week period including hospitalization and post-hospitalization. Houwing (2003) found an intake of at least $75 \%$ of the supplements among approximately $75 \%$ of participants. Miller et al. (2006) found that the median consumption of ONS by patients following lower limb fractures over a 42-day period was $67 \%$. These patients would not have been 
acutely ill during this entire time frame; some performed resistance training during the course of the study. 
Table 1

Summary of the Literature on Nutrition Interventions, ONS Use, Malnutrition, and Clinical and Hospital Outcomes

\begin{tabular}{|c|c|c|c|c|c|c|c|}
\hline $\begin{array}{l}\text { Author \& } \\
\text { Year }\end{array}$ & Title & Study Design & Study Population & $\begin{array}{l}\text { Independent } \\
\text { Variables }\end{array}$ & $\begin{array}{l}\text { Dependent } \\
\text { variables }\end{array}$ & Results & Other \\
\hline $\begin{array}{l}\text { Agarwal, E., } \\
\text { Ferguson, M., } \\
\text { Banks, M., } \\
\text { Batterham, M., } \\
\text { Bauer, J., } \\
\text { Capra, S., } \\
\text { Isenring, E. } \\
\text { (2013) }\end{array}$ & $\begin{array}{l}\text { Malnutrition and } \\
\text { poor food intake } \\
\text { are associated with } \\
\text { prolonged hospital } \\
\text { stay, frequent } \\
\text { readmissions, and } \\
\text { greater in-hospital } \\
\text { mortality: results } \\
\text { from the Nutrition } \\
\text { Care Day Survey } \\
2010\end{array}$ & $\begin{array}{l}\text { Prospective } \\
\text { cohort study }\end{array}$ & $\begin{array}{l}3122 \text { patients } \\
\text { recruited from } 56 \\
\text { hospitals in } \\
\text { Australia and } \\
\text { New Zealand }\end{array}$ & $\begin{array}{l}\text { Nutritional } \\
\text { status: } \\
\text { malnourished, } \\
\text { severely } \\
\text { malnourished, or } \\
\text { well-nourished; } \\
\text { meal intake }\end{array}$ & $\begin{array}{l}\text { LOS, } \\
\text { readmission } \\
\text { rates, in- } \\
\text { hospital } \\
\text { mortality }\end{array}$ & $\begin{array}{l}\text { LOS greater in malnourished patients } \\
\text { ( } 15 \text { days vs. } 10 \text { days in well-nourished } \\
\text { patients); } p<.0001 \text { ), regardless of } \\
\text { disease status. Median LOS } \\
\text { significantly greater in patients with } \\
\text { meal intake of } \leq 25 \% \text { (13 days) } \\
\text { compared to intake } \geq 50 \% \text { (11 days); } p \\
<.0001 \text {. } \\
\text { Readmissions rates significantly higher } \\
\text { in malnourished patients ( } 36 \% \text { ) vs. } \\
\text { well-nourished patients ( } 30 \%) ; p< \\
.001 \text {. } \\
\text { OR for } 90 \text {-day in-hospital mortality for } \\
\text { malnourished patients =1.91, CI [1.09, } \\
3.34], \mathrm{p}=.023 \text {. } \\
\text { OR for } 90 \text {-day in-hospital death for } \\
\text { intake }<25 \%,=1.99, \text { CI [ } 1.13,3.51] \text {, } \\
\text { p }=.017\end{array}$ & $\begin{array}{l}\text { Significant } \\
\text { association } \\
\text { between } \\
\text { malnutrition and } \\
\text { age } \geq 65 \text {; } \\
\text { emergency } \\
\text { admissions; } \\
\text { non-surgical, non- } \\
\text { medical } \\
\text { admissions. } \\
\text { Nutritional status } \\
\text { was } \\
\text { based on the ICD- } \\
10-A M 2,13 \text {; } \\
\text { malnutrition was } \\
\text { defined as BMI } \\
\leq 18.5 \text {, and SGA } \\
\text { ratings of moderate } \\
\text { or severely } \\
\text { malnourished }\end{array}$ \\
\hline
\end{tabular}




\begin{tabular}{|c|c|c|c|c|c|c|c|}
\hline $\begin{array}{l}\text { Author \& } \\
\text { Year }\end{array}$ & Title & Study Design & Study Population & $\begin{array}{l}\text { Independent } \\
\text { Variables }\end{array}$ & $\begin{array}{l}\text { Dependent } \\
\text { variables }\end{array}$ & Results & Other \\
\hline $\begin{array}{l}\text { Arnaud- } \\
\text { Battandier, F. } \\
\text { Malvy, D. } \\
\text { Jeandel, C. } \\
\text { Schmitt, C. } \\
\text { Aussage, P. } \\
\text { Beaufrère, B. } \\
\text { Cynober, L. } \\
\text { (2004) }\end{array}$ & $\begin{array}{l}\text { Use of oral } \\
\text { supplements in } \\
\text { malnourished } \\
\text { elderly patients } \\
\text { living in the } \\
\text { community: a } \\
\text { pharmaco- } \\
\text { economic study }\end{array}$ & $\begin{array}{l}\text { Prospective } \\
\text { longitudinal } \\
\text { cohort study, } \\
12 \text { months } \\
\text { follow-up. } \\
\text { Group 1- } \\
\text { physicians } \\
\text { frequently } \\
\text { prescribe } \\
\text { ONS, Group } 2 \\
\text { rarely }\end{array}$ & $\begin{array}{l}378 \text { patients of } \\
90 \text { general } \\
\text { practitioners in } \\
\text { France. All } \\
\text { participants were } \\
\text { over } 70 \text { years of } \\
\text { age, } \\
\text { malnourished, } \\
\text { and living at } \\
\text { home or in } \\
\text { institutions. }\end{array}$ & $\begin{array}{l}\text { Frequent or rare } \\
\text { use of ONS }\end{array}$ & $\begin{array}{l}\text { 1. Nutritional } \\
\text { status using } \\
\text { MNA (Mini- } \\
\text { Nutritional } \\
\text { Assessment) } \\
\text { 2. Cost of } \\
\text { medical and } \\
\text { hospital care }\end{array}$ & $\begin{array}{l}\text { MNA improved significantly more in } \\
\text { group } 2(\mathrm{p}<0: 01) \text {. (Repeated } \\
\text { measures over time, regression with } \\
\text { propensity score method; Student's } t \text { - } \\
\text { test). } \\
\text { Net cost savings including cost of } \\
\text { supplements: EUR }-195 ; 90 \% \text { CI } \\
{[929,478]}\end{array}$ & $\begin{array}{l}\text { Measured } \\
\text { malnutrition using } \\
\text { MNA tool }\end{array}$ \\
\hline
\end{tabular}

\begin{tabular}{|c|c|c|c|c|c|}
\hline $\begin{array}{l}\text { Botella- } \\
\text { Carretero et } \\
\text { al. (2010) }\end{array}$ & $\begin{array}{l}\text { Perioperative oral } \\
\text { nutritional } \\
\text { supplements in } \\
\text { normally or mildly } \\
\text { undernourished } \\
\text { geriatric patients } \\
\text { submitted to } \\
\text { surgery for hip } \\
\text { fracture: a } \\
\text { randomized } \\
\text { clinical trial }\end{array}$ & $\begin{array}{l}\text { Randomized, } \\
\text { controlled } \\
\text { clinical trial }\end{array}$ & $\begin{array}{l}60 \text { participants } \\
\text { ( } 30 \text { in } \\
\text { intervention } \\
\text { group, } 30 \\
\text { control), from } \\
\text { one hospital in } \\
\text { Spain; post-hip } \\
\text { fracture patients } \\
\text { over } 65 \text { years old } \\
\text { requiring } \\
\text { surgery, admitted } \\
5 / 07 \text { to } 9 / 08, \\
\text { excluding } \\
\text { patients with } \\
\text { severe/ } \\
\text { moderate } \\
\text { malnutrition }\end{array}$ & $\begin{array}{l}\text { Perioperative } \\
\text { ONS, vs. no } \\
\text { ONS }\end{array}$ & $\begin{array}{l}\text { A. For intervention group vs. control } \\
\text { (using repeated measures GLM): } \\
\text { 1. Less decrease in albumin in } \\
\text { intervention group. } \mathrm{F}=22.536, p< \\
.001 \text { (within subjects factor). } \\
\text { 2. Improved post-op recovery } \\
(F=5.763, p<.002 \text { ). } \\
3 . \text { Smaller decrease in prealbumin . } F \\
=6.654, p<.001 \text { (within-subjects } \\
\text { factor). } \\
4 \text {. No significant difference for change } \\
\text { in BMI: } F=2.509, p<.089 \text { (within- } \\
\text { subjects factor) } \\
5 . \text { Fewer post-op complications; not } \\
\text { significant. } \\
\text { B. Rate of post-op complications } \\
\text { associated with lower intake of } \\
\text { protein; No significant difference in }\end{array}$ \\
\hline
\end{tabular}




\begin{tabular}{|c|c|c|c|c|c|c|c|}
\hline $\begin{array}{l}\text { Author \& } \\
\text { Year }\end{array}$ & Title & Study Design & Study Population & $\begin{array}{l}\text { Independent } \\
\text { Variables }\end{array}$ & $\begin{array}{l}\text { Dependent } \\
\text { variables }\end{array}$ & Results & Other \\
\hline $\begin{array}{l}\text { Bourdel } \\
\text {-Marchasson, } \\
\text { I., Barateau, } \\
\text { M., Rondeau, } \\
\text { V., Dequae- } \\
\text { Merchadou, } \\
\text { L., Salles- } \\
\text { Montaudon, } \\
\text { N., Emeriau, } \\
\text { J., \& ... } \\
\text { Dartigues, J. } \\
(2000) \text {. }\end{array}$ & $\begin{array}{l}\text { A multi-center } \\
\text { trial of the effects } \\
\text { of oral nutritional } \\
\text { supplementa-tion } \\
\text { in critically ill } \\
\text { older inpatients. } \\
\text { GAGE Group. } \\
\text { Groupe Aquitain } \\
\text { Geriatrique } \\
\text { d'Evaluation }\end{array}$ & $\begin{array}{l}\text { Propsective } \\
\text { multicenter } \\
\text { trial over } 19 \\
\text { hospital } \\
\text { wards. } \mathrm{N}= \\
672 \text { (total); } \\
295 \text { in the } \\
\text { nutritional } \\
\text { intervention } \\
\text { group; } 377 \text { in } \\
\text { the control } \\
\text { group }\end{array}$ & $\begin{array}{l}672 \text { critically ill } \\
\text { hospitalized } \\
\text { patients > 65 } \\
\text { years old, from } \\
19 \text { hospital wards } \\
\text { in SW France; } \\
295 \text { participants } \\
\text { in intervention } \\
\text { group; } 377 \text { in the } \\
\text { control group. } \\
\text { Patients in } \\
\text { control group } \\
\text { comparable by } \\
\text { age, C-reactive } \\
\text { protein, and sex } \\
\text { distribution }\end{array}$ & $\begin{array}{l}\text { Provision of two } \\
\text { high protein } \\
\text { ONS daily, vs no } \\
\text { supplements. }\end{array}$ & $\begin{array}{l}\text { ONS } \\
\text { tolerance, time } \\
\text { from surgery } \\
\text { to } \\
\text { mobilization. } \\
\text { Protein \& } \\
\text { energy intake, } \\
\text { incidence of } \\
\text { pressure } \\
\text { ulcers }\end{array}$ & $\begin{array}{l}\text { Protein \& energy intake higher in } \\
\text { intervention group all days measured; } \\
p<.001 \text { for all } 5 \text { days for protein, } 3 \text { of } \\
\text { the } 5 \text { days measured for energy } \\
\text { (Student's } t \text {-test). } \\
\text { Relative risk of pressure ulcer } \\
\text { development at } 15 \text {-day follow-up for } \\
\text { control group }=1.57 ; 95 \% \text { CI }[1.03 \text {, } \\
2.38] ;(p=.04) \text { using multivariate } \\
\text { Cox proportional model }\end{array}$ & . \\
\hline $\begin{array}{l}\text { Chima, C. S, } \\
\text { Barco, K., } \\
\text { Marci L. A. } \\
\text { Dewitt, M. L. } \\
\text { A., Maeda, } \\
\text { M.,Teran, J. } \\
\text { C.,Mullen, K. } \\
\text { D. (1997) }\end{array}$ & $\begin{array}{l}\text { Relationship of } \\
\text { Nutritional Status } \\
\text { to Length of Stay, } \\
\text { Hospital Costs, } \\
\text { and Discharge } \\
\text { Status of Patients } \\
\text { Hospitalized in the } \\
\text { Medicine Service }\end{array}$ & $\begin{array}{l}\text { Prospective } \\
\text { cohort }\end{array}$ & $\begin{array}{l}\text { Patients in } 3 \\
\text { medicine units in } \\
\text { tertiary-care } \\
\text { hospital in } \\
\text { Midwestern U.S., } \\
\text { admitted } \\
\text { throughout } \\
\text { December } 1994\end{array}$ & $\begin{array}{l}\text { At-risk or not-at- } \\
\text { risk for } \\
\text { malnutrition }\end{array}$ & $\begin{array}{l}\text { LOS, costs } \\
\text { and } \\
\text { reimburse- } \\
\text { ment, and } \\
\text { discharge } \\
\text { placement }\end{array}$ & $\begin{array}{l}\text { Median LOS } 4 \text { days for not-at-risk } \\
\text { group, } 6 \text { days for at-risk group }(p< \\
.001) \text {. } \\
\text { Mean cost: } \$ 4,563 \text { for not-at-risk } \\
\text { patients, } \$ 6,196 \text { for at-risk }(p<.02) \text {. } \\
\text { Readmission rates not significantly } \\
\text { different. } \\
\text { Highest rates of malnutrition in } \\
\text { patients with liver disease }\end{array}$ & $\begin{array}{l}\text { Malnutrition } \\
\text { defined by any of } \\
\text { the following: } \\
\text { weight for height } \\
<75 \% \mathrm{IBW}^{4} \text {, } \\
\text { albumin level }<30 \\
\mathrm{~g} / \mathrm{L} \text { on admission, } \\
\text { or weight loss of } \\
\geq 10 \% \text { in month } \\
\text { prior to admission }\end{array}$ \\
\hline
\end{tabular}

(table continues) 


\begin{tabular}{|c|c|c|c|c|c|c|c|}
\hline $\begin{array}{l}\text { Author \& } \\
\text { Year }\end{array}$ & Title & Study Design & Study Population & $\begin{array}{l}\text { Independent } \\
\text { Variables }\end{array}$ & $\begin{array}{l}\text { Dependent } \\
\text { variables }\end{array}$ & Results & Other \\
\hline $\begin{array}{l}\text { Correia, M. I.. } \\
\text { T. D., } \\
\text { Waitzberg, D } \\
\text { L. (2003) }\end{array}$ & $\begin{array}{l}\text { The impact of } \\
\text { malnutrition on } \\
\text { morbidity, } \\
\text { mortality, length } \\
\text { of } \\
\text { hospital stay and } \\
\text { costs evaluated } \\
\text { through a } \\
\text { multivariate } \\
\text { model analysis }\end{array}$ & $\begin{array}{l}\text { Retrospective } \\
\text { cohort study }\end{array}$ & $\begin{array}{l}709 \text { patients, } \\
\text { aged } 18 \text { or over, } \\
\text { chosen randomly } \\
\text { from } 25 \\
\text { Brazilian } \\
\text { hospitals }\end{array}$ & $\begin{array}{l}\text { Nutritional } \\
\text { status: Well- } \\
\text { nourished or } \\
\text { malnourished }\end{array}$ & $\begin{array}{l}\text { LOS, } \\
\text { complications, } \\
\text { mortality, } \\
\text { hospital costs }\end{array}$ & $\begin{array}{l}\text { Cox multivariate model for IV and } \\
\text { LOS: OR 0.7, CI [0.59, } 0.83] \text {; multiple } \\
\text { regression for complications on } \\
\text { malnutrition: OR } 1.60, \text { CI [1.09, 2.35]; } \\
\text { univariate analysis with chi-square test } \\
\text { to determine RR between IV and } \\
\text { morbidity, LOS, and mortality. } \\
\text { Overall costs for hospitalized } \\
\text { malnourished patients } 308.9 \% \text { higher } \\
\text { than well-nourished patients. }\end{array}$ & $\begin{array}{l}\text { Malnutrition } \\
\text { determined by } \\
\text { Subjective Global } \\
\text { Assessment }\end{array}$ \\
\hline $\begin{array}{l}\text { Gariballa, } \\
\text { Forster, } \\
\text { Walters, \& } \\
\text { Powers } \\
\text { (2006) }\end{array}$ & $\begin{array}{l}\text { A randomized, } \\
\text { double-blind, } \\
\text { placebo-controlled } \\
\text { trial of nutritional } \\
\text { supplementation } \\
\text { during acute } \\
\text { illness }\end{array}$ & $\begin{array}{l}\text { Randomized, } \\
\text { double-blind, } \\
\text { controlled } \\
\text { study }\end{array}$ & $\begin{array}{l}445 \text { hospitalized } \\
\text { patients aged } 65 \\
\text { to } 92 \text { years, in } \\
\text { the UK }\end{array}$ & $\begin{array}{l}\text { Receipt of high- } \\
\text { calorie ONS vs. } \\
\text { placebo }\end{array}$ & $\begin{array}{l}\text { 1. Hospital } \\
\text { readmission } \\
\text { 2. Hospital } \\
\text { LOS } \\
\text { 3. Mortality at } \\
6 \text { months } \\
\text { 4. Nutritional } \\
\text { status }\end{array}$ & $\begin{array}{l}\text { 1. Adjusted hazard ratio for } \\
\text { readmission: } 0.68 \%, \text { CI }[0.49-0.94] \text {. } \\
\text { 2. LOS: supplement group }=9.4 \text { days, } \\
\text { placebo group }=10.1 \text { days. } \\
\text { 3. Mortality at six months: } 14 \% \text { for } \\
\text { the supplement group, } 9 \% \text { for the } \\
\text { placebo group. } \\
\text { 4. Serum albumin at } 6 \text { months: } 42.0 \\
\text { (supplement group), } 40.5 \text { (placebo } \\
\text { group), respectively }(P=.04) \text {. No } \\
\text { change in BMI, body weight, MUAC, } \\
\text { or TSF, or serum transferrin. }\end{array}$ & \\
\hline $\begin{array}{l}\text { Hoekstra, J. } \\
\text { C., } \\
\text { Goosen, J. H. } \\
\text { M., } \\
\text { de Wolf, G., } \\
\text { \& Verheyen, } \\
\text { C. (2011) }\end{array}$ & $\begin{array}{l}\text { Effectiveness of } \\
\text { multidisciplinary } \\
\text { nutritional care on } \\
\text { nutritional intake, } \\
\text { nutritional status } \\
\text { and quality of life } \\
\text { in patients with } \\
\text { hip fractures: a } \\
\text { controlled } \\
\text { prospective cohort } \\
\text { study }\end{array}$ & $\begin{array}{l}\text { Controlled } \\
\text { prospective } \\
\text { cohort study }\end{array}$ & $\begin{array}{l}\text { Hospital } \\
\text { inpatients with } \\
\text { operative } \\
\text { intervention } \\
\text { following hip } \\
\text { fracture, over age } \\
65 \text {. Intervention } \\
\text { group = 61 } \\
\text { patients; control } \\
\text { group = 66 } \\
\text { patients. }\end{array}$ & $\begin{array}{l}\text { Multidisciplinary } \\
\text { Nutrition } \\
\text { Intervention. } \\
\text { Dietitian consult } \\
\text { for high-risk } \\
\text { patients. }\end{array}$ & $\begin{array}{l}\text { Protein \& } \\
\text { energy intake; } \\
\text { quality of life } \\
\text { (EQ-5D index } \\
\text { scores \& } \\
\text { VAS-scores); } \\
\text { Number } \\
\text { classified as } \\
\text { malnourished }\end{array}$ & $\begin{array}{l}\text { Significant increase in protein \& } \\
\text { energy intake in intervention group. } \\
\text { Significantly less reduction in EQ-5D } \\
(\mathrm{p}=.004) \text { and VAS }(\mathrm{p}=.039) \text { in } \\
\text { intervention group. } \\
\text { At } 3 \text {-month follow-up, control group } \\
\text { had significant increase in patients } \\
\text { classified as malnourished or at } \\
\text { nutrition risk; intervention group had } \\
\text { significantly fewer than control ( } p \\
=.019) \text {. }\end{array}$ & $\begin{array}{l}\text { Nutritional status } \\
\text { was determined by } \\
\text { the Mini } \\
\text { Nutritional } \\
\text { Assessment } \\
\text { (MNA), }\end{array}$ \\
\hline
\end{tabular}




\begin{tabular}{|c|c|c|c|c|c|c|c|}
\hline $\begin{array}{l}\text { Author \& } \\
\text { Year }\end{array}$ & Title & Study Design & Study Population & $\begin{array}{l}\text { Independent } \\
\text { Variables }\end{array}$ & $\begin{array}{l}\text { Dependent } \\
\text { variables }\end{array}$ & Results & Other \\
\hline $\begin{array}{l}\text { Houwing, R. } \\
\text { (2003). }\end{array}$ & $\begin{array}{l}\text { A randomised, } \\
\text { double-blind } \\
\text { assessment of the } \\
\text { effect of } \\
\text { nutritional } \\
\text { supplementation } \\
\text { on the prevention } \\
\text { of pressure ulcers } \\
\text { in hip-fracture } \\
\text { patients }\end{array}$ & $\begin{array}{l}\text { Double-blind, } \\
\text { randomised, } \\
\text { placebo- } \\
\text { controlled trial }\end{array}$ & $\begin{array}{l}103 \text { hip fracture } \\
\text { patients from } 3 \\
\text { centers in the } \\
\text { Netherlands; } 51 \\
\text { received } \\
\text { supplements, } 52 \\
\text { received placebo. }\end{array}$ & $\begin{array}{l}400 \mathrm{ml} \text { daily of } \\
\text { ONS vs. placebo }\end{array}$ & $\begin{array}{l}\text { Incidence of } \\
\text { stage I and II } \\
\text { pressure } \\
\text { ulcers (PUs); } \\
\text { time to } \\
\text { development } \\
\text { of PU; } \\
\text { duration of } \\
\text { ulcer; } \\
\text { maximum } \\
\text { wound size. }\end{array}$ & $\begin{array}{l}\text { ONS group vs. placebo group: } \\
\text { Incidence of stage I PU: } 31.4 \% \text { vs. } \\
36.7 \%(p=.674) \text {; stage II pressure } \\
\text { ulcers: } 18 \% \text {, vs. } 28 \%(p=.345) \text {. } \\
\text { First day of PU: } 3.6 \pm 0.9 \text { (ONS) vs. } \\
1.6 \pm 0.9 \text { (placebo), } p=.090 . \\
\text { Size: } 1.6 \pm 0.3 \text { vs. } 2.2 \pm 0.4(p=.232)\end{array}$ & $\begin{array}{l}\text { Supplement } \\
\text { fortified with } \\
\text { protein, zinc, } \\
\text { arginine, and } \\
\text { antioxidants }\end{array}$ \\
\hline $\begin{array}{l}\text { Lawson, R. } \\
\text { M., Dishi, M. } \\
\text { K., Barton, J. } \\
\text { R., \& Cobden, } \\
\text { I. (2003) }\end{array}$ & $\begin{array}{l}\text { The effect of } \\
\text { unselected post- } \\
\text { operative } \\
\text { nutritional } \\
\text { supplementation } \\
\text { on nutritional } \\
\text { status and clinical } \\
\text { outcome } \\
\text { of orthopaedic } \\
\text { patients }\end{array}$ & $\begin{array}{l}\text { Prospective } \\
\text { controlled }\end{array}$ & $\begin{array}{l}181 \text { patients in } \\
\text { two adult } \\
\text { orthopedic wards } \\
\text { in hospital in } \\
\text { UK. Study } \\
\text { group: } n=84 ; \\
\text { control group: } \\
\text { n=97. } \\
\text { Overall, } \\
\text { participants were } \\
\text { not malnourished } \\
\text { (p. } 45)\end{array}$ & $\begin{array}{l}\text { Two ONS daily } \\
\text { starting after } \\
\text { surgery (study } \\
\text { group) }\end{array}$ & $\begin{array}{l}\text { Number of } \\
\text { major \& } \\
\text { minor } \\
\text { complications } \\
\text { Energy intake, } \\
\text { Protein intake, } \\
\text { nutritional } \\
\text { status, } \\
\text { albumin, CRP, } \\
\text { transferrin }\end{array}$ & $\begin{array}{l}\text { Significantly more major } \\
\text { complications in control group; no } \\
\text { significant difference in minor } \\
\text { complications. } \\
(p=0.2) \text {. } \\
\text { No significant difference in nutritional } \\
\text { status, albumin change, or CRP change } \\
\text { Transferrin and hgb changes: Week } 1 \\
\text { reduction significantly greater in } \\
\text { control group ( } p=.002 \text { for each). } \\
\text { Control group had higher hospital } \\
\text { costs and treatments. }\end{array}$ & $\begin{array}{l}\text { Not malnourished } \\
\text { patients }\end{array}$ \\
\hline $\begin{array}{l}\text { Lim, S. L., } \\
\text { Ong, K. C. B., } \\
\text { Chan, Y. H., } \\
\text { Loke, W. C., } \\
\text { Ferguson, M., } \\
\text { \& Daniels, L. } \\
(2012)\end{array}$ & $\begin{array}{l}\text { Malnutrition and } \\
\text { its impact on cost } \\
\text { of hospitalization, } \\
\text { length of stay, } \\
\text { readmission and 3- } \\
\text { year mortality }\end{array}$ & $\begin{array}{l}\text { Prospective 3- } \\
\text { year cohort } \\
\text { study and a } \\
\text { matched case } \\
\text { control study }\end{array}$ & $\begin{array}{l}\text { Newly admitted } \\
\text { hospital patients, } \\
\text { 18-74 years old; } \\
818 \text { participants. }\end{array}$ & $\begin{array}{l}\text { Nutritional } \\
\text { status: } \\
\text { Malnourished vs. } \\
\text { well-nourished }\end{array}$ & $\begin{array}{l}\text { LOS; } \\
\text { readmission in } \\
15 \text { or } 90 \text { days } \\
\text { and } 6 \text { months; } \\
\text { inpatient } \\
\text { mortality, cost } \\
\text { of hospital } \\
\text { stay }\end{array}$ & $\begin{array}{l}\text { Malnutrition found in } 29 \% \text { of patients. } \\
\text { These had greater LOS ( } 6.9-7.3 \text { days, } \\
\text { vs. } 4.6-5.6 \text { days }(\mathrm{p}<.001) \text {, and greater } \\
\text { change of readmission within } 15 \text { days } \\
(R R 1.9, \text { CI }[1.1,3.2]) \text {; } \\
\text { Malnutrition significant predictor of } \\
\text { mortality: Adjusted hazard } \\
\text { ratio }=4.4,95 \% \text { CI }[3.3,6.0], \mathrm{p}<.001\end{array}$ & $\begin{array}{l}\text { Nutritional status } \\
\text { determined by } \\
\text { Subjective Global } \\
\text { Assessment }\end{array}$ \\
\hline
\end{tabular}




\begin{tabular}{|c|c|c|c|c|c|c|c|}
\hline $\begin{array}{l}\text { Author \& } \\
\text { Year }\end{array}$ & Title & Study Design & Study Population & $\begin{array}{l}\text { Independent } \\
\text { Variables }\end{array}$ & $\begin{array}{l}\text { Dependent } \\
\text { variables }\end{array}$ & Results & Other \\
\hline $\begin{array}{l}\text { Neelemaat, F., } \\
\text { Bosmans, J. } \\
\text { E., Thijs, A., } \\
\text { Seidell, J. C., } \\
\text { \& van } \\
\text { Bokhorst-de } \\
\text { van der } \\
\text { Schueren, } \\
(2012)\end{array}$ & $\begin{array}{l}\text { Oral nutritional } \\
\text { support in } \\
\text { malnourished } \\
\text { elderly decreases } \\
\text { functional } \\
\text { limitations with no } \\
\text { extra costs }\end{array}$ & $\begin{array}{l}\text { Randomized } \\
\text { controlled trial }\end{array}$ & $\begin{array}{l}210 \\
\text { malnourished } \\
\text { hospitalized } \\
\text { patients aged } 60 \\
\text { or over; } 105 \text { in } \\
\text { intervention } \\
\text { group; } 105 \text { in } \\
\text { control group, }\end{array}$ & $\begin{array}{l}\text { Special diet, } \\
\text { ONS, calcium- } \\
\text { vitamin D } \\
\text { supplement, } \\
\text { telephonic } \\
\text { dietitian } \\
\text { counseling until } \\
3 \text { months post- } \\
\text { discharge. }\end{array}$ & $\begin{array}{l}\text { 1. Quality } \\
\text { Adjusted Life } \\
\text { Years } \\
\text { 2. Frequency } \\
\text { and duration } \\
\text { of physical } \\
\text { activities } \\
\text { 3. Functional } \\
\text { Limitations }\end{array}$ & $\begin{array}{l}\text { 1. No significant difference in QALYs } \\
\text { 2. No significant difference in physical } \\
\text { activities } \\
\text { 3. Significantly greater decrease in } \\
\text { functional limitations in intervention } \\
\text { group: Mean difference }=-0.72,95 \% \\
\text { CI [-1.15, }-0.28]\end{array}$ & \\
\hline $\begin{array}{l}\text { Park, L. } \\
\text { Andrade, D. } \\
\text { Mastey, A. } \\
\text { Sun, J. } \\
\text { Hicks, L. } \\
\text { (2014) }\end{array}$ & $\begin{array}{l}\text { Institution specific } \\
\text { risk factors for } 30- \\
\text { day readmission at } \\
\text { a community } \\
\text { hospital: a } \\
\text { retrospective } \\
\text { observational } \\
\text { study }\end{array}$ & $\begin{array}{l}\text { Retrospective } \\
\text { Observational }\end{array}$ & $\begin{array}{l}101 \text { patients (the } \\
34 \text { readmitted } \\
\text { patients above as } \\
\text { well as } 67 \text { non- } \\
\text { readmitted } \\
\text { patients) } \\
\text { discharged } \\
\text { between January } \\
1,2011 \text { to April } \\
31,2011 \text { with } \\
\text { CHF or PNA. }\end{array}$ & $\begin{array}{l}\text { Hospitalist } \\
\text { census and hours } \\
\text { worked on the } \\
\text { discharge day; } \\
\text { hospital } \\
\text { associated factors } \\
\text { (i.e. floor of } \\
\text { discharge, } \\
\text { Season, day of } \\
\text { week of d/c) }\end{array}$ & $\begin{array}{l}\text { 30-day } \\
\text { hospital } \\
\text { readmission } \\
\text { for dx of CHF, } \\
\text { pneumonia } \\
\text { and COPD }\end{array}$ & $\begin{array}{l}\text { Readmission rates by } \mathrm{dx}: \\
\mathrm{CHF}=19.6 \% \\
\text { Pneumonia }=13.0 \% \\
\text { Chronic obstructive pulmonary disease } \\
=14.7 \% \\
\text { Readmissions significantly more likely } \\
\text { in winter than summer; } O R=1.54 ; p= \\
.0008 . \\
\text { Fewer readmissions for patients } \\
\text { discharged from the cardiac floor vs. } \\
\text { medical/oncology: } O R=0.85, \mathrm{p}=.08 \text { ). }\end{array}$ & \\
\hline $\begin{array}{l}\text { Somanchi, M. } \\
\text { Tao, X., \& } \\
\text { Mullin, G. E. } \\
\text { (2011) }\end{array}$ & $\begin{array}{l}\text { The Facilitated } \\
\text { Early Enteral and } \\
\text { Dietary } \\
\text { Management } \\
\text { Effectiveness } \\
\text { Trial in } \\
\text { Hospitalized } \\
\text { Patients With } \\
\text { Malnutrition }\end{array}$ & $\begin{array}{l}\text { Prospective; } \\
\text { Intervention, } \\
\text { cohort with } \\
\text { comparison } \\
\text { group }\end{array}$ & $\begin{array}{l}400 \text { patients in } \\
\text { two medical } \\
\text { wards at Johns } \\
\text { Hopkins } \\
\text { Hospital. }\end{array}$ & $\begin{array}{l}\text { Clinical nutrition } \\
\text { screening, } \\
\text { consultation, } \\
\text { Assessments. }\end{array}$ & $\begin{array}{l}\text { Prevalence of } \\
\text { malnutrition; } \\
\text { LOS, Case } \\
\text { Mix Index, } \\
\text { DRG coding } \\
\text { of } \\
\text { malnutrition, } \\
\text { nutrition } \\
\text { intervention }\end{array}$ & $\begin{array}{l}\text { Malnutrition found in } 53 \% \text { of study } \\
\text { population. } \\
\text { Reduced LOS of } 1.93 \text { days in nutrition } \\
\text { intervention cohort; reduction by } 3.2 \\
\text { days in } \\
\text { severely malnourished group }\end{array}$ & $\begin{array}{l}\text { Malnutrition } \\
\text { screening tool } \\
\text { included: } \\
\text { Poor intake, wt } \\
\text { loss, BMI, \%IBW, } \\
\text { albumin }\end{array}$ \\
\hline
\end{tabular}

Notes. ONS = Oral Nutrition Supplements; ICD-10-AM = International Classification of Disease and Related Health Problems, Tenth Revision, Australian Modification; IBW = Ideal body weight.; $\mathrm{CHF}=$ congestive heart failure; $\mathrm{COPD}=$ chronic obstructive pulmonary disease.

${ }^{a}$ In this study, patients with severe/moderate malnutrition were "those with a weight loss of more than $5 \%$ in the previous month or more than $10 \%$ in the previous 6 months from their usual weight, and/or serum albumin concentrations below $2.7 \mathrm{~g} / \mathrm{dL}$ " (Botella-Carretero et al., 2010, p. 575). 


\section{Critique of Methods}

Most of the studies found on malnutrition and the benefits of in-hospital nutrition interventions involve only elderly patients (over 65years of age). Many involve only malnourished patients. In the latter studies, definitions of malnutrition vary: Many studies use the SGA tool, others use lab values, weight changes, or BMI. The SGA is a long questionnaire and it would not be practical to administer it to every hospital patient on a routine basis. Also, some measures of nutritional status--such as weight changes, dietary intake, or lab values--may vary greatly during a given hospital stay, so defining a "high-risk" or malnourished patient may be problematic at times; a patient may be considered to be malnourished based on measurements from one day but well-nourished on another, depending on measures used.

Measures of nutritional status may vary by country. For example, BMI is used as one indicator of nutritional status, but the cutoff point for underweight or malnutrition vary in studies from different countries. As mentioned earlier, a BMI of less than 18.5 is considered below normal, or underweight, in the United States (CDC, 2014), and used in medical coding to define malnutrition in Australia (Agarwal et al., 2013). Therefore, Agarwal et al. used this value of BMI as one criteria for malnutrition in their study of hospitalized patients in Australia and New Zealand. However, Neelemaat et al. (2012) used BMI $<20$ as an indicator of malnutrition in their study of the effects of nutritional support on malnourished hospital patients in the Netherlands. 
Lawson et al. (2003) analyzed change in BMI rather than weight during seven days of their hospital stays and found no significant change, despite previous evidence showing that ONS were associated with weight gain. The use of BMI changes instead of weight changes, while useful in showing if subjects moved into higher-risk BMI categories, can introduce measurement errors, since it requires measurement of height and weight. Except in unusual circumstances (bilateral amputations, or compression fractures), a person's height remains constant over the course of a hospitalization. Height is not easily measured in a bed-ridden person; therefore, an additional extra measurement of height provides the opportunity for additional error in results.

Most of the studies available were focused on specific diagnoses, such as hip fractures (Botella-Carretero et al., 2010; Hoekstra et al., 2011; Lawson et al., 2003) or wound healing (Miller et al., 2006) ; one involved pressure ulcers in orthopedic patients (Houwing, 2003). Additionally, several provided supplements in the hospital and continued them post-discharge Neelemaat et al. (2012) offered supplements during hospitalization and for 3 months after hospital discharge; Gariballa et al. (2006) provided supplements for 6 weeks - at least 1 month longer than the average LOS in their study.

In a study showing reduced LOS associated with a nutrition intervention at Johns Hopkins Hospital (Somanchi et al., 2011), the details of the nutrition intervention are not described. The title and content of the paper suggest that an enteral nutrition intervention (tube feeding) was involved, but no description of a type or dose of feeding product are provided. 
Some studies that considered nutritional intake as an outcome only used a 24-hour intake window. This was true in a study by Agarwal et al. (2013) of malnutrition in Australia and New Zealand. Nutritional intake, one of the IVs in the study, was determined for only one 24-hour period. Lawson et al., 2003) also only used a 24-hour period to assess adequacy of nutritional intake; they looked at energy and protein intake as one outcome in a study of post-operative ONS provision in orthopedic patients, using data from a random 24-hour intake analysis among a subsample of participants. Intake for only a 24-hour period may not be a reliable measure of a patient's intake during a hospital stay, because it may be affected by so many factors, such as whether they were on special dietary restrictions for that day, or whether they had nausea/vomiting for just that day, had a recent procedure, or various other factors that could affect meal intake. Several studies used subjective estimations of amount of meals eaten. While this can provide an idea of amount eaten, it can also vary among those observing and recording meal intake, and may not be a reliable estimate of kcal and protein consumed. For example, a person may be considered to have eaten $50 \%$ of a meal, because they ate $100 \%$ of their rice and vegetables; however, this may only provide about $124 \mathrm{kcal}$ and $4-5$ grams of protein. Another patient may also be scored at 50\% of meal eaten after consuming only their meat and dessert, but this may amount to $500 \mathrm{kcal}$ and 22 grams protein. Another may drink several drinks and eat dessert, providing perhaps $500 \mathrm{kcal}$ but only 1-3 grams protein, and be scored at $25 \%$ consumed. In contrast to this, Miller et al. (2006) used 5-day plate waste to determine patient intake levels. 
Supplements were also provided at different times during the hospitalization, or for different periods of time in different studies, making the results hard to compare. For example, Gariballa et al. (2006) gave supplements over a period of six weeks, but mean hospital LOS among participants was 9.4 days for the intervention group, and 10.1 days for the placebo group, indicating that supplements were provided after discharge in addition to the hospital stay. However, LOS was one of the outcomes. Additionally, during the hospital stay, the participants received standard hospital diets, but there was no indication of what participants ate once they left the hospital. As discussed earlier, Botella-Carretero et al. (2008) looked at ONS use after surgery among elderly hip fracture patients compared to a control without supplement provision. The second study by the same authors (Botella-Carretero et al., 2010) examined the same outcomes among patients in whom the supplement was started prior to surgery.

The small study of ONS among outpatients with HF and cachexia by Rozentryt et al. (2010) was too small for definitive conclusions; out of 29 patients starting the study, only 24 patients remained in the study after the 18 weeks were completed, with only 5 receiving placebo drinks. The authors also appeared to compare initial data of all 29 patients with final data for only 24 patients.

Lacking in all the studies reviewed is the use of the epidemiological triad to examine variables. There is little information on how various personal characteristics (other than older age), patient location in the hospital, and timing of supplementation, are related to outcomes. The only personal characteristic studied is ONS use in patients over 
65 years of age. In this care, there is good evidence that patients 65 years of age and older are more likely to be malnourished, and ONS supplementation in malnourished patients has been more likely to produce significantly positive outcomes.

\section{Summary and Conclusions}

As described above, malnutrition has been identified in 30-69\% of hospital patients worldwide. Malnutrition among hospitalized patients has been shown to adversely affect individual health outcomes and has been associated with increased LOS; increased rates of complications, mortality, readmissions; and increased hospitalization costs.

There is evidence that ONS use in hospitals may be an effective and efficient way to prevent or reduce the adverse consequences of malnutrition. Its use has been associated with improved patient and hospital outcomes, reduced LOS, and reduced readmission ratesNutrition intervention by clinical nutrition staff, which often includes the administration of ONS or enteral nutrition support, was shown to be an effective way to improve clinical outcomes in several studies (Hoekstra et al., 2011; Neelemaat et al., 2012; Somanchi et al., 2011).

Previous prospective case-controlled studies have demonstrated improved patient and hospital outcomes or reduced costs among selected patient populations, including elderly patients in the community (Arnaud-Battandier et al., 2004), elderly hospitalized patients (Gariballa et al., 2007), and hospitalized orthopedic patients. Clinical benefits among orthopedic patients have included reduced weight loss (Miller et al., 2006), 
improved recovery and smaller drops in serum albumin (Botella-Carretero et al., 2010), and fewer complications (Lawson et al, 2003); Neelemaat et al. (2012) showed fewer functional limitations among patients receiving ONS. In a review of 55 studies, Milne et al. (2006) found that the provision of ONS in elderly undernourished hospital patients was associated with fewer complications and lower mortality rates compared to controls. Benefits have also been shown among elderly hospitalized patients at risk for pressure ulcer development (Bourdel-Marchasson et al., 2000), and elderly undernourished hospital patients (Milne et al., 2006). Results of improved outcomes among patients through nutrition interventions were especially salient in elderly patients, and appear to be magnified among patients with poor nutritional status (Milne et al., 2006; Philipson et al., 2013).

Nutrition intervention by clinical nutrition staff, which often includes the administration of ONS or enteral nutrition support, has also been shown to be an effective way to improve clinical outcomes (Hoekstra et al., 2011; Neelemaat et al., 2012; Somanchi et al., 2011). Stratton and Elia (2007), in their meta-analysis on the use of ONS in hospital and community settings, revealed consistent clinical benefits - such as improved nutritional status and reductions in complications - associated with the use of ONS.

Regarding HF patients, Aziz et al. (2011) found a significant association between LOS and lower nutrition risk scores among HF patients, using a risk score derived from albumin levels and weight changes, however ONS were not involved in this study. In a 
small prospective placebo-controlled study of 29 outpatient heart clinic patients, Rozentryt et al (2010) found significant improvements in weight and quality of life among HF patients receiving ONS; but there were only six patients in the placebo group, which was not large enough to make definitive conclusions.

\section{Gap Addressed by this Study}

All of the studies described using clinical and individual hospital data were prospective; some were randomized controlled studies. While these are of benefit in established associations, they do not reflect what happens in typical day-to-day hospital practice. Limited research was found regarding the use of ONS in usual hospital practice, and no studies were identified that looked at epidemiological triad factors of person, place, and time and how these variables relate to the benefit of nutritional intervention and supplementation.

Most available evidence in recent years showing improved outcomes related to ONS use is among selected populations. This includes elderly patients (ArnaudBattandier et al., 2004; Botella-Carretero et al., 2010; Bourdel-Marchasson et al., 2000; Neelemaat et al., 2012), orthopedic patients (Lawson et al., 2003)—especially those with hip fractures (Botella-Carretero et al., 2010; Hoekstra et al., 2011), and patients with pressure ulcers (Houwing, 2003).

Evidence is limited, however, on the effectiveness of ONS for patients with a primary diagnosis of heart failure. No studies specifically on ONS among hospitalized HF patients could be found, and the study on outpatients with CHF by Rozentryt et al. 
(2010), had too small of a sample size for definitive conclusions. Therefore, a gap exists for the study of ONS among hospitalized HF patients in general. Additionally, no studies were found that considered the epidemiological triad in choice of covariates. Therefore, my study is intended to help fill a gap on studies of the relationship of ONS use to clinical and hospital outcomes among HF patients, with the added consideration of the epidemiological triad in the analysis of covariates.

Additionally, most of the current research appears to be from outside the United States. Several studies (Agarwal et al., 2012; Agarwal et al., 2013; Miller et al., 2006) took place in Australia and New Zealand; two in France (Arnaud-Battandier, et al., 2004; Bourdel-Marchasson et al, 2000); others in Spain (Botella-Carretero et al., 2010); the UK (Lawson et al., 2003); and the Netherlands (Hoekstra et al., 2011; Neelemat et al, 2012); one was in the Baltimore, Maryland (Somanchi et al., 2011). The latter appeared to involve only enteral nutrition support, and not oral supplements. None of the studies found were performed in the Southeastern United States, which has unique cultural factors that could affect intake, health status, and outcomes related to nutrition interventions.

In summary, a number of factors have been identified in the existing literature that are related to the outcomes of LOS, weight changes, and albumin levels among malnourished and adequately-nourished individuals, including diagnosis, baseline albumin, baseline BMI, diagnosis, comorbidities, age, and race. Other factors, such as nutritional status, appear to moderate the effect of ONS on these outcomes. ONS has 
been demonstrated to be an effective intervention among patients with certain diagnoses or conditions, such as orthopedic injuries, surgery, and pressure ulcers. Much of the previous research has been outside the United States, and no other study has been identified that has examined the epidemiological triad. This study will address a common and costly diagnosis, $\mathrm{HF}$, for which nutrition is an important factor in recovery, but for which there is inadequate data on the use of ONS in daily practice in an acute care facility. In addition, this study uniquely addresses the population of HF patients in an acute care setting in the southeastern United States. The retrospective approach, evaluating outcomes for persons on ONS with a comparison group who did not receive ONS, will capture the results of ONS use in the daily practice of a hospital, and help identify whether routine ONS prescription may be cost-effective and of tangible benefit to patients.

The following chapter provides details of the research design and methodology to address the research questions presented earlier, by evaluating the relationship between ONS and the outcomes of changes in serum albumin, changes in weight, and LOS, and the effects of the following covariates: baseline (initial) BMI, initial serum albumin level, BNP levels, age, race, gender, CCI, payer, planned discharge destination, diagnosis of malnutrition, nutrition risk screening score, RD consultation, location in hospital, and season of year of admission. 
Chapter 3: Research Method

\section{Introduction}

This study sought to provide further insight into whether intervention with ONS is related to improved nutrition outcomes and hospital outcomes in hospitalized patients. As mentioned previously, a manufacturer of one ONS in the United States has recommended routine ONS use for patients who meet certain criteria in hospitals, citing evidence that the use of ONS in hospitals may be an effective and efficient way to improve patient and hospital outcomes, reduce LOS, and reduce readmission rates (Alliance to Advance Patient Nutrition, 2013; Abbott Laboratories, 2014). At the same time, hospitals are under pressure to improve patient outcomes and reduce costs. Research has revealed the benefits of ONS for orthopedic patients and for wound healing, but less information is available on its benefits for other diagnoses. This study focused on patients with a primary diagnosis of heart failure, because of the large number of discharges for this diagnosis from MRMC in recent years (874 episodes or cases in 2012, and 806 cases in 2013), and because this is a diagnosis targeted by Medicare for improved outcomes. This study examined whether there is a relationship between the provision of ONS and patient and hospital outcomes among patients with this diagnosis in the normal day-to-day practice of a regional medical center between July 2012 and December 2014. The following covariates were evaluated for their effects on the relationship between ONS and the outcomes: baseline (initial) BMI, initial serum albumin level, BNP levels, age, 
race, gender, CCI, payer, planned discharge destination, diagnosis of malnutrition, RD consultation, location in hospital, and season of year of admission.

The remainder of this chapter includes a description of the study variables, covariates, research design, research questions and hypotheses, sampling procedures, description of instruments and constructs used, determination of sample size, a data analysis plan, and description of threats to validity.

\section{Research Design and Rationale}

The independent variable (IV) in this study is nutrition intervention using ONS. As described in the Definitions section of Chapter 2, to be counted as a nutrition intervention using ONS, the supplement had to be ordered at least twice daily, with a daily provision of at least $660 \mathrm{kcal}, 58$ grams carbohydrate, 26 grams protein, and 22 grams fat (at this institution, this would be provided by two servings of Ensure Plus ${ }^{\circledR}$, three servings of Glucerna ${ }^{\circledR}$ Therapeutic Nutrition Shakes, or two servings of Nepro® with Carb Steady®, or a combination of these).

The dependent variables (DVs) examined included two clinical outcomes (albumin, and weight changes); and one hospital outcome (LOS). The available data allowed only for a final analysis of the LOS outcome. Covariates were initial BMI, age, initial BNP, CCI, gender, location in the hospital, and time of year (by season) in which patients were admitted. Multiple logistic regression analysis was used to evaluate the relationship between ONS and LOS, controlling for these covariates. 
In an aspect unique to my study, the covariates cover the three aspects of the epidemiological triad: person, place, and time. Personal characteristics include age, gender, and body-mass index (BMI) in relation to supplement use and patient and hospital outcomes. The place variable refers to location in the hospital by unit or floor on which patients received the supplements. This aspect has been shown previously to have a possible effect on my chosen outcomes (Agarwald et al., 2012). Time aspects of my study include an evaluation of the time of year (by quarters) in which patients were admitted, time patterns of supplement provision — such as whether it was started on admission or later during the hospital stay--and whether the impact of supplement use on patient and hospital outcomes is affected by such timing factors.

Selection of study cases and comparison cases. The word case in the following descriptions will refer to an episode of hospitalization. If a patient was hospitalized more than once during the study period, each hospitalization was considered a separate case. From a list of all patients aged 18 or over discharged with the primary diagnoses of HF between July 2012 and December 2014, cases were selected that met the following criteria:

- Order for ONS in an appropriate quantity to provide at least $660 \mathrm{kcal}, 26$ grams protein, and 22 grams fat daily

- Order for any qualifying ONS will be active for at least $50 \%$ of hospital stay

- Provider order for any oral diet other than a clear liquids diet

- Patient was not on tube feeding or parenteral nutrition. 
The comparison group consisted of all discharged cases from the same time period who met the last three criteria above, and who did not meet the criteria for cases (i.e., on ONS).

Descriptive statistics were run for each variable, then two-way tables were run between the LOS outcome and each IV or covariate. A multivariate logistic regression model was developed using those IVs that showed a significant relationship with LOS in the two-way tables, with ONS as the primary predictor. Results included analyses of relationships between the various covariates and supplement use.

The research design was a retrospective observational design. This study was designed as an epidemiological study rather than a clinical trial. My covariates covered the three aspects of the epidemiological triad: person, place, and time. Quantitative methods of analysis were used to compare outcomes for hospital patients who received ONS with patients who did not receive supplements over a 2-year period of time. The observational retrospective design allowed for evaluation of the effectiveness of ONS use in a "real-world" setting that reflects day-to-day operations in an acute care setting. The large majority of similar studies are prospective, case-control studies. While a retrospective design does not have the strong internal validity of a randomized controlled trial (RCT), it has the advantage of greater external validity; RCTs may not be as generalizable to populations outside of the sample population (Hannan, 2008). This study attempted to produce results that may apply to other hospital settings and potentially other diagnoses. 
Additionally, because of the use of clinical data in a retrospective epidemiological design, this study design has the advantage of being able to capture results of actual patterns of practice by the usual clinicians who normally provide these interventions in the acute care setting (Hannan, 2008). Therefore, this study better reflects the realities and limits of normal hospital operations, such variation in personnel, varying approaches by different providers, varying patient loads, and limited time to identify and assess highrisk patients. Because of the epidemiological perspective, my covariates cover the three aspects of the epidemiological triad: person, place and time.

The hospital started using electronic medical records (EMRs) in March, 2012 (H. Harker, personal communication, October 2, 2014). Therefore, I requested data from a period of time during which EMRs were in place. There were no other special timerelated or resource-related constraints.

\section{Methodology}

\section{Population}

The target population consisted of inpatient cases discharged between July 2012 and December 2014, aged 18 or over, at a regional medical center, with a primary diagnoses of HF. The sample was taken from total number of discharges for the selected diagnoses from July 2012 through December 2013. The study was originally planned to include the diagnoses of acute myocardial infarction (AMI), HF, pneumonia, and chronic obstructive pulmonary disease (COPD). However, after determining sample size according to the following information, the study was narrowed down to only one 
diagnosis, HF. The hospital provided the following discharge numbers for 2012 and 2013, respectively: AMI - 765, 715; HF - 874, 806; Pneumonia - 557, 604; COPD 740, 834. These numbers were used to estimate sample size.

On September 23, 2014, there were 20 patients receiving ONS in the hospital, out of approximately 400 patients; and on September 30, 2014, there were 17 patients on supplements out of a total of 336 patients in the hospital (J. Plassmeyer, personal communication, September 30, 2014). These numbers provided an estimate of $5 \%$ of patients on ONS. Extrapolating this gives the following predicted number of patients on ONS for a 2.5-year period: AMI - 93 patients; $\mathrm{HF}$ - 105 patients; pneumonia -73 patients; and COPD - 99 patients.

On September 30, 2014, out of a census of 336, 74 patients (22\%) were either NPO, on clear liquids or on tube-feedings (J. Plassmeyer, personal communication, September 30, 2014). This percentage was used to estimate how many potential controls would be available. As seen in table 2, because of the large number of discharges, I determined that there will be adequate numbers of controls for a 4:1 or 3:1 ratio of controls to cases.

For exclusions for those under 18 years of age, I used an estimate from staff at the Children's' Hospital: There was an estimated average daily census of approximately 48 pediatric patients out of an estimated average hospital census of around 350 (M. Narayanan, personal communication, $\sim$ September 30, 2014). These cases were excluded 
from estimates, where appropriate, since Children's Hospital data was included in hospital data received.

Table 2

Estimated Available ONS Cases and Comparison (July 2012 - December 2014)

\begin{tabular}{|c|c|c|c|c|c|c|}
\hline Diagnosis & $\begin{array}{l}\text { Total } \\
\text { on } \\
\text { ONS }\end{array}$ & $\begin{array}{c}\text { Available } \\
\text { ONS cases } \\
\text { low }^{\mathrm{a}}\end{array}$ & $\begin{array}{c}\text { Available } \\
\text { ONS cases } \\
\text {-high }^{\mathrm{a}}\end{array}$ & $\begin{array}{c}\text { Total } \\
\text { Discharges }\end{array}$ & $\begin{array}{c}\text { Available } \\
\text { comparison } \\
\text { cases-low }^{\mathrm{b}}\end{array}$ & $\begin{array}{c}\text { Available } \\
\text { comparison } \\
\text { cases -high }\end{array}$ \\
\hline AMI & 93 & 74 & 79 & 1750 & 1191 & 1366 \\
\hline $\mathrm{HF}$ & 105 & 84 & 89 & 2100 & 1428 & 1638 \\
\hline Pneumonia & 73 & 58 & 61 & 1451 & 789 & 929 \\
\hline COPD & 99 & 79 & 84 & 1968 & 1338 & 1474 \\
\hline
\end{tabular}

Note. Numbers are after exclusions. Estimates were based on September-October 2014 percentages of patients on ONS ( 5\%), and 2012-2013 discharge figures. An estimated 15-20\% of patients on ONS were expected to be excluded per exclusion criteria. Approximately $36 \%$ of patients in the comparison group for pneumonia were expected to be excluded because they would not meet criteria (22\% per hospital diet order exclusion criteria, and $14 \%$ aged under 18 ). Approximately $22 \%$ of comparison cases with diagnoses of AMI, HF, and COPD were expected to be excluded based on hospital diet order exclusion criteria alone, with no exclusion for pediatric patients since few pediatric patients were expected to be included in the discharge data for these diagnosis which are rare in the pediatric population.

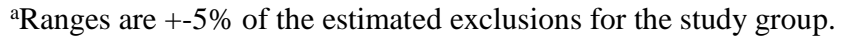

${ }^{b}$ Ranges are $+-5 \%$ of the estimated exclusions for the control group, as described above.

\section{Sampling and Sampling Procedures}

Because of the limited number of available cases, and the need for ONS group sample sizes approximating the available cases, this study used data for all available qualifying cases on ONS for at least $50 \%$ of the hospital stay, who were discharged during the 2.5-year study period. As described above, ONS = yes cases must meet the following criteria: 
- Order for ONS in an appropriate quantity to provide at least $660 \mathrm{kcal}, 26$ grams protein, and 22 grams fat daily

- Order for any qualifying ONS will be active for at least $50 \%$ of hospital stay

- Age 18 or greater on admission

- Provider order for any oral diet other than a clear liquids diet for at least $50 \%$ of their hospital stay

- Patient was not on tube feeding or parenteral nutrition for more than $25 \%$ of stay.

- Control cases had to meet the last three of these criteria, and not be prescribed any ONS.

Sample size calculations. Sample size was estimated using OpenEpi (Dean, Sullivan, \& Soe, 2014). Sample size analysis was carried out for each of the three dependent variables (albumin, weight change, and LOS), to give a power of $80 \%$, and a 95\% two-sided confidence interval (CI). The largest sample size below is 350 total cases, with 70 in the ONS = yes group and 280 comparison $(\mathrm{ONS}=$ no $)$ cases; therefore, this will be the sample size used. The following sample sizes were estimated:

Changes in albumin levels. Lawson et al. (2003), in their study of ONS among orthopedic surgery patients, found a drop in serum albumin of $0.28 \mathrm{~g} / \mathrm{L}$ in the study group, and 0.47 in the control group, with a mean difference of 0.19 between the study and control groups. Botella-Carretero et al. (2010), in a study of ONS among geriatric patients undergoing surgery for hip fracture, found significant differences in albumin 
changes between the study group and control group, but presented only graphical information with F-statistics and $p$-values showing significance. Graphs appear to show approximately $0.1-0.2 \mathrm{~g} / \mathrm{L}$ differences in albumin changes between the study groups and control groups. Therefore, I calculated sample size to detect a difference of $0.15 \mathrm{~g} / \mathrm{L}$ with SD of 0.4 , resulting in an estimated sample size of 350 cases, with 70 in the study group and 280 controls.

Weight changes. Using data from Potter et al. (2001), the difference in weight change between the treatment group and control group was $2.8 \%$ weight improvement, as seen by an increase of $2.0 \%(\mathrm{SD} 4.5 ; \mathrm{n}=113)$ in the treatment group, compared to a weight loss of $0.8 \%$ (SD 5.3; $n=121$ ) in the control group. Therefore, I calculated sample size for weight changes using a more conservative estimate of $2 \%$ weight change, (SDs $=$ 4.5 and 5.3), giving an estimated sample size of 236 cases: 59 in the study group, and 177 controls. If a weight change of $2.5 \%$ is used, the sample size for the weight change variable is 152 total: 38 in the study group, and 114 in the control group.

Changes in LOS. Somanchi et al. (2011) found an average LOS reduction of 2.6 days in those receiving a nutrition intervention with enteral and dietary management, from $8.71 \pm 11.7$ days, to $6.11 \pm 5.4$ days. Botella-Carretero et al. (2008) found a mean difference in LOS of approximately 2 days ( 13.5 days vs. $\sim 11.5$ days) between orthopedic surgery patients receiving ONS (SD 6) and not receiving ONS (SD 4). Averaging these, I used a change in LOS of 2.3 days, $\mathrm{SD}=4.7$ (study group); and $\mathrm{SD}=9$ (control group). Philipson et al. (2013) found a decrease of LOS by 2.29 days, with 
standard error $(\mathrm{SE})$ of $0.0657(\mathrm{n}=1,160,088)$; however, because of the large sample size, this SE is not comparable to my study. Their difference in LOS of 2.29 days, however, is compatible with my estimation of 2.3 days for sample size calculations. Therefore, I estimated a sample size for LOS differences using change of 2.3 days, with SD $=4.7$ and 9. The resulting sample size was 315 total cases, 63 in the study group, and 252 cases in the control group (total 315).

For each diagnosis studied, I would have needed to use a separate sample of 350 patients. Because of this large sample needed for significant results, and because the largest estimated number of cases would be available from HF patients, I chose to focus on HF patients for this study.

\section{Procedures for Data Collection}

The following de-identified raw data were requested from the hospital (because the information will be de-identified, no informed consent was needed):

List of all cases discharged from MRMC, aged 18 or over on admission, from July 2012 to December 2014, with a primary diagnosis of Heart Failure, or anything within ICD-9 code 428. For each case, the following information was requested:

- Date of admission

- Date of discharge

- Age on admission

- Gender 
- Race/ethnicity

- All available heights (this is to help rule out potential recorded errors that may significantly skew data, such as a recorded height of 63 inches for someone who is $63^{\prime \prime}$ tall).

- All available weights, in pounds, for each day of hospitalization (caution with units, sometimes they have weight in pounds, sometimes in $\mathrm{kg}$ )

- First available BMI

- Albumin levels each day of hospitalization

- BNP levels for each day of hospitalization

- Diet orders for each day of hospital stay

- All orders in the EMR for ONS, with wording (or quantity ordered daily), for each day of hospital stay

- All dietitian referrals for each day of hospitalization, with content of any comments entered reason/trigger for each referral (such as poor intake $>3$ days)

- All dietitian consults for each day of hospitalization, with content of any comments entered

- List of all diagnoses and ICD-9 codes for each patient (for CCI and malnutrition diagnosis covariate). Preferably, a yes/no column for each diagnostic code for the CCI and for diagnosis of malnutrition 
- Locations of patient (by hospital unit) by dates throughout the hospital stay, including any transfers

- Primary payer

- Planned discharge destination (home, nursing home, other)

- Daily fluid intake

- Average daily fluid intake

Cases were selected from this data for the study group (patients on ONS) and control group, using sample size calculation results.

\section{Instrumentation and Operationalization of Constructs}

Charlson Comorbidity Index (CCI). This is a comorbidity index with 17-19

items, weighted according to association with mortality (Degroot et al., 2003; Farley et al., 2006). It was introduced in 1987 by Charlson, Pompei, Ales, and MacKenzie (1987). It is intended to help provide appropriate matched controls to reflect overall severity of illness. The relationship between the index and ONS use was demonstrated by Philipson et al. (2013) in their large retrospective study that used billing and diagnostic data from the Premier Perspectives Database to show the impact of ONS use on hospital outcomes. They found a significantly higher $(\mathrm{p}<.0001)$ mean CCI score of 3.4 for patients using ONS (724,027 episodes), compared to a score of 2.1 all hospitalization episodes $(\mathrm{N}=$ 43,244,540). As mentioned in the Definitions section, an expanded ICD-9 coding algorithm developed by Quan et al. (2005) was used to determine CCI scores. 
Nutritional Risk Screening Tool. Nutritional screening of patients in hospitals within 24 hours is a national standard of The Joint Commission (TJC) (Somanchi et al., 2011), however the tools used and criteria used to determine risk vary by hospital. Patients who are determined to be at higher risk nutritionally are then automatically referred to a Registered Dietitian.

The nutritional screening risk score used in this study is derived from the screening tool used at MRMC. It was developed by the dietitians at the hospital based on recognized factors indicating a patient is at high risk for malnutrition. The tool contained criteria used by nurses to screen patients for nutritional risk within 12 hours of admission and during shift assessments every 12 hours. It included the following items: head/neck cancer with chemotherapy/radiation therapy; diagnosis of malnutrition/failure to thrive; hyperemesis gravidarium; LOS >11 days; NPO (nil per os, or nothing by mouth) or clear liquids diet >5 days; poor oral intake of 3 or more days; stage 2-4 pressure sore, nonhealing wound, or deep tissue injury; and unplanned weight loss of $>10$ pounds in the past 3 months.

If a nurse checked off any one of these items during the initial nursing assessment or 12-hour shift assessment for a patient at any time during the hospital stay, an automatic referral was triggered for a Registered Dietitian consultation (see definition below). See Appendix for a screenshot of the tool used by the nurses for nutrition screening.

\section{Data Analysis Plan}

Microsoft Excel and EpiInfo were used for the analyses. 
Data cleaning. Data were reviewed for duplicate cases, clear inconsistencies, and missing data to determine whether cases involved could be retained. Patients who were admitted more than once in the data collection period were treated as separate cases. Descriptive statistics were performed on each variable and graphed as needed to determine outliers or data that is obviously erroneous, such as a weight of 2 pounds.

Selection and screening of study group cases. All cases with orders for any of the following products were selected for the study group:

- Ensure Plus®, two or more daily

- Glucerna ${ }^{\circledR}$ Therapeutic Nutrition Shakes, three or more daily

- Nepro® with Carb Steady®, two or more servings daily

Exclusions from study group. The following cases were excluded from the study group:

- Cases on ONS for less than 50\% of LOS.

- Cases with orders for parenteral or enteral nutrition at the time of ONS provision. Selection and screening of comparison group cases. Those cases not in the ONS group (and not excluded from it) were selected for the comparison group. The following were excluded from the comparison group:

- Cases with orders for parenteral or enteral nutrition for over 50\% of the hospital stay

- Cases with NPO orders lasting for more than $50 \%$ of the hospital stay 
Research questions and hypotheses. For the following questions and hypotheses, all participants are hospitalized patients at the study facility, and all nutrition interventions are in relation to this population.

Research Question 1: How is the provision of ONS related to changes in albumin levels in participants over the course of hospitalization?

$H_{0} 1$ : Changes in patients' serum albumin levels will not be significantly different between patients receiving ONS and those not receiving ONS during the course of hospitalization after adjusting for baseline level of body mass index, age, race, gender, BNP levels, season of the year, location in the hospital, weight changes, initial albumin level, CCI, RD consultation, and diagnosis of malnutrition.

$H_{\mathrm{a}} 1$ : Changes in patients' serum albumin levels will be significantly different between patients receiving ONS and those not receiving ONS during the course of hospitalization after adjusting for baseline level of body mass index, age, race, gender, BNP levels, season of the year, location in the hospital, weight changes, initial albumin level, CCI, RD consultation, and diagnosis of malnutrition.

Method of measurement: $t$-test derived from multiple linear regression analysis to compare mean changes in albumin levels in patients receiving ONS with those not receiving ONS.

Research Question 2: How is the provision of ONS related to patient weight changes during the course of hospitalization? 
$H_{0}$ : Changes in patients' weights will not be significantly different between patients receiving ONS and the those not receiving ONS after adjusting for baseline level of body mass index, age, race, gender, BNP levels, season of the year, location in the hospital, initial albumin level, CCI, RD consultation, and diagnosis of malnutrition.

$H_{\mathrm{a}} 2$ : Changes in patients' weights will be significantly different between patients receiving ONS and the those not receiving ONS during the course of hospitalization after adjusting for baseline level of body mass index, age, race, gender, BNP levels, season of the year, location in the hospital, weight changes, initial albumin level, CCI, RD consultation, and diagnosis of malnutrition.

Method of measurement: $t$-test derived from multiple linear regression analysis to compare mean weight change for patients receiving ONS with those not receiving ONS.

Research Question 3: How is the provision of ONS related to patient LOS in the hospital?

$H_{0} 3$ : There will be no statistically significant difference in the mean LOS between patients receiving ONS and those not receiving ONS after adjusting for baseline level of body mass index, age, race, gender, BNP levels, season of the year, location in the hospital, weight changes, initial albumin level, CCI, RD consultation, and diagnosis of malnutrition.

$H_{\mathrm{a}} 3$ : There will be a statistically significant difference in the mean LOS between patients receiving ONS and those not receiving ONS after adjusting for baseline level of 
body mass index, age, race, gender, BNP levels, season of the year, location in the hospital, weight changes, initial albumin level, CCI, RD consultation, and diagnosis of malnutrition.

Method of Measurement: Odds ratios determined from multiple logistic regression analysis with ONS as the main predictor, controlling for covariates above shown to be associated with LOS through two-way tables.

Description of data analysis plan. The Data were requested in spreadsheet format, and were provided in report format on eight Excel spreadsheets. They were limited to patients 18 years and over on day of admission. After the data had been cleaned and exclusions had been removed from the data set (excluded diet orders, tube feedings, ONS less than the specified amount or time), study group cases were identified. Using the remaining cases, a random number table was used to select at least 350 comparison cases (499 cases were used) to provide adequate power for significant results.

I performed tests to evaluate whether assumptions for multiple linear regression analysis were met. I calculated descriptive statistics on all variables. This provided information for further analyses, including identification of outliers and evaluation of whether each variable is normally distributed. This included review of where the mean and quartiles fell within the variable distributions.

I reviewed descriptive statistics for each dependent variable to determine whether adequate data were available to keep that variable as an outcome. Unequal variances in the LOS variable were tested using Bartlett's test in EpiInfo. This was done in univariate 
means tests. Because of the lack of normal distribution (positive skew) and unequal variances for LOS, the assumptions for linear regression were not met for this variable. Therefore, this DV was categorized into high and low groups and logistic regression was used instead to test the hypothesis.

Where normal distributions were not found for continuous IVs, I transformed them into categorical data to meet assumptions and allow appropriate statistical testing. Because of the large number of variables, and lack of normality in many of the distributions, I ultimately transformed all IVs into categorical data to meet assumptions and allow appropriate statistical tests to be used.

Obvious outliers were removed if values appeared obviously erroneous. Results from chi-square analysis in two-way tables between each IV and each DV was used to determine which variables were significantly associated with the dependent variables.

Covariates were chosen because they had been shown in prior research, described previously, to be related to one or more of my independent or dependent variables. These included variables shown to be related to LOS (CCI, race, age); illness severity or LOS (CCI, BNP levels, diagnosis of malnutrition, payer, planned discharge destination, nutrition screening score, age, race); ONS use or decision to order ONS (BMI, RD consultation, nutrition risk screening, diagnosis of malnutrition, weight changes, albumin level); or nutritional risk (BMI, weight changes, albumin level), which often precipitates an order for ONS. Location in hospital and time of year have been associated with readmissions (Park et al., 2014) and are aspects of the epidemiological triad. 
The original plan called for three separate regression models to be evaluated; one for albumin change, one for weight change and one for LOS. Each model would include ONS as the main predictor, controlling for the covariates listed above. This study ultimately only considered the LOS outcome. I evaluated whether and how much each covariate appeared to affect this outcome, first for unadjusted relationships, then adjusted for relevant covariates. Results are shown using odds ratios and respective confidence intervals.

\section{Threats to Validity}

\section{Threats to External Validity}

Every hospital has its own methods of identifying patients at high risk nutritionally; and its own policies, procedures, and customs for patient interventions. Physicians, other providers, and dietitians all use clinical judgment and have their own approaches. Therefore, what works well in one hospital does not necessarily work well in another hospital or setting. However, there is also general agreement among medical practitioners, hospitals, payers, and accreditation organizations about the need to address poor nutrition among hospitalized patients and to improve outcomes for patients and for the institution. The use of ONS makes the intervention I am studying very reproducible, because of the common use of standard ONS; using the same ONS products would make this more reproducible in other hospitals and settings. 


\section{Threats to Internal Validity}

One potential threat to internal validity was the extent to which my statistical test assumptions are met. This was discussed above for LOS, and because assumptions for linear regression were not met for this outcome, a change was made to logistic regression for analysis. Other adaptions were made for other variables to improve internal validity and are discussed in chapter. A big challenge was also being sure that I had controlled for all relevant covariates, since most people getting ONS in a hospital tend to be sicker and at higher risk nutritionally. To address these issues, I tried to include any covariate of which I am aware, based on previous studies, as well as my 13 years' experience as a registered dietitian (RD) in the acute care setting; I also had this information reviewed by another experienced RD.

\section{Threats to Construct or Statistical Conclusion Validity}

Threats to construct or statistical conclusion validity in this study may be found in potential selection bias, in that patients who are found to have received ONS or nutrition consultation are generally those patients who were considered at higher risk nutritionally by medical or nursing staff, or identified through initial nursing assessment nutrition screening. I sought to overcome this bias by adjusting for nutritional risk, as well as other factors affecting supplement use--age, sex, BMI, diagnosis of malnutrition, and comorbidity score--through multiple logistic regression analysis.

A potential threat to statistical conclusion validity was inadequate power if I had been unable to identify enough patients on ONS after exclusion and data cleaning for an 
adequate sample size. I attempted to avoid this by using at a 2.5 -year data collection period, and excluding from the final logistic regression model any covariates that did not show statistically significant effects on the DV. I also excluded the albumin change outcome because of inadequate albumin data.

Another threat to statistical conclusion validity would be if statistical analyses were performed when the assumptions for the statistical tests are not met, such as lack of normality of the error distribution or nonlinear relationship in linear regression analysis. These assumptions were checked to prevent this type of lack of validity, and continuous variables were changed to categorical variables so that statistical conclusions would be valid. Statistical conclusion validity could also be violated if there were too much heterogeneity in the cases. Therefore, as described above, I used appropriate data transformations or nonparametric tests when appropriate to avoid this threat to validity. Additionally, using only a diagnosis of HF helped reduce this aspect of threat to validity.

Inaccurate data could also be a threat. In this case, I am depending on data from the hospital. It is likely that lab tests have a high degree of validity, however, my experience indicates that weight and height data may be less reliable, due to measurement errors because of different instruments of measurement (bed scale versus lift or stand-up scale), or failure of staff to follow protocol for measurement - especially a problem with bed scales when one must only have certain items on the bed, and zero the scale when appropriate. Values for height may also be inaccurate if they are estimates from patients or staff. Data review and cleaning prior to analysis were performed to reduce some of this 
type of error; also it was assumed that similar rates and patterns of error were present in the study group and comparison group.

\section{Ethical Procedures}

This proposal was approved by the Walden University IRB (IRB approval number 12-23-14-0146221), as well as the hospital IRB before commencing the study. The hospital IRB gave me permission to perform the study in a letter dated February 9, 2015. A HIPAA waiver of authorization and waiver of informed consent were provided.

I abided by HIPAA regulations as stipulated by the hospital, and in consultation with the hospital's HIPAA Officer. I requested de-identified data, but since the data came in eight separate reports, there were common identification codes in each spreadsheet to tie together the data for each case. After I had selected the study group and comparison group cases and had entered all the required data onto one spreadsheet, I deleted those identifiers from my working table before analysis. I shared this table only with my Dissertation Committee Chair for advice and assistance during analysis. No one else had access to the tables, and data was kept on my password-protected laptop. I spoke with the facility HIPAA officer as needed during the process to be sure I was in compliance.

As a previous employee of the hospital (PRN from January to October, 2014; and full-time from October 2001 until January 2014), it is possible I had seen or assessed patients in the study, but I could not tell from the data if this were so since there were no recognizable identifying data. While I may also have known medical practitioners who took care of patients, I had no way of knowing who took care of any patients on the list. 
Additionally, this study was not evaluating how well the hospital or employees did a job, but only how well a certain intervention appeared to help patients.

\section{Summary}

This study was a retrospective observational study, with quantitative analysis of the relationship between ONS use and LOS for individual patients. I used multiple logistic regression analysis to evaluate whether there were significant differences in outcomes between those receiving ONS and a comparison group during the course of hospitalization after adjusting for baseline level of body mass index, age, gender, season of the year, location in the hospital, CCI, RD consultation, and diagnosis of malnutrition. Inclusion of variables related to time, person, and place provided an epidemiological approach to the effectiveness of ONS in the hospital setting for patients with a diagnosis of heart failure. Data collection details and results will be provided in the following chapter. 
Chapter 4: Results

\section{Introduction}

This study was intended to show whether intervention with nutrient-rich, liquid ONS was associated with improved hospital and patient outcomes among hospitalized patients with a primary diagnosis of HF. Odds ratios for high LOS were determined for patients who received ONS compared to patients not receiving ONS using multiple logistic regression analysis, while controlling for covariates known or suspected to be associated with these outcomes. This chapter will describe the data collection, descriptive and demographic characteristics of the sample, data analysis, and results.

The following alternate hypotheses were originally proposed:

$H_{\mathrm{a}} 1$ : Changes in patients' serum albumin levels will be significantly different between patients receiving ONS and those not receiving ONS during the course of hospitalization after adjusting for baseline level of body mass index, age, race, gender, BNP levels, season of the year, location in the hospital, weight changes, initial albumin level, CCI, RD consultation, and diagnosis of malnutrition.

$H_{\mathrm{a}} 2$ : Changes in patients' weights will be significantly different between patients receiving ONS and the those not receiving ONS during the course of hospitalization after adjusting for baseline level of body mass index, age, race, gender, BNP levels, season of the year, location in the hospital, weight changes, initial albumin level, CCI, RD consultation, and diagnosis of malnutrition. 
$H_{\mathrm{a}} 3$ : There will be a statistically significant difference in the mean LOS between patients receiving ONS and those not receiving ONS after adjusting for baseline level of body mass index, age, race, gender, BNP levels, season of the year, location in the hospital, weight changes, initial albumin level, CCI, nutrition risk screening score, RD consultation, and diagnosis of malnutrition.

\section{Data Collection and Cleaning}

Data were provided incrementally by the hospital over a period of 4 months, in eight separate reports, ranging from 1772-3090 cases per report. Reports included diagnosis and ICD-9 codes; demographic data; visit dates; all diet orders and dates of orders; dietitian referrals and consults, with reasons for consults (but not referrals), dates and comments; all heights and weights and dates recorded; all BNP and albumin results with dates; average daily fluid intake for each case; patient room location for each case; and dates in each room, list of hospital units and rooms associated with those units. I reviewed the data, clarified information, and corrected errors in consultation with the hospital data analyst. I then retrieved data from the reports, moved them into a single spreadsheet, and formatted them for analysis by EpiInfo. I had to copy and paste or transfer most of the data from a variety of partial spreadsheets onto a master spreadsheet so that information would line up properly, with one row per case. Moving and reformatting the data was completed over a 5-month period. Data were not available on the reports for all IVs; $n$ for IVs ranged from 541-570. 
Because of the potential for error in the data consolidation process, I incorporated several methods to limit the introduction of errors; I double-checked certain data during the entry process, or incorporated other checks into my data retrieval process. For example, when I started to enter lab data for a given case, I highlighted the case number in blue so I would not lose track of which row I was working on. I compared admission date to dates of lab data to be sure it fit. Since the comparison cases (ONS = no) were randomly chosen, the search for other data required some jumping over data on other data sheets, and I double-checked case numbers for newly entered data against admission and discharge dates. The need to manually enter or move most of the data allowed me to better review the actual data and identify obvious outliers or likely errors (such as large differences or inconsistencies in heights or weights, or probable erroneous lab data such as a BNP of 6,000 at 4 am and 0 at 5 am).

\section{Selection of ONS Cases}

Diet orders for all cases were reviewed for selection of ONS=Yes (received supplements as defined previously), with a total of 90 cases qualifying and used in the study. According to my sample size calculations (Chapter 3), I needed at least 70 cases in the ONS=Yes group and 270 in the ONS=No group to give a power of $80 \%$, and $95 \%$ two-sided CI. Of the ONS=No cases, 499 were selected using random numbers generated by Microsoft Excel, with the expectation that at least $20 \%$ of these might be excluded according to criteria for exclusion. After some exclusions related to discrepancies or problems with the data (dates of diet orders or heights and weights not within period of 
hospitalization, missing outcomes data), 481 ONS=No cases and 89 ONS=Yes cases were retained, for a total of 570 cases.

The overall sample can be considered to be representative of the population of interest. I used all patients who actually received ONS for most of their hospitalization in the given time period, so I studied all subjects in this population. For those not receiving ONS, a random sample was used so it is assumed to be representative of the population of interest.

ONS group classification and exclusions. When the electronic medical record system started in 2012, there was initially no way to enter frequency for supplements, so the kitchen sent all ordered supplements three times daily (J. Plassmeyer, personal communication, 5/1/15). When frequencies became available in the ordering system, I noticed Glucerna ${ }^{\circledR}$ (supplement for people with diabetes) was often ordered only twice a day, compared with three daily for some other supplements. Because this did not meet my pre-defined criteria for ONS=Yes, these former patients were excluded.

Other Exclusions. The following other exclusions were made when a patient did not fit clearly into either $\mathrm{ONS}=$ Yes or $\mathrm{ONS}=\mathrm{No}$ classifications:

- NPO, or on clear liquids $25-50 \%$ of stay

- On ONS $12.5-50 \%$ of their total stay

- If diets started more than a day before admission date, and LOS was < 4 days (1/2day for $\mathrm{LOS}=1$ day) 
- Patient on supplements of a different type or inadequate quantities of supplement to meet criteria

NPO days. To calculate days NPO, I focused on waking hours NPO and considered meals missed in these calculations. So if they were NPO from midnight until 9 am, they were considered NPO only 0.2 days. . If they were NPO from midnight until 6 am, they were not considered to have missed any meals

Cases to be excluded were not given a code for ONS. I highlighting all cases to be excluded (per above criteria); then I sorted the data by ONS vs. no ONS, to be sure that no highlighted data were accidently coded (with a " 1 " or " 0 " in the ONS column) for inclusion. When cases were chosen for the study, only those with ONS codes were then included.

\section{LOS}

LOS was provided by the hospital to the nearest day, so I calculated exact LOS from the admission and discharge dates/times. Because of the lack of normal distribution for LOS, the assumptions for linear regression were not met for this variable. Therefore, this DV was categorized and logistic regression was used instead.

\section{BMIs, Weights, and Heights}

BMI values. I was given a report showing all weights, heights, and hospitalcalculated BMI values obtained during a patient's hospitalization. I used the BMI values if the height and weight appeared valid, and recalculated it if I noticed that a questionable height or weight had been used to determine BMI. 
Weights. I used my clinical judgment and experience as a registered dietitian in evaluating and transferring heights and weights to the spreadsheet. For an initial weight to be counted, it had to be within 24 hours of admission. I required final weights to be on the day of discharge, or within the last quarter of the hospital stay. Some were unavailable, so no values could be entered.

The report automatically converted all weights from pounds (lb.) to kilograms (kg) (by dividing by 2.2), according to my request for weights in $\mathrm{kg}$. However, I noticed that some initial weights had actually been in $\mathrm{kg}$ and the conversion factor led to erroneous weights. I was able to catch these and use the actual weight in $\mathrm{kg}$ (available on the same report). If there was an extreme change between the initial weight and the next day's weight (such as 40 pounds), and the second day's weight follows the trend of the other weights, I used the second day's weight. If a weight changed more than $1 \mathrm{lb}$. per hour, I considered there to be a discrepancy and did not enter data that appeared to be in error.

In some cases, the initial weight (or occasionally, the final weight) was outside the time frame of the hospitalization LOS dates; in such cases I excluded the case unless it was within a few hours. In such cases, I could assume that the person was admitted through the emergency department, and if there was a significant weight discrepancy (over $1 \mathrm{lb}$. per hour) weight change between it and the next weight, I excluded the initial pre-admission weight and used the next weight within the LOS. 
Heights. There were also some inconsistent values for height. If height changed over the time of the hospitalization, I used the second one. This is based on my experience that some nurses would enter their best guess for height if the patient was unable to talk or tell them on admission, because it was a required field for nursing assessments in the hospital. A later height was more likely to have been obtained directly from the patient, family, or dietitian. If some issues cannot be solved by looking at the data (such as large jumps in height or weight), I did not enter weight data for that case.

\section{BNP and Albumin Levels}

Initial laboratory values were only used if they were within 2 days after admission or 0.5 days before admission (assuming they were in the ED contiguous with admission, or awaiting or anticipating admission); and final values within 2 days before discharge. For very long stays (over 10 days, 2.5 days on either side was acceptable). For shorter LOS, such as 3-5 days, initial value needed to be within one day of admission.

\section{Patient Location in Hospital}

The hospital reports showed locations throughout a patient's hospitalization. Patient location was indicated by room numbers. A separate list was provided by the hospital showing lists of room numbers for each hospital units/floor. In cases where the same room numbers were listed for several units, I used the most logical or normal classification (e.g., if room 717 was listed on $7^{\text {th }}$ floor and ED, I used the $7^{\text {th }}$ floor classification). Because some floors/units had too few cases, I used available information 
on the hospital unit classification to combine units into similar groups of floors/units by function, such as intensive care units, progressive care floors, or medical-surgical floors.

When I retrieved room data, I entered initial location, location on day 2 (24-48 hours after admission), and location at discharge. Most patients entered the hospital via the emergency department (ED), so I did not count this as the initial location unless the patient remained there for over 6 hours ( 4 hours for LOS=1) after time of admission to the hospital. While many were in the ED for a few hours prior to admission, I only used data after admission. For patients in the Inpatient ED for over 6 hours, I listed the ED as initial location. A review of location data showed that many patients moved within the first 1-2 days, and the Day 2 location appeared to give a better picture of where the patient was located for the majority of the hospital stay. Therefore, I used this location for the final analysis.

\section{Discharge Destination}

Discharge destination was listed on the same row as patient ID, so could easily be included in my table. I did not have to do any editing but was able to copy them onto the master spreadsheet along with age, ethnicity, gender, and dates of admission and discharge. There were 11 different discharge destinations listed for my sample. Some categories only had one or two cases so had to be combined with others. I combined most of those with very low frequencies into the Other category. This included Hospice Home, Hospice Medical Facility, Left Against Medical Advice, Other Death, Other Hospital, 
and Speciality Hospital/Center. Intermediate Care Facility discharges were added to the Rehab.

\section{Dietitian Consults and Referrals}

I received a list showing date and time of all referrals and consults to the $\mathrm{RD}$, and reason for consult if listed. However, no reasons for referrals were provided; therefore, I was unable to determine nutrition risk scores (as described in Chapter 3, under Instrumentation and Operationalization of Constructs). Many patients who received consults also received referrals. Because of the small number of cases with referrals $(11.5 \%)$, and overlapping referral and consult data, I combined the referrals and consults into one RD Consult category. Further details are provided in the data analysis section. The RD referral lists showed that $88.5 \%$ of cases (483) had no RD referrals; $3.9 \%$ had one referral; and $2.6 \%$ had 2 referrals; the remaining $5.1 \%$ had 3 or more referrals. $59.9 \%$ of cases had no consults, $37.4 \%$ had one consult, $1.8 \%$ had two or more.

I double-checked $70 \%$ of the RD consultations and referral data after entering them, and checked the other as I went along, with a final spot-check. I found and corrected two discrepancies in all those I double-checked.

\section{Diagnosis of Malnutrition}

There were not enough cases with this diagnosis to analyze its contribution (only $2.8 \%$ of all cases). I considered adding the diagnosis of Failure to Thrive, Adult (FTT). This latter diagnosis may have various causes, not all of which are malnutrition; but it often indicates malnutrition. However, a quick count of FTT diagnoses showed 50 out of 
3090 cases with this diagnosis, which — if proportional to the number of cases in my sample — would have only given 9-10 cases with this diagnosis out of the 570 cases in my sample. This would not be enough to provide the power I would need to show significant contributions to my analysis.

\section{Charlson Comorbidity Index (CCI) Scoring}

As mentioned in the definitions and methodology sections, I used expanded ICD9 codes provided by Quan et al. (2005) in determining CCI coding. Because Quan et al. did not show points for categories displayed, I used additional guidance for points from Charlson et al. (2008), Halfon et al. (2002); Rohrer, Adamson, et al. (2008); and Rohrer, Rasmussen, \& Adamson (2008). If there was an inconsistency among these references for point values, I used those from Halfon et al. This included 1 point for mild liver disease (including viral hepatitis), 3 for severe liver disease; 2 points for moderate to severe renal disease, no points for mild renal disease; but 1 point for the general code of 585.9 (CKD, NOS, unspecified) since there was no guidance available for it. One exception was that I applied updated ICD-9 codes for pulmonary disease (http://www.icd9data.com/2014/), developed after the publication by Halfon et al. These diagnoses were all given 1 point for pulmonary disease.

\section{Data Accuracy for Spreadsheet Entries}

To improve accuracy of my copying of locations to my main spreadsheet (since the process was very time-consuming, I could not -in the interest of completing my 
dissertation - redo every entry to ensure accuracy, so I used the following checks and balances to minimize errors:

- Highlighted lines on the page of locations when I started to work on each one, to prevent using data from the wrong line or accidently using data from a previous entry

- Checked admission dates and discharge dates against location dates to be sure they synced; in some cases there were wrong location dates not within the time of a patient's hospital stay. In these situations, the cases had to be removed from the list.

- Frequent scrutinizing of data to be sure dates and times and location sequences "made sense."

- After entering locations in the spreadsheet, I would go back to the source sheet and before moving on to the next case, I would often double-check the previous case. This provided some double-checking or spot-checking of my entries.

\section{Initial Data Review: Variable Inclusions and Exclusions}

Data were analyzed for a total of 570 cases, 89 of which were in the supplement group $(\mathrm{ONS}=$ yes $)$. The average age among the sample was 68.4 years ( $S D$ 14.2); with $56.5 \%$ male and $43.5 \%$ females. There were slightly more black than white patients-$51.5 \%$ black, $47.2 \%$ white--and $1.4 \%$ were from other racial or ethnic groups. 
LOS ranged from 0.7 to 34.9 days, with a mean of 5.8 days (SD, 4.4). Its distribution was positively skewed; the median was 4.5 days, and the mode was 1.8 days, with the 75 th percentile at 7.5 days. Because it did not meet the assumptions for linear regression, I made it a binary categorical variable, with high LOS for cases over the $75^{\text {th }}$ percentile of 7.5 days. Logistic regression was then used instead of linear regression. Because of the large number of variables, and lack of normality in many of the distributions, I also transformed the other variables into categories to meet assumptions and allow significant results for statistical tests used.

\section{Descriptive Statistics}

\section{Demographic Characteristics}

Age, gender, and ethnicity. Demographic data are displayed in Table 3. Age ranged from 24 to 101 years of age, with an average age of 68.4 years $(S D=14.2)$. Fifty percent of all cases were between 59 and 78.5 years of age. Of 570 cases, $322(56.5 \%)$ were male and $248(43.5 \%)$ were female. Blacks accounted for 51.4\% $(N=293)$ of cases, and $47.2 \%(N=269)$ were white. The remaining $1.4 \%(N=8)$ were from one or more of the following categories: American Indian, Alaskan Native, Asian, Hispanic, Native Hawaiian/Pacific Islander, "Other", or "Declined to Specify." Because this group was so small, it produced an entry in the chi-square tables below 5, and thus could not be used in the two-way table analyses. Therefore, these cases were coded as missing values and dropped from the table analysis. 
Payer. There were 54 different payers recorded in this sample as "primary payer". Some of the payers were Medicare supplements, meaning the primary payer would actually have been Medicare. There were also a number of different Medicaid plans, although 101 out of the 122 cases with Medicaid Plans had regular or traditional Medicaid. Because of the small numbers in some payer groups, it was necessary to combine many into larger groups, although I tried to avoid combining payers as much as possible because of potential large differences in coverage terms. I separated out plans with large numbers in the sample, such as Blue Cross Blue Shield and Care Improvement Plus, but had to combine all other private plans. However, I combined all Medicare or Medicare-related plans (where a Medicare supplement was listed as primary insurance) since, by definition, supplements are the secondary insurance with Medicare as the primary payer. I combined all Medicaid-related plans. The frequency analysis for various payers is displayed in Table 3. 
Table 3

Demographic Characteristics on Admission

\begin{tabular}{|c|c|c|}
\hline Variable & Frequency & $\%$ \\
\hline \multicolumn{3}{|l|}{ Age $(N=570)$} \\
\hline Under 59 & 134 & 23.5 \\
\hline $59-68$ & 145 & 25.4 \\
\hline $69-77$ & 141 & $24.7 \%$ \\
\hline 78 and Over & 150 & $26.3 \%$ \\
\hline \multicolumn{3}{|l|}{ Gender $(\mathrm{N}=570)$} \\
\hline Male & 322 & $56.5 \%$ \\
\hline Female & 248 & $43.5 \%$ \\
\hline \multicolumn{3}{|l|}{ Ethnicity $(\mathrm{N}=570)$} \\
\hline Black & 293 & $51.4 \%$ \\
\hline White & 269 & $47.2 \%$ \\
\hline Other/Not specified & 8 & $1.4 \%$ \\
\hline \multicolumn{3}{|l|}{ Payer $(\mathrm{N}=570)$} \\
\hline Blue Cross Blue Shield & 67 & $11.75 \%$ \\
\hline Care Improvement Plus & 56 & $9.82 \%$ \\
\hline Medicaid Plans & 122 & $21.40 \%$ \\
\hline Medicare Plans & 200 & $35.09 \%$ \\
\hline Missing & 41 & $7.19 \%$ \\
\hline Other Private Insurance & 47 & $8.25 \%$ \\
\hline Self-pay & 37 & $6.49 \%$ \\
\hline
\end{tabular}




\section{Clinical Data}

Descriptive statistics for clinical data are displayed in Table 4.

Length of stay. Mean LOS among all cases was 5.8 days (+-4.4), with the $75 \%$ quartile at 7.5 days. Descriptive statistics indicated that it did not have a normal distribution, and the Bartlett's test showed unequal variances when cross-tabulated by ONS group, as seen in Table 3 (below). Therefore, I divided it into two categories, with high LOS over the 75 th percentile, or $>7.5$ days $(75 \%=7.484$ days $)$. It was then necessary to use logistic regression for the analysis instead of linear regression.

Weight changes. Weight change had originally been chosen as an outcome as an indicator of nutritional status, since weight loss has been associated with inadequate nutrition among hospitalized patients as described previously. It was also originally chosen as a biomarker in the context of the general hospitalized population rather than for heart failure patients only. However, because of the nature of HF, many patients enter the hospital with excessive fluid weight, and lose weight over the course of hospitalization; while others have fluctuating weights, or gain over the course of hospitalization. This made it a difficult outcome to evaluate for my study population. The mean percent weight change over the course of hospitalization was $2.9 \%$. The average net weight change was 2.5 lb. (+- 8.5 lb.). Several attempts were made to categorize the percent weight changes, using either weight gain versus weight loss, or dividing weight change at the mean percent weight change. While percent weight change was found in two-way tables to be 
associated with some covariates, multiple logistic regression models did not show significant relationships between percent weight change and any of the IVs, including ONS.

BMI. Only 18 cases $(3.4 \%$ ) had a low BMI of less than 18.5 , which was an inadequate number for the logistic regression analysis; therefore, this was combined with the normal BMI group (18.5-24.99) for the analysis. This new group (BMI < 25) had 154 cases $(28.9 \%)$. The largest number of cases (156 cases, or $29.3 \%$ of all sample cases) were in the overweight grouping (BMI 25-29.99); frequencies for other groups are shown in Table 4.

Albumin levels. Initial albumin levels were only available for 271 cases. Cases that had a final albumin as well as an initial albumin were rare; therefore, albumin change could not be kept as a dependent variable. I attempted logistic regression for other outcomes using initial albumin values, as well as categories $(\mathrm{Alb} \leq 3.30$, and alb $\geq 3.31)$, however it did not make a meaningful contribution to the logistic regression model, and therefore was not included in the final model.

BNP. Mean initial BNP ranged from 0 to $260,000 \mathrm{pg} / \mathrm{ml}$. The mean value was $15,966 \mathrm{pg} / \mathrm{ml}$; however, the standard deviation $(30,561)$ was too large to give usable information for this variable in the logistic regression model. I tried putting it into categories split at the median $(7,090 \mathrm{pg} / \mathrm{ml})$, or just over the $75^{\text {th }}$ percentile $(14,550)$, but these categories did not provide useful contributions to the logistics equation. 
Dietitian consults and referrals. The RD referral and consult lists showed that $88.5 \%$ of cases (483) had no RD referrals; $3.9 \%$ had one referral; and $2.6 \%$ had 2 referrals; the remaining $5.1 \%$ had 3 or more referrals. For dietitian consults, $59.9 \%$ of cases had no consults, $37.4 \%$ had one consult, and $1.8 \%$ had two or more consults. As mentioned in the Data Collection section above, some patients who received consults also received referrals. Because of the small number of cases with referrals (11.5\%), and overlapping referral and consult data, I combined the referrals and consults into one RD Consult category. There were 546 cases with referral or consult data for the combined category. Most (53.5\%) had neither an RD consult nor referral; 35.4\% had one referral or consult; and $11.2 \%$ had two or more.

Diagnosis of malnutrition. Only $2.8 \%$ (15 patients) had a diagnosis of malnutrition, an inadequate number to allow for significant results in the analysis. Therefore, this variable could not be used in the analysis.

CCI Scores. All cases had at least a score of 1 for the HF diagnosis. Nearly onefourth $(23.9 \%)$ had scores of $1-2 ; 20.5 \%$ had a score of $3 ; 37.4 \%$ had scores of 4 or 5 ; $13.5 \%$ had scores of 6 or more, and $4.7 \%$ of cases were missing scores. When I ran the initial frequencies and multiple logistic analysis models, there were 27 cases with missing CCI values. The resulting multiple logistic regression data showed an odds ratio of 10.4, and a very high CI of $333(p=0.184)$. Therefore, imputation was used to reclassify the missing values into the highest CCI category of CCI $=3-4$, which initially had 213 cases, 
or $37.4 \%$ of the cases out of the five CCI categories. This imputation brought the total to 240 cases in this category, or $42.11 \%$ of all cases. 
Table 4

Descriptive Statistics - Clinical Information

\begin{tabular}{|c|c|c|}
\hline Variable & Frequency & $\%$ \\
\hline \multicolumn{3}{|l|}{ ONS $(N=570)$} \\
\hline Yes & 89 & $15.61 \%$ \\
\hline No & 481 & $84.39 \%$ \\
\hline \multicolumn{3}{|l|}{ Initial BNP $(N=543)$} \\
\hline $15,000 \mathrm{pg} / \mathrm{ml}$ or less & 348 & $76.82 \%$ \\
\hline Over $15,000 \mathrm{pg} / \mathrm{ml}$ & 105 & $23.18 \%$ \\
\hline \multicolumn{3}{|l|}{ Initial Albumin $(N=271)$} \\
\hline$\leq 3.3 \mathrm{~g} / \mathrm{dL}$ & 79 & $29.15 \%$ \\
\hline$>3.3 \mathrm{~g} / \mathrm{dL}$ & 192 & $70.85 \%$ \\
\hline \multicolumn{3}{|c|}{ Diagnosis of Malnutrition $(N=541)$} \\
\hline No & 526 & $97.23 \%$ \\
\hline Yes & 15 & $2.77 \%$ \\
\hline \multicolumn{3}{|c|}{ Number of RD Consultations/Referrals $(N=546)$} \\
\hline 0 & 292 & $53.48 \%$ \\
\hline 1 & 193 & $35.35 \%$ \\
\hline 2 or more & 61 & $11.17 \%$ \\
\hline \multicolumn{3}{|c|}{ Charlson Comorbidity Index Scores $(N=570)$} \\
\hline $1-2$ & 136 & $23.86 \%$ \\
\hline 3 & 117 & $20.53 \%$ \\
\hline $4-5$ & 213 & $37.37 \%$ \\
\hline 6 or more & 77 & $13.51 \%$ \\
\hline Missing & 27 & $4.74 \%$ \\
\hline
\end{tabular}




\begin{tabular}{ccc}
\hline Variable & Frequency & $\%$ \\
\hline BMI $(N=570)$ & 154 & $28.90 \%$ \\
$<25^{\mathrm{a}}$ & 18 & $3.38 \%$ \\
$<18.5^{\mathrm{a}}$ & 136 & $25.52 \%$ \\
$18.5-24.99^{\mathrm{a}}$ & 156 & $29.27 \%$ \\
$25-29.99$ & 86 & $16.14 \%$ \\
$30-34.99$ & 63 & $11.82 \%$ \\
$35-39.99$ & 74 & $13.88 \%$ \\
40 or more & &
\end{tabular}

${ }^{a}$ The number of cases in the lowest BMI group $(<18.5)$ was too small to complete the regression analysis with this group, so it was combined with the next group (18.5-24.99) for the analysis.

\section{Time and Place Data}

Descriptive statistics for time and place data are shown in Table 5.

Discharge destination. Out of 570 patients, $60.1 \%$ were discharged home, $16.0 \%$ were discharged to home health, $7.9 \%$ to long-term care facilities, $4.4 \%$ to an inpatient rehabilitation facility, $5.4 \%$ to other destinations (including unknown, death, against medical advice), and 5.4\% were missing discharge information.

Season of admission (time variable). The season with the highest number of admissions was fall (179 admissions, or $31.4 \%$ of yearly admissions), while the lowest number of admissions (97, or 17.0\%) was in the summer. Spring and winter had similar numbers of admissions: There were 148 (26.0\%) in the spring, and $146(25.6 \%)$ in the winter.

Hospital location. More patients (112, or 19.7\%) were located on the $3^{\text {rd }}$ floor (cardiac floor) than any other hospital unit. There were 61 patients $(10.7 \%)$ in the 
Coronary Care Unit on day 2, and 52 (9.1\%) in the Heart and Vascular Progressive care (cardiac) unit. The $5^{\text {th }}, 6^{\text {th }}$, and $7^{\text {th }}$ floors together held 48 patients $(8.4 \%)$, while the $10^{\text {th }}$ floor had 46 patients $(8.1 \%)$. There were less than 40 patients on each of the other floor classifications, including 8 North (39 patients), other progressive care or step-down units (33 patients altogether), Medical Progressive Care/Cardiac area (32 patients), 8 South and $11^{\text {th }}$ floor (31 patients combined), and $4^{\text {th }}$ floor (renal floor, 26 patients). 
Table 5

Descriptive Statistics - Time and Place Variables

\begin{tabular}{|c|c|c|}
\hline Sample Characteristic & Frequency & $\%$ \\
\hline \multicolumn{3}{|l|}{ Discharge destination $(N=570)$} \\
\hline Home & 347 & $60.88 \%$ \\
\hline Home Health & 91 & $15.96 \%$ \\
\hline LTC & 45 & $7.89 \%$ \\
\hline Missing & 31 & $5.44 \%$ \\
\hline Other & 31 & $5.44 \%$ \\
\hline Rehab & 25 & $4.39 \%$ \\
\hline \multicolumn{3}{|l|}{ Season of Admission $(\mathrm{N}=570)$} \\
\hline Fall & 179 & $31.40 \%$ \\
\hline Spring & 148 & $25.96 \%$ \\
\hline Summer & 97 & $17.02 \%$ \\
\hline Winter & 146 & $25.61 \%$ \\
\hline \multicolumn{3}{|l|}{ Location $(N=570)$} \\
\hline 10th Floor & 46 & $8.07 \%$ \\
\hline $8 \mathrm{~S}$ or 11 th Floor & 31 & $5.44 \%$ \\
\hline 3rd Floor (cardiac) & 112 & $19.65 \%$ \\
\hline 4th Floor (renal) & 26 & $4.56 \%$ \\
\hline 5th, 6th, 7th Floors & 48 & $8.42 \%$ \\
\hline $8 \mathrm{NTH}$ & 39 & $6.84 \%$ \\
\hline Coronary Care Unit & 61 & $10.70 \%$ \\
\hline Other ICUs - CVICU, MICU, TICU & 44 & $7.72 \%$ \\
\hline Heart and Vascular Progressive Care/Cardiac & 52 & $9.12 \%$ \\
\hline Medical Progressive Care/Cardiac & 32 & $5.61 \%$ \\
\hline Other Progressive Care/Step-Down Units & 33 & $5.79 \%$ \\
\hline Missing & 46 & $8.07 \%$ \\
\hline
\end{tabular}




\section{Data Analysis: Two-Way Tables for LOS}

I analyzed the data using two-way tables, then used results to determine appropriate variables to include in the multiple logistic regression model. Two-way table analysis results for the IV (ONS) and LOS, as well as between each covariate and LOS, are shown in Table 6 . A high LOS ( $\geq 7.5$ days) was observed among a significantly larger proportion $(55.1 \%)$ of patients on ONS, compared to $19.3 \%$ of patients not receiving ONS $(\mathrm{p}<.001)$

\section{Demographic Characteristics and LOS}

Two-way tables showing demographic characteristics in relation to LOS are summarized in Table 6. The proportion of patients with high LOS gradually increased as age increased, but not significantly $(p=.4)$ : For patients under 59 years $(n=134), 20.2 \%$ had high LOS; patients aged 59-68 $(n=145), 24.1 \%$ had high LOS. For those aged 69-77 $(n=141), 26.24 \%$ had high LOS; and for those 78 and over $(n=150), 28.67 \%$ had high LOS. (Age groups were divided approximately by quartiles).

Gender was significantly associated with high LOS $(\mathrm{p}=.003)$, with a greater proportion of females $(31.1 \%)$ having a high LOS, compared to males (20.2\%). Ethnicity was also associated with high $\operatorname{LOS}(p=.064)$ : $28.6 \%$ of Whites $(n=269)$ compared with $21.8 \%$ of Blacks ( $n=293$ Payer did not show a significant association with high LOS ( $p$ $=.122)$. 
Table 6

Two-Way Table Results - High LOS and Demographic Information

\begin{tabular}{|c|c|c|c|c|c|}
\hline \multirow[t]{3}{*}{ Variable } & \multicolumn{4}{|c|}{ High LOS ( $\geq 7.5$ Days) } & \multirow[b]{3}{*}{$p$-value } \\
\hline & \multicolumn{2}{|c|}{ Yes } & \multicolumn{2}{|c|}{ No } & \\
\hline & $N$ & $\%$ & $N$ & $\%$ & \\
\hline Age (years) $(\mathrm{N}=570)$ & & & & & .402 \\
\hline Under 59 & 27 & $20.15 \%$ & 107 & $79.85 \%$ & \\
\hline $59-68$ & 35 & $24.14 \%$ & 110 & $75.86 \%$ & \\
\hline $69-77$ & 37 & $26.24 \%$ & 104 & $73.76 \%$ & \\
\hline 8 and Over & 43 & $28.67 \%$ & 107 & $71.33 \%$ & \\
\hline Gender $(\mathrm{N}=570)$ & & & & & $.003^{\mathrm{a}}$ \\
\hline Male & 65 & $20.19 \%$ & 257 & $79.81 \%$ & \\
\hline Female & 77 & $31.05 \%$ & 171 & $68.95 \%$ & \\
\hline Ethnicity $(\mathrm{N}=562)$ & & & & & $.064^{\mathrm{a}}$ \\
\hline Black & 64 & $21.84 \%$ & 229 & $78.16 \%$ & \\
\hline White & 77 & $28.62 \%$ & 192 & $71.38 \%$ & \\
\hline Payer $(\mathrm{N}=570)$ & & & & & .122 \\
\hline Blue Cross Blue Shield & 11 & $16.42 \%$ & 56 & $83.58 \%$ & \\
\hline Care Improvement Plus & 11 & $19.64 \%$ & 45 & $80.36 \%$ & \\
\hline Medicaid Plans & 40 & $32.79 \%$ & 82 & $67.21 \%$ & \\
\hline Medicare Plans & 49 & $24.50 \%$ & 151 & $75.50 \%$ & \\
\hline Missing & 7 & $17.07 \%$ & 34 & $82.93 \%$ & \\
\hline Other Private Insurance & 15 & $31.91 \%$ & 32 & $68.09 \%$ & \\
\hline Self-pay & 9 & $24.32 \%$ & 28 & $75.68 \%$ & \\
\hline
\end{tabular}

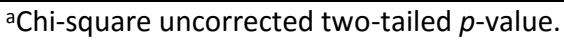




\section{Clinical Information and LOS}

Two-way table results for clinical information in relation to high LOS is displayed in table 7. ONS use was significantly associated with high LOS $(\mathrm{p}<.001)$, with $55.1 \%$ of patients on ONS having high LOS, compared to only $19.3 \%$ high LOS among patients not receiving ONS. BMI classification was not significantly associated with $\operatorname{LOS}(p=$ .913). More patients with high initial BNP had high LOS, but the difference was not significant $(\mathrm{p}=.131)$; for BNP in the top quartile (BNP > 15,000), 33.3\% had high LOS; while $25.0 \%$ of those with lower BNP levels $(\leq 15,000)$ had high LOS. Similarly, among the 271 patients with initial albumin levels, those with lower albumin levels appeared more likely to have high LOS $(35.4 \%$ high LOS with albumin $\leq 3.3 \mathrm{~g} / \mathrm{dL}$; and $27.1 \%$ for albumin >3.3), but the difference was not significant $(\mathrm{p}=.170)$. Diagnosis of malnutrition was seen in only 15 patients; surprisingly, $20 \%$ of them had high LOS compared to $25.5 \%$ of other patients $(\mathrm{p}=.631)$.

RD consultations were significantly and positively associated with high LOS $(p<$ $.001 ; \mathrm{n}=546)$ : Among those with two or more consultations, the rate of high LOS was 49.2\%, more than double those with $0-1$ consults: $21.2 \%$ for 1 consult and $22.3 \%$ for those with 0 consults. CCI scores also showed a significant association with LOS $(p<$ .001 ), with noticeable increase in high LOS from $12 \%$ to $35 \%$ as CCI increased from 1 to $\geq 6$; from $11.8 \%$ high $\operatorname{LOS}$ for $\mathrm{CCI}=1-2$, to $35.1 \%$ for patients with $\mathrm{CCI} \geq 6$. 
Table 7

Two-Way Table Results for High LOS -- Clinical Information

\begin{tabular}{|c|c|c|c|c|c|}
\hline \multirow[t]{3}{*}{ Variable } & \multicolumn{4}{|c|}{ High LOS ( $\geq 7.5$ days) } & \multirow{3}{*}{$p$-value } \\
\hline & \multicolumn{2}{|c|}{ Yes } & \multicolumn{2}{|c|}{ No } & \\
\hline & $\mathrm{N}$ & $\%$ & $\mathrm{~N}$ & $\%$ & \\
\hline $\mathrm{BMI}(N=570)$ & & & & & 0.913 \\
\hline$<25$ & 36 & $23.38 \%$ & 118 & $76.62 \%$ & \\
\hline $25-29.99$ & 40 & $25.64 \%$ & 116 & $74.26 \%$ & \\
\hline $30-34.99$ & 20 & $23.26 \%$ & 66 & $76.74 \%$ & \\
\hline $35-39.99$ & 16 & $25.40 \%$ & 47 & $74.60 \%$ & \\
\hline 40 or more & 22 & $29.73 \%$ & 52 & $70.27 \%$ & \\
\hline Missing & 8 & $21.62 \%$ & 29 & $78.38 \%$ & \\
\hline ONS $(N=570)$ & & & & & $<.001^{\mathrm{a}}$ \\
\hline Yes & 49 & $55.1 \%$ & 40 & $44.94 \%$ & \\
\hline No & 93 & $19.3 \%$ & 388 & $80.67 \%$ & \\
\hline Initial BNP $(N=453)$ & & & & & $0.092^{\mathrm{a}}$ \\
\hline $15,000 \mathrm{pg} / \mathrm{ml}$ or less & 87 & $25.00 \%$ & 261 & $75.00 \%$ & \\
\hline Over $15,000 \mathrm{pg} / \mathrm{ml}$ & 35 & $33.33 \%$ & 70 & $66.67 \%$ & \\
\hline Initial Albumin $(N=271)$ & & & & & $0.170^{\mathrm{a}}$ \\
\hline$\leq 3.3 \mathrm{~g} / \mathrm{dL}$ & 28 & $35.44 \%$ & 51 & $64.56 \%$ & \\
\hline$>3.3 \mathrm{~g} / \mathrm{dL}$ & 52 & $27.08 \%$ & 140 & $72.92 \%$ & \\
\hline Diagnosis of Malnutrition $(N=541)$ & & & & & $0.631^{\mathrm{a}}$ \\
\hline No & 134 & $25.48 \%$ & 392 & $74.52 \%$ & \\
\hline Yes & 3 & $20.0 \%$ & 12 & $80.0 \%$ & \\
\hline
\end{tabular}




\begin{tabular}{|c|c|c|c|c|c|}
\hline \multirow[t]{3}{*}{ Variable } & \multicolumn{4}{|c|}{ High LOS ( $\geq 7.5$ days) } & \multirow{3}{*}{$p$-value } \\
\hline & \multicolumn{2}{|c|}{ Yes } & \multicolumn{2}{|c|}{ No } & \\
\hline & $\mathrm{N}$ & $\%$ & $\mathrm{~N}$ & $\%$ & \\
\hline $\begin{array}{l}\text { Number of RD Consultations/Referrals } \\
(\mathrm{N}=546)\end{array}$ & & & & & $<.001$ \\
\hline 0 & 65 & $22.26 \%$ & 227 & $77.74 \%$ & \\
\hline 1 & 41 & $21.24 \%$ & 152 & $78.76 \%$ & \\
\hline 2 or more & 30 & $49.18 \%$ & 31 & $50.82 \%$ & \\
\hline CCI Scores $(\mathrm{N}=570)$ & & & & & $<.001$ \\
\hline $1-2$ & 16 & $11.76 \%$ & 120 & $88.24 \%$ & \\
\hline 3 & 29 & $24.79 \%$ & 88 & $75.21 \%$ & \\
\hline $4-5$ & 70 & $29.17 \%$ & 170 & $70.83 \%$ & \\
\hline 6 or more & 27 & $35.06 \%$ & 50 & $64.94 \%$ & \\
\hline
\end{tabular}

Note: $\mathrm{CCI}=$ Charlson Comorbidity Index

${ }^{a}$ Chi-square uncorrected two-tailed $p$-value

\section{Time and Place Variables in Relation to LOS}

Time and place data in relation to high LOS are presented in Table 8. Discharge destination was significantly associated with LOS $(\mathrm{p}<.001)$. The Other discharge category had the highest percentage of high LOS (48.4\%, possibly because it included death and AMA); followed by discharge to long term care facilities (46.7\% high LOS), rehabilitation facilities $(44.0 \%)$, discharge to home health services $(33.0 \%)$, then discharge home (17.6\%). High LOS was seen in $12.9 \%$ of those with missing discharge data.

Season of admission was not associated with LOS $(\mathrm{p}=.369)$, although a larger percentage of those admitted in the summer (29.9\%) had high LOS compared with admissions in the fall (20.7\%), spring (25.7\%), or winter (26.0\%). It was interesting that 
summer, the season with the lowest number of admissions, had the greatest frequency of high LOS; while the season with the highest number of admissions, fall, had the lowest LOS.

Patient location on day 2 was significantly associated with LOS $(p<.001)$, with the largest proportion of high LOS among patients in the coronary care unit $(50.8 \%)$, closely followed by all other intensive care units (47.7\%). The heart and vascular progressive care - cardiac units (also partly designated as non-step-down cardiac floors during the study period) had 19.2\% high LOS; medical progressive care/cardiac unit (including some non-step-down cardiac beds) $21.9 \%$ high LOS; while all other progressive care or step down units together had $30.3 \%$ high LOS. The $10^{\text {th }}$ floor was at $17.4 \%$ high LOS; $8^{\text {th }}$ or $11^{\text {th }}$ floors totaled $16.1 \%$ high LOS, and $3^{\text {rd }}$ floor/cardiac was $10.7 \%$ high LOS. 
Table 8

Two-Way Table Results for High LOS -- Time and Place Information

\begin{tabular}{|c|c|c|c|c|c|}
\hline \multirow[t]{3}{*}{ Variable } & \multicolumn{4}{|c|}{ High LOS ( $\geq 7.5$ days) } & \multirow{3}{*}{$p$-value } \\
\hline & \multicolumn{2}{|c|}{ Yes } & \multicolumn{2}{|c|}{ No } & \\
\hline & $N$ & $\%$ & $N$ & $\%$ & \\
\hline Discharge destination $(\mathrm{N}=570)$ & & & & & $<.001$ \\
\hline Home & 61 & $17.58 \%$ & 286 & $82.42 \%$ & \\
\hline Home Health & 30 & $32.97 \%$ & 61 & $67.03 \%$ & \\
\hline LTC & 21 & $46.67 \%$ & 24 & $53.33 \%$ & \\
\hline Rehab & 11 & $44.00 \%$ & 14 & $56.00 \%$ & \\
\hline Other & 15 & $48.39 \%$ & 16 & $51.61 \%$ & \\
\hline Missing & 4 & $12.90 \%$ & 27 & $87.10 \%$ & \\
\hline Season of Admission $(N=570)$ & & & & & .369 \\
\hline Fall & 37 & $20.67 \%$ & 142 & $79.33 \%$ & \\
\hline Spring & 38 & $25.68 \%$ & 110 & $74.32 \%$ & \\
\hline Summer & 29 & $29.90 \%$ & 68 & $70.10 \%$ & \\
\hline Winter & 38 & $26.03 \%$ & 108 & $73.97 \%$ & \\
\hline Location $^{\mathrm{a}}(\mathrm{N}=570)$ & & & & & $<.001$ \\
\hline 10th Floor & 8 & $17.39 \%$ & 38 & $82.61 \%$ & \\
\hline $8 \mathrm{~S}$ or 11 th Floor & 5 & $16.13 \%$ & 26 & $83.87 \%$ & \\
\hline 3rd Floor (cardiac) & 12 & $10.71 \%$ & 100 & $89.29 \%$ & \\
\hline 4th Floor (renal) & 13 & $50.0 \%$ & 13 & $50.0 \%$ & \\
\hline 5th, 6th, 7th Floors & 10 & $20.83 \%$ & 38 & $79.17 \%$ & \\
\hline $8 \mathrm{NTH}$ & 9 & $23.08 \%$ & 30 & $76.92 \%$ & \\
\hline Coronary Care Unit & 31 & $50.82 \%$ & 30 & $49.18 \%$ & \\
\hline Other ICUs - CVICU, MICU, TICU & 21 & $47.73 \%$ & 23 & $52.27 \%$ & \\
\hline Heart and Vascular Progressive Care/Cardiac & 10 & $19.23 \%$ & 42 & $80.77 \%$ & \\
\hline Medical Progressive Care/Cardiac & 7 & $21.88 \%$ & 25 & $78.13 \%$ & \\
\hline Other Progressive Care/Step-Down Units & 10 & $30.30 \%$ & 23 & $69.70 \%$ & \\
\hline Missing & 6 & $13.04 \%$ & 40 & $86.96 \%$ & \\
\hline
\end{tabular}

. ${ }^{\mathrm{a} C h i}$-square uncorrected two-tailed $p$-value 


\section{Summary of Two-Way Table Results for LOS}

Overall, the two-way analyses showed significant positive associations $(\mathrm{p}<.05)$ between LOS and ONS use $(\mathrm{p}<.001)$, gender $(\mathrm{p}=.003)$, with a greater proportion of males on ONS; number of RD consultations ( $\mathrm{p}=.0024)$, with LOS increasing as RD consults went from 0 to 1 to 2 or more; CCI ( $\mathrm{p}=.0002)$, with larger proportions of high LOS as CCI increased; discharge destination $(\mathrm{p}<.001)$, with highest proportions among those going to LTC facilities; and hospital location $(\mathrm{p}<.001)$, with highest proportions in the CCU, renal floor, other ICUs, and progressive care units. Because ethnicity was close to the desired level of significance $(\mathrm{p}=.064)$, it was also considered in the logistic regression model. BMI, initial albumin, and initial BNP did not show significant associations with high $\operatorname{LOS}(\mathrm{p}=.131, .170$, and .631 , respectively). Neither did payer, season of admission, or age ( $\mathrm{p}=.122, .369$, and .402 , respectively). Diagnosis of malnutrition was not significantly associated with high $\operatorname{LOS}(\mathrm{p}=.631)$, although this may have been related to the inadequate number of cases with this diagnosis.

\section{Data Analysis: Two-Way Tables for ONS}

Two-way tables for ONS and each of the covariates showed significant associations $(\mathrm{p}<.05)$ between ONS use and the following categorized variables: age category $(\mathrm{p}<.001)$, with increasing rates of ONS use as age increased; gender $(\mathrm{p}=$ .0087), with higher rates among females than males; and ethnicity $(\mathrm{p}=.0289)$, with higher ONS use among Whites compared to Blacks. BMI category was also significantly related to ONS use $(\mathrm{p}<.001)$, with higher rates of ONS use for lower BMI values: For 
$\mathrm{BMI}<25,25.3 \%$ of patients received ONS; for BMI 30-35, $128 \%$ of patients received ONS, and for BMI over 40, only $6.8 \%$ of patients received ONS. High LOS $(\mathrm{p}<.001)$ was also associated with ONS use, with a higher proportion of patients with high LOS being on ONS. A significantly larger proportion of patients with low initial albumin were on ONS ( $=.0016)$; and a significantly greater number of patients diagnosed with malnutrition were on ONS ( $\mathrm{p}<.001)$. A significant association was seen between ONS and RD consults $(\mathrm{p}<.001)$ : As the number of RD consults increased, the proportion of patients on ONS increased, from $9.9 \%$ of patients with no RD consults received ONS, while $52.5 \%$ of patients with two or more consults received ONS. Discharge destination was also significantly associated with increased ONS use $(\mathrm{p}<.001)$, with the largest proportion of patients on ONS among those being discharged to long term care $(42.2 \%)$ or the Other discharge category (38.7\%); and the lowest proportion (10.4\%) among those being discharged home. Significant associations were not found for initial BNP ( $\mathrm{p}=$ $.066), \mathrm{CCI}(\mathrm{p}=.075)$, location $(\mathrm{p}=.094)$, payer $(\mathrm{p}=.913)$ or season of admission $(\mathrm{p}=$ .727). 
Table 9

Two-Way Table Results for ONS-Demographic Information

\begin{tabular}{|c|c|c|c|c|c|}
\hline \multirow[t]{3}{*}{ Variable } & \multicolumn{4}{|c|}{ ONS } & \multirow{3}{*}{$p$-value } \\
\hline & \multicolumn{2}{|c|}{ Yes } & \multicolumn{2}{|c|}{ No } & \\
\hline & $\mathrm{N}$ & $\%$ & $\mathrm{~N}$ & $\%$ & \\
\hline Age (years) $(\mathrm{N}=570)$ & & & & & $<.001$ \\
\hline Under 59 & 126 & $94.03 \%$ & 8 & $5.97 \%$ & \\
\hline $59-68$ & 134 & $92.41 \%$ & 11 & $7.59 \%$ & \\
\hline $69-77$ & 112 & $79.43 \%$ & 29 & $20.57 \%$ & \\
\hline 78 and Over & 109 & $72.67 \%$ & 41 & $27.33 \%$ & \\
\hline Gender $(\mathrm{N}=570)$ & & & & & $.0087^{\mathrm{a}}$ \\
\hline Male & 283 & $87.89 \%$ & 39 & $12.11 \%$ & \\
\hline Female & 198 & $79.84 \%$ & 50 & $20.16 \%$ & \\
\hline Ethnicity $(\mathrm{N}=562)$ & & & & & $.0289^{\mathrm{a}}$ \\
\hline Black & 257 & $87.71 \%$ & 36 & $12.29 \%$ & \\
\hline White & 218 & $81.04 \%$ & 51 & $18.96 \%$ & \\
\hline Payer $(\mathrm{N}=570)$ & & & & & .043 \\
\hline Blue Cross Blue Shield & 50 & $74.63 \%$ & 17 & $25.37 \%$ & \\
\hline Care Improvement Plus & 48 & $85.71 \%$ & 8 & $14.29 \%$ & \\
\hline Medicaid Plans & 101 & $82.79 \%$ & 21 & $17.21 \%$ & \\
\hline Medicare Plans & 171 & $85.50 \%$ & 29 & $14.50 \%$ & \\
\hline Missing & 39 & $95.12 \%$ & 2 & $4.88 \%$ & \\
\hline Other Private Insurance & 37 & $78.72 \%$ & 10 & $21.28 \%$ & \\
\hline Self-pay & 35 & $94.59 \%$ & 2 & $5.41 \%$ & \\
\hline
\end{tabular}

${ }^{\mathrm{a}}$ Chi-square uncorrected two-tailed $p$-value 
Table 10

Two-Way Table Results for ONS - Clinical Information

\begin{tabular}{|c|c|c|c|c|c|}
\hline \multirow[t]{3}{*}{ Variable } & \multicolumn{4}{|c|}{ ONS } & \multirow{3}{*}{$p$-value } \\
\hline & \multicolumn{2}{|c|}{ No } & \multicolumn{2}{|c|}{ Yes } & \\
\hline & $N$ & $\%$ & $N$ & $\%$ & \\
\hline BMI $(\mathrm{N}=541)$ & & & & & $<.001$ \\
\hline$<25$ & 115 & $74.68 \%$ & 39 & $25.32 \%$ & \\
\hline $25-29.99$ & 129 & $82.69 \%$ & 27 & $17.31 \%$ & \\
\hline $30-34.99$ & 75 & $87.21 \%$ & 11 & $12.79 \%$ & \\
\hline $35-39.99$ & 56 & $88.89 \%$ & 7 & $11.11 \%$ & \\
\hline 40 or more & 69 & $93.24 \%$ & 5 & $6.76 \%$ & \\
\hline Missing & 37 & $100 \%$ & 0 & $0 \%$ & \\
\hline High LOS (N =570) & & & & & $<.001^{\mathrm{a}}$ \\
\hline Yes & 93 & $65.49 \%$ & 49 & $34.51 \%$ & \\
\hline No & 388 & $90.65 \%$ & 40 & $9.35 \%$ & \\
\hline Initial BNP $(\mathrm{N}=453)$ & & & & & $.066^{\mathrm{a}}$ \\
\hline $15,000 \mathrm{pg} / \mathrm{ml}$ or less & 298 & $85.63 \%$ & 50 & $14.37 \%$ & \\
\hline Over $15,000 \mathrm{pg} / \mathrm{ml}$ & 82 & $78.10 \%$ & 23 & $21.90 \%$ & \\
\hline Initial Albumin $(\mathrm{N}=271)$ & & & & & $.0016^{\mathrm{a}}$ \\
\hline$<3.3 \mathrm{~g} / \mathrm{dL}$ & 56 & $70.89 \%$ & 23 & $29.11 \%$ & \\
\hline$>3.3 \mathrm{~g} / \mathrm{dL}$ & 167 & $86.98 \%$ & 25 & $13.02 \%$ & \\
\hline Diagnosis of Malnutrition $(\mathrm{N}=541)$ & & & & & $<.001^{\mathrm{a}}$ \\
\hline No & 447 & $84.98 \%$ & 79 & $15.02 \%$ & \\
\hline Yes & 7 & $46.67 \%$ & 8 & $53.33 \%$ & \\
\hline
\end{tabular}




\begin{tabular}{|c|c|c|c|c|c|}
\hline \multirow[t]{3}{*}{ Variable } & \multicolumn{4}{|c|}{ ONS } & \multirow{3}{*}{$p$-value } \\
\hline & \multicolumn{2}{|c|}{ No } & \multicolumn{2}{|c|}{ Yes } & \\
\hline & $N$ & $\%$ & $N$ & $\%$ & \\
\hline $\begin{array}{l}\text { Number of RD } \\
\text { Consultations/Referrals }(\mathrm{N}=546)\end{array}$ & & & & & $<.001$ \\
\hline 0 & 263 & $90.07 \%$ & 29 & $9.93 \%$ & \\
\hline 1 & 165 & $85.49 \%$ & 28 & $14.51 \%$ & \\
\hline 2 or more & 29 & $47.54 \%$ & 32 & $52.46 \%$ & \\
\hline $\begin{array}{l}\text { Charlson Comorbidity Index Scores } \\
(\mathrm{N}=570)\end{array}$ & & & & & .075 \\
\hline $1-2$ & 124 & $91.18 \%$ & 12 & $8.82 \%$ & \\
\hline 3 & 97 & $82.91 \%$ & 20 & $17.09 \%$ & \\
\hline $4-5$ & 199 & $82.82 \%$ & 41 & $17.08 \%$ & \\
\hline 6 or more & 61 & $79.22 \%$ & 16 & $20.78 \%$ & \\
\hline
\end{tabular}

${ }^{\mathrm{a}}$ Chi-square uncorrected two-tailed $p$-value 
Table 11

Two-Way Table Results for ONS - Time and Place Information

\begin{tabular}{|c|c|c|c|c|c|}
\hline \multirow[t]{3}{*}{ Variable } & \multicolumn{4}{|c|}{ ONS } & \multirow{3}{*}{$p$-value } \\
\hline & \multicolumn{2}{|c|}{ No } & \multicolumn{2}{|c|}{ Yes } & \\
\hline & $N$ & $\%$ & $N$ & $\%$ & \\
\hline Discharge destination $(\mathrm{N}=570)$ & & & & & $<.001$ \\
\hline Home & 311 & $89.63 \%$ & 36 & $10.37 \%$ & \\
\hline Home Health & 75 & $82.42 \%$ & 16 & $17.58 \%$ & \\
\hline LTC & 26 & $57.78 \%$ & 19 & $42.22 \%$ & \\
\hline Rehab & 19 & $76.00 \%$ & 6 & $24.00 \%$ & \\
\hline Other & 19 & $61.29 \%$ & 12 & $38.71 \%$ & \\
\hline Missing & 31 & $100.00 \%$ & 0 & $0 \%$ & \\
\hline Season of Admission $(\mathrm{N}=570)$ & & & & & .727 \\
\hline Fall & 153 & $85.47 \%$ & 26 & $14.53 \%$ & \\
\hline Spring & 127 & $85.81 \%$ & 21 & $14.19 \%$ & \\
\hline Summer & 82 & $84.54 \%$ & 15 & $15.46 \%$ & \\
\hline Winter & 119 & $81.51 \%$ & 27 & $18.49 \%$ & \\
\hline Location $^{\mathrm{a}}(\mathrm{N}=570)$ & & & & & .094 \\
\hline 10th Floor & 38 & $82.61 \%$ & 8 & $17.39 \%$ & \\
\hline $8 \mathrm{~S}$ or 11 th Floor & 27 & $87.19 \%$ & 4 & $12.90 \%$ & \\
\hline 3rd Floor (cardiac) & 100 & $89.29 \%$ & 12 & $10.71 \%$ & \\
\hline 4th Floor (renal) & 20 & $76.92 \%$ & 6 & $23.08 \%$ & \\
\hline 5th, 6th, 7th Floors & 40 & $83.33 \%$ & 8 & $16.67 \%$ & \\
\hline $8 \mathrm{NTH}$ & 34 & $87.18 \%$ & 5 & $12.82 \%$ & \\
\hline Coronary Care Unit & 45 & $73.77 \%$ & 16 & $26.23 \%$ & \\
\hline Other ICUs - CVICU, MICU, TICU & 34 & $77.27 \%$ & 10 & $22.73 \%$ & \\
\hline Heart and Vascular Progressive Care/Cardiac & 45 & $86.54 \%$ & 7 & $13.46 \%$ & \\
\hline Medical Progressive Care/Cardiac & 26 & $81.25 \%$ & 6 & $18.75 \%$ & \\
\hline Other Progressive Care/Step-Down Units & 27 & $81.82 \%$ & 6 & $18.18 \%$ & \\
\hline Missing & 45 & $97.83 \%$ & 1 & $2.17 \%$ & \\
\hline
\end{tabular}




\section{Data Analysis: Logistic Regression Results}

The final analysis concerned only an examination of the research question, "How is the provision of ONS related to patient LOS in the hospital?" Reasons for limiting the final analysis to this question have been discussed in previous sections (see the Clinical Data section under Descriptive Statistics above regarding problems with weight change and albumin change data).

Using results from two-way tables, the following variables were entered into a logistic regression model for the high LOS outcome, with ONS as the primary predictor: ONS, CCI, discharge destination, ethnicity, gender, location, and RD consultation.

Multiple logistic regression results for the high LOS outcome, showing IVs, ORs, lower and upper CIs, and $p$-values, are shown in Table 12.

In the multiple logistic regression model, the adjusted odds of high LOS for persons receiving ONS was 2.43 times that for patients not on ONS $(p=.0037)$. In comparison, before controlling for the covariates, the odds ratio of high LOS for patients on ONS (versus no ONS) was 5.11.

The adjusted odds of high LOS were also significantly greater for patients with higher CCI scores compared to those with the lowest scores. Compared to CCI scores of 1-2, those with a CCI score of 3 had 2.8 times the odds of high LOS ( $p=.011$ ); OR for

those with a score of $4-5$ was 3.34 ( $p<.001)$; and OR for patients with CCI $\geq 6$ was 3.99 $(\mathrm{p}=.001)$. 
Patients being discharged to a long term care facility had 2.4 times the odds of high LOS compared to home discharge; those discharged to other destinations had an OR of $3.97(\mathrm{p}=.003)$. This other category was mixed and the 31 patients in it included those who left against medical advice, those going to hospice, other or specialty hospitals, unspecified locations, and patients who died. In many of these cases, the lack of a safe discharge option or need to await admission to another facility may have prolonged the LOS.

While not significant, the data showed that Whites had 1.55 times the odds of high LOS compared to Blacks $(\mathrm{p}=.07)$; unadjusted bivariate results also showed a higher proportion of Whites with high LOS. Female patients had 1.56 times the odds of males for high $\operatorname{LOS}(\mathrm{p}=.067)$ in the logistic regression analysis. In comparison, the unadjusted data showed a greater percentage of high LOS in males than females, but ONS use was greater among females.

In regard to location, it has been mentioned previously that location on day 2 was used for the location variable in this study, after a review of the data showed it was more likely to be where patients spent most of their time, in contrast to initial or final locations. Patients staying on the $4^{\text {th }}$ floor (renal floor) had 4.35 times the odds of high LOS $(\mathrm{p}=$ .016) compared to the $10^{\text {th }}$ floor (a general medical-surgical floor); patients located in the Coronary Care Unit had an OR of $6.06(\mathrm{p}<.001)$ compared to $10^{\text {th }}$ floor patients; and patients in other intensive care locations had an OR of $6.12(\mathrm{p}=.001)$ compared to $10^{\text {th }}$ 
floor patients. These floors also had the highest proportion of patients when unadjusted chi-square tables analysis with LOS.

Patients with two or more RD consults had an OR of 2.22 compared to those with no RD consults $(\mathrm{p}=.0334)$. 
Table 12

Results of Multiple Logistic Regression for High LOS Outcome

\begin{tabular}{|c|c|c|c|c|}
\hline \multirow[t]{2}{*}{ Independent Variables } & \multirow{2}{*}{$\begin{array}{l}\text { Odds } \\
\text { Ratio }^{\mathrm{a}}\end{array}$} & \multicolumn{2}{|c|}{$95 \% \mathrm{CI}$} & \multirow[t]{2}{*}{$p$-value } \\
\hline & & Lower & Upper & \\
\hline \multicolumn{5}{|l|}{ ONS } \\
\hline Yes & 2.43 & 1.34 & 4.41 & .0033 \\
\hline No & 1.0 & & & \\
\hline
\end{tabular}

Charlson Comorbidity Index Scores $(\mathrm{N}=570)$

$\begin{array}{lcccc}1-2 & 1.0 & & & \\ 3 & 2.80 & 1.27 & 6.19 & .011 \\ 4-5 & 3.34 & 1.64 & 6.83 & <.001 \\ 6 \text { or more } & 3.99 & 1.75 & 9.12 & .001\end{array}$

Discharge destination $(\mathrm{N}=570)$

Home

Home health

Long term care

Rehab

Other

Missing

Ethnicity

Black

White

Gender

Male

Female
1.0

1.69

2.40

2.88

3.97

1.22

1.0

1.55

0.97

2.48

.070

$3.18 \quad .100$

$5.14 \quad .024$

$8.63 \quad .059$

$9.91 \quad .003$

$\begin{array}{ll}7.28 & .827\end{array}$

$\begin{array}{lll}0.20 & 7.28 & .827\end{array}$

1.0

1.56

0.97

2.52

.067 


\begin{tabular}{|c|c|c|c|c|}
\hline \multirow[t]{2}{*}{ Independent Variables } & \multirow{2}{*}{$\begin{array}{l}\text { Odds } \\
\text { Ratio }^{\mathrm{a}}\end{array}$} & \multicolumn{2}{|c|}{$95 \% \mathrm{CI}$} & \multirow{2}{*}{$p$-value } \\
\hline & & Lower & Upper & \\
\hline \multicolumn{5}{|l|}{ Location $(\mathrm{N}=570)$} \\
\hline 10th Floor & 1.0 & & & \\
\hline $8 \mathrm{~S}$ and 11th Floor & 0.72 & 0.18 & 2.83 & .64 \\
\hline 3rd Floor (cardiac) & 0.68 & 0.23 & 2.00 & .48 \\
\hline 4th Floor (renal) & 4.35 & 1.31 & 14.43 & .016 \\
\hline 5th, 6th, 7th Floors & 1.24 & 0.39 & 3.94 & .710 \\
\hline $8 \mathrm{NTH}$ & 1.61 & 0.50 & 5.22 & .421 \\
\hline Coronary Care Unit & 6.06 & 2.19 & 16.79 & $<.001$ \\
\hline $\begin{array}{l}\text { Other ICUs - CVICU, MICU, } \\
\text { TICU }\end{array}$ & 6.12 & 2.07 & 18.08 & .001 \\
\hline $\begin{array}{l}\text { Heart and Vascular Progressive } \\
\text { Care/Cardiac }\end{array}$ & 1.15 & 0.36 & 3.61 & .816 \\
\hline Missing & 0.52 & 0.08 & 3.29 & .491 \\
\hline Medical Progressive Care/Cardiac & 1.33 & 0.37 & 4.74 & .665 \\
\hline $\begin{array}{l}\text { Other Progressive Care/Step- } \\
\text { Down Units }\end{array}$ & 2.50 & 0.750 & 8.37 & .136 \\
\hline \multicolumn{5}{|l|}{ Number of RD } \\
\hline 0 & 1.0 & & & \\
\hline 1 & 1.03 & 0.61 & 1.75 & .9101 \\
\hline 2 or more & 2.22 & 1.06 & 4.65 & .0334 \\
\hline
\end{tabular}

${ }^{\mathrm{a} C}$ ross-product odds ratio. 


\section{Summary of Findings}

The primary research question I investigated in my final analysis asked how the provision of ONS was related to patient LOS in the hospital. My study examined the role of demographic, clinical, time and place covariates that were shown in previous research to be related to either LOS or ONS provision, as well as time, person, and place aspects of the epidemiological triad. The null hypothesis, that "there will be no statistically significant difference in the odds of high LOS between patients receiving ONS and those not receiving ONS after adjusting for baseline level of body mass index, age, race, gender, BNP levels, season of the year, location in the hospital, weight changes, initial albumin level, CCI, RD consultation, and diagnosis of malnutrition," was rejected. The alternative hypothesis was found to be true. i.e. there was a statistically significant difference in the odds of high LOS between patients receiving ONS and those not receiving ONS after adjusting for the covariates.

However, the relationship between ONS use and LOS was the opposite of what was seen in other studies reviewed that showed decreased LOS among patients receiving ONS (Gariballa et al., 2006; Philipson et al., 2013). In this study, I found an increased rate of high $\operatorname{LOS}(\mathrm{OR}=2.43 ; \mathrm{p}=.0037)$ for patients who received ONS compared to those who did not receive ONS, even after adjusting for a number of covariates known to increase LOS.

Factors positively significantly associated with high $\operatorname{LOS}(\mathrm{p}<.05)$ included increased CCI (values of 3, 4-5, or CCI $\geq 6$ ); discharge to long term care, location on the 
$4^{\text {th }}$ floor (renal floor), coronary care unit, or other intensive care unit; and two or more RD consults.

Further discussion of the relationship of ONS and these other factors to high LOS may be found in chapter 5 . In addition, chapter 5 will provide an interpretation of these results, comparison of these results with previous research in the field; discussions of limitations, generalizability, validity and reliability of my results; conclusions; social change implications, and recommendations for further research. 
Chapter 5: Discussion, Conclusions, and Recommendations

\section{Introduction}

The literature review for this study included a review of the relationship of malnutrition to patient and hospital outcomes. Studies that used various biomarkers, such as weight loss, albumin levels, decreased dietary intake, functional capacity, and BMI, showed rates of malnutrition in hospitals to be anywhere from 30-69\% (Agarwal et al., 2012; Barker et al., 2011; Singh et al., 2006; Somanchi et al., 2011; Young et al., 2013).

This study was based on previous data showing that better nourished hospital patients have better outcomes and shorter LOS, and that malnourished patients have worse outcomes. According to research described previously, the prevention and treatment of malnutrition in hospital patients reduces cost of care, LOS, readmission rates, mortality, and complication rates among patients (Correia \& Waitzberg, 2003; Somanchi, et al., 2011; Rasheed \& Woods, 2013, Tappenden et al., 2013).

Aziz et al. (2011) found a significant association between LOS and lower nutrition risk scores among HF patients, using a risk score derived from albumin levels and weight changes. ONS use is one intervention used in treating or preventing malnutrition; but while previous evidence had shown benefits of ONS on patient outcomes and LOS, no conclusive studies were found that analyzed such outcomes exclusively for heart failure patients. The only one I found that examined outcomes for HF patients receiving ONS was a very small study by Rozentryt et al. (2010), in which the authors found improvements in weight and quality of life among cachectic HF 
patients receiving ONS, but the sample size was too small for results to be conclusive, and LOS was not a measured outcome.

This study sought to provide further insight into whether intervention with ONS is related to patient and hospital outcomes in hospitalized patients with $\mathrm{HF}$, and the nature of that relationship, while controlling for and evaluating the effects of covariates known to affect nutritional status and LOS. As discussed in Chapter 4, I examined only the outcome of LOS in this study because the data would not support analysis of clinical outcomes at this time. This study was unique in that the retrospective design better represented normal day-to-day hospital operations and included the perspective of the epidemiological triad.

I performed bivariate analysis using chi-square tests to determine whether there were significant associations between LOS and each covariate, as well as between ONS use and each covariate. Covariates evaluated included baseline BMI, age, race, gender, initial BNP, season of the year of admission, location in the hospital, initial albumin level, CCI, RD consultation, and diagnosis of malnutrition.

Results for two-way tables for ONS and each of the covariates are described in detail in Chapter 4. In summary, these results showed significant associations $(p<.05)$ between ONS use and the following categorized variables: age category $(p<.001)$; gender $(p=.0087)$; ethnicity $(\mathrm{p}=.0289)$; BMI $(p<.001)$; high LOS $(p<.001)$; initial albumin $(p=.0016)$; diagnosis of malnutrition $(p<.001)$; number of RD consults $(p<$ $.001)$; and discharge destination $(p<.001)$. The following were related to higher ONS 
use: greater age, female gender, White ethnicity, lower BMI, higher LOS, low albumin, diagnosis of malnutrition, and receiving RD consultation. Significant associations were not found for initial BNP $(p=.066), \mathrm{CCI}(p=.075)$, location $(p=.094)$, payer $(p=.913)$ or season of admission $(p=.727)$.

In bivariate tests between covariates and the LOS outcome, the following were significantly $(\mathrm{p}<.05)$ associated with high LOS: ONS use $(p<.001)$, gender $(p=.003)$, RD consults, CCI of 3, 4-5, or $\geq 6(p<.001)$, discharge destination $(p<.001)$, and location ( $p<.001)$. Using these results, a multiple logistic regression model was developed to evaluate LOS and the influence of each of these covariates while controlling for other variables. Ethnicity ( $p=.064$ in the two-way tables) was also included in the model. In the multiple logistic regression model, the adjusted odds of high LOS for persons receiving ONS was 2.43 times that for patients not on ONS $(p=.0037)$. This was a reduction in OR from $5.11(p<.001)$ in the unadjusted bivariate analysis between ONS and high LOS. However, the final OR showing an increased odds of high LOS was the opposite of the relationship shown in other studies reviewed, which had shown reductions in LOS with ONS use. A randomized, placebo-controlled study by Gariballa et al. (2006) and a large retrospective study by Philipson et al. (2013) both reported reduced adjusted LOS among patients who received ONS compared to those who did not receive ONS. Gariballa et al. (2006) found LOS among acutely ill elderly patients to be reduced by a mean of 0.7 days, from 10.1 days among patients not receiving ONS to 9.4 days among matched patients receiving ONS. Patients on ONS in the study by Philipson et al. (2013), 
which used only administrative data, tended to be older and sicker than a matched nonONS comparison group, but had shorter adjusted LOS by $21 \%$, or 2.3 days on average (95\% CI [-2.4, -2.2] versus the comparison group - 8.7 versus 11.0 adjusted days. While there were clear differences between these studies and mine, the magnitude of the OR for my study — nearly $2 \frac{1}{2}$ times the odds of high LOS for ONS recipients--was surprising.

For the covariates in the regression model, CCI, discharge destination, hospital location, and RD consultations had significant results in relation to adjusted LOS. The adjusted odds of high LOS were significantly greater for patients with higher CCI scores compared to those with the lowest scores. Compared to CCI scores of 1-2, those with a CCI score of 3 had an OR of 2.8 for high LOS ( $p=.011)$; OR for those with a score of 4-5 was $3.34(p<.001)$; and OR for patients with CCI $\geq 6$ was $3.99(p=.001)$.

Patients being discharged to a long term care facility had 2.4 times the odds of high LOS compared to home discharge; those discharged to other locations had an OR of $3.97(p=.003)$. This other location category was mixed and the 31 patients in it included those who left against medical advice; as well as those discharged to hospice, other or specialty hospitals, unspecified locations, and patients who died. In many of these cases, the lack of a safe discharge option or need to await admission to another facility may have prolonged the LOS.

While not significant, the data showed that White patients had 1.55 times the odds of high LOS compared to Black patients $(p=.07)$. Unadjusted bivariate results showed ethnicity to be significantly associated with LOS $(p=.003)$; Whites had a higher rate of 
high LOS (28.6\%) compared to Blacks (21.8\%). Also not significant, but noteworthy in the results: Female patients had 1.56 times the odds of males for high $\operatorname{LOS}(p=.067)$ in the logistic regression analysis. The unadjusted bivariate analysis showed $31.1 \%$ of females had high LOS, compared to $21.2 \%$ of males, and ONS use was also greater among females.

Patients staying on the $4^{\text {th }}$ floor (renal floor) had 4.35 times the odds of high LOS $(p=.016)$ compared to the $10^{\text {th }}$ floor (a general medical-surgical floor); patients located in the Coronary Care Unit had an OR of $6.06(p<.001)$ compared to $10^{\text {th }}$ floor patients; and patients in other intensive care locations had an OR of $6.12(p=.001)$ compared to $10^{\text {th }}$ floor patients. These floors also had the highest proportion of patients with high LOS in unadjusted chi-square tables analysis. Patients with two or more RD consults had an OR of 2.22 compared to those with no RD consults $(p=.0334)$.

\section{Interpretation of the Findings}

The information cited in my literature review regarding proportions of malnourished patients in hospitals suggest that $30-55 \%$ of patients in acute care hospitals worldwide are malnourished (Agarwal et al., 2012; Barker et al., 2011; Singh et al., 2006; Somanchi et al., 2011). I was unable to evaluate malnutrition or nutritional status like the cited studies because the combined data supporting this classification-including weight loss, decreased dietary intake, albumin levels, decreased functional capacity, and BMI-was not available for most patients. I attempted to include albumin, weight loss, and BMI, but insufficient or questionable data in some cases did not support the analysis for 
all these indicators. For example, there were not enough patients for the chi-square table in the low or underweight BMI category $(\mathrm{BMI}<18.5)$ used to indicate poor nutrition; therefore, I had to combine this category with the normal BMI category of 18.5-24.99. Initial albumin levels were only available on 271 , or $48 \%$ of cases. There were a number of unusually large weight fluctuations, and patients moved around, rendering many weights or weight changes somewhat questionable, and giving too large variances to use in the logistic model. Therefore, I could not classify patients as malnourished in the same way these studies did, but was able to evaluate other indicators generally associated with poor nutrition or poor outcomes, and controlled for these in order to give a valid comparison group. Only $2.8 \%$ of patients in this study had actual ICD-9 diagnoses of malnutrition. The diagnosis of failure to thrive (FTT) may have been used instead of this in some cases, but this diagnosis encompasses more than just malnutrition; malnutrition is only one cause of FTT. Additionally, only an estimated $1.7 \%$ of patients in my sample had this diagnosis. Malnutrition is one major reason for RD consultation, especially when triggered by nursing assessments, but there were other reasons that RDs were consulted to see patients.

Because of the abundance of previous research showing proportions of malnourished patients ranging generally from 30-55\%, I might assume that this hospitalized population had similar proportions of malnourished patients, or at least $30 \%$. With this in mind, ONS in my study could have been assumed to have been treating some malnourished patients, and thus one might expect improved outcomes in the malnourished population. 
In this study, however, the rate of high LOS was significantly greater for patients on ONS, with 2.43 times the odds of high LOS among patients receiving ONS compared to those not receiving it. The two-way tables between ONS and various covariates show that ONS use was associated in the expected directions with age, low albumin, RD consults, BMI, discharge destination, and diagnosis of malnutrition. Therefore, by considering these factors in the analysis with LOS, I was able to control for factors related to malnutrition that affected LOS. I also controlled for other variables, such as discharge destination and other variables related to severity of illness. Yet ONS use was still clearly associated with much greater odds for high LOS; and despite known benefits of ONS, its inclusion in patients' dietary provisions did not overcome the other factors that lead to longer LOS in these patients.

I tried in this study to evaluate ONS use from different perspectives: I used an epidemiological triad approach that included time, place, and person, to add an additional dimension to my study. This also helped ensure that I did not miss unexpected factors related to patient care or patient volume in different locations in the hospital or at different times of the year. I did find that location in the hospital was significantly related to high LOS, especially when patients were in intensive care units or the renal unit. It was not surprising that patients in higher-acuity units had greater proportions of high LOS, and I controlled for this factor in the logistic model. Season did not seem to ultimately affect my findings, although I observed that the season with the lowest number of admissions, spring, had the greatest frequency of high LOS; while the season with the highest number of admissions, fall, had the lowest LOS. 
This study gave further insight also into other variables associated with high LOS, including CCI, discharge destination, location in hospital, and RD consultations. Most of these are related to severity of illness in some way. CCI by definition is measuring severity of illness; many RD consults are on patients who are eating poorly or who need diet education; and location in the hospital reflects need for special care related to medical condition.

Hospitals have a limited amount of control over discharge destination and its effect on LOS. They often must wait for a nursing home bed to become available; so while a patient may be ready for discharge to a lower level of care, there is no available discharge destination and the patient must be held in the hospital longer than needed.

\section{Limitations of the Study}

One of the disappointing aspects of my study was inability to use weight change or albumin change as outcomes. Thus, only one outcome, LOS, could be examined.

Results for this study were dependent on the accuracy of the data provided. I assumed most of it was accurate, but there were opportunities for errors - such as in anthropometric measurements. Because it was a retrospective study, certain measurements could not be mandated before collecting the data; therefore, not all desired data were available. For some variables, there were several choices as to which values to use; I had to make the best judgment on which was the most accurate choice. This was true for initial weight, albumin, BNP, and location, and my criteria for choice of values was discussed in the data analysis section. I also had to make some judgments as I 
assigned CCI values, because of changes in ICD-9 codes over the years. The CCI may not be as valid in indicating severity of illness as it was 10-20 years ago because of changes in understanding of the impact of certain conditions. Some are not as impactful on health outcomes, because of significant advances in treatments and outcomes, such as HIV/AIDS, which had a score of 6. Other conditions which not included in earlier CCI scoring keys are recognized to have a greater impact on outcomes. These include hypertension, depression, use of warfarin, skin ulcers/cellulitis, wounds, and malnutrition. The first four of these were added by Charlson et al. (2008) in a study that adapted the CCI to predict yearly costs of chronic disease among patients in a primary care setting. However, I did not this adaptation when I started my analysis since the focus of that study was on primary care patients and limited to chronic disease costs. It is possible that my use of CCI and its inclusion in the regression model might have yielded different results if I had used this adaptation.

There were some assumptions involved with the ONS variable. One is that the supplement was actually consumed by the patient. The data did not show whether or how much of the ordered ONS was consumed, nor whether it was actually given to the patient. My clinical experience indicated that supplements are not always consumed. An order for the product may have been discontinued if the patient was not drinking it, but not always. At times, in my experience as a registered dietitian at the hospital, an ordered supplement was not sent to the patient because of a shortage of the supplement, shortage of the requested flavor, or error. ONS also was ordered by a number of different health professionals, since it could be ordered by any physician, physician extender, or 
registered dietitian. It would have been ordered for different reasons by different persons, although in my experience, the main reasons were poor dietary intake, recent weight loss, or low body weight, severe wounds, recent surgery, or lab values suggesting poor nutritional status. Some professionals are much more aggressive about ordering; others did not order it even if many of the above reasons were present.

Issues with weight - and therefore BMI values--have been discussed previously. The main issues concern validity of the weight as representing the patient's true weight, since patients hospitalized with HF often have fluid retention and shifts in bodily fluids during hospitalization. Accuracy of weights can also be an issue if the patients changed locations frequently, was weighed on a less accurate scale, or could not be weighed on admission (such as in the ED). In the latter case, staff would need to use the patient's stated weight, or estimate current weight in order to complete required fields in the EMR. Different scales in different locations, or different weighing practices, may have resulted in weights that varied somewhat from actual weight or from one another. The unrecognized or unavoidable presence of various items on a bed, certain mattress covers, blankets, patient apparel, or appliances (such as leg braces, intermittent pneumatic compression devices for prevention of deep vein thrombosis, casts, shoes, or articles of clothing) could affect weight. This should be minimized because hospital personnel are trained to remove extraneous items before weighing, but errors can occasionally occur. Since BMI value depends on weight and height, any error in weight or height could adversely affect BMI values. 
LOS was determined based on time of admission to the hospital. If the patient spent time awaiting a bed and/or being treated in the ED before actual hospital admission time, this would not be considered part of the LOS. However, any such variation of this type was assumed to be similar in the ONS = yes and ONS = no groups.

While the sample was large $(N=570)$, the large number of variables and small numbers in some categories, meant that the sample size was too small to analyze the data for all categories within all variables. This was true with discharge destination, location, and payer, for which categories (e.g., types of payers, different hospital floors) had to be combined. Discharge destination results were influenced by how categories were combined, but this was unavoidable, given small numbers in some categories. For location in the hospital, analysis by each separate unit would have been ideal, but impossible with the small number of cases in some locations. Therefore, locations were combined into logical groups based on the functions of various floors. However, this could have reduced the reliability of results. The payer category was the most difficult to put into groups, because of the large number of payers, and known variability in coverage among different payers. I tried to combine them in the most logical groupings, but perhaps different types of combinations would have yielded different results.

My study was also limited by missing data such as laboratory results, as well as other missing data as noted in the results section, which may affect results. 


\section{Recommendations}

Additional research is needed on the effectiveness of this specific intervention in the HF population, as well evaluation of other interventions to improve nutritional status and reduce LOS. Future studies could more effectively show benefits it they could identify whether HF patients consumed supplements received, or whether there are more benefits if ONS provision is part of a combined intervention, similar to the design of the study performed by Somachi et al. (2011) among malnourished patients. Also, because other studies have shown benefits of ONS among certain populations such as elderly patients, or conditions such as malnutrition and pressure ulcers, I would recommend that research be done to examine whether positive benefits might be gained through ONS provision for hospitalized HF patients who have evidence of malnutrition and/or wounds.

There may be additional factors associated with ONS use that lead to greatly increased odds for high LOS. Investigation of potential other factors could be very beneficial to find other interventions to reduce LOS among these patients. Other potential research might be to consider a similar study using updated adaptation of the CCI or some other more recent or more detailed comorbidity indicator, such as the Elixhauser Index or a "count method," as described by Farley et al. (2006).

Individualized approaches to help reduce LOS could also be studied for effectiveness. For example, because of large numbers of hospitalized patients reported in previous studies to be malnourished, more individualized attention by dietitians to such patients, without requiring a consult, may be needed rather than only ordering 
supplements. More effective screening by nursing could help identify patients most in need of individualized attention by dietitians. This would address nutritional issues in the $35 \%$ of ONS = yes (29 out of 89 ) patients who did not receive dietitian consults. For those with discharge destinations associated with highest LOS, increased attention by care managers and nursing staff, or other approaches could target this cause of high LOS.

\section{Implications}

Shortened LOS can benefit patients, their families, and hospitals. It can reduce costs of hospital care, as well as provide positive social benefit to the community or general population, as well as individuals receiving hospital care. Use of ONS and other nutrition interventions, such as dietitian consultations, have been shown in other studies to potentially improve the healing process, prevent complications, and reduce the time patients spend in the hospital. However, my data did not show a benefit in routine administration of ONS in the normal hospital setting. This points to a need for further study on when and whether ONS could be helpful in more specific cases, and implies that investment in ONS on a routine basis may not be beneficial unless there is a special need for them. It should also prompt researchers to examine other ways to improve LOS.

The number of patients diagnosed with malnutrition and failure to thrive in this study was extremely low, and based on previous studies, may be greatly underdiagnosed. Diagnosis of malnutrition was associated with ONS use, and it is possible that ONS use could be a marker for malnutrition. Providers may want to consider whether more of their patients may actually qualify for the diagnosis of malnutrition, especially if they believe 
the patient would benefit from ONS or other nutrition interventions. Earlier, more frequent, and accurate identification of such patients has the potential to contribute to positive social change by improving care for patients in special need of attention. Improved care positively impacts not only patients, but their families. It also helps hospitals make more effective and efficient use of health care resources.

This study has the potential to promote positive social change by providing guidance on which variables are associated with high LOS, in order to better address those issues and potentially reduce LOS in hospitalized patients. This study also helps provide information on the use of ONS as an intervention. In this case, the data showed that ONS in itself did not improve LOS among the general population of HF patients, but was associated with 2.43 times the odds of high LOS. It is hoped that further research would be performed to examine whether ONS use among hospitalized HF patients may be more beneficial when certain other conditions are also present--such as malnutrition or wounds - or among certain populations such as elderly patients.

It would be beneficial in current practice to consider more expanded approaches to address nutritional risk factors than solely with only the use of ONS. RD consults and further evaluation by care coordinators for HF patients; especially for patients in the $\mathrm{CCU}$, other ICUs, on the renal floor, patients destined for discharge to long-term care facilities, and those with CCI scores of 3 or greater; may be beneficial methods to reduce LOS. 


\section{Conclusion}

This study shows that routine ONS use alone is not sufficient to improve LOS among the general hospitalized HF population. While I attempted to control for aspects of hospitalization that would lead to high LOS, I did not see reduced LOS for patients on ONS compared to those not receiving supplements. In fact, patients receiving ONS had nearly $2 \frac{1}{2}$ times the odds of high LOS compared to those who did not receive ONS. This suggests that patients on ONS have other issues contributing to high LOS, and ONS is inadequate by itself to reduce LOS compared patients for whom ONS was not prescribed. ONS has been shown to be beneficial in some cases, and is not a high-cost intervention. But as used in normal everyday hospital operations in this medical center, the existence of diet orders for ONS did not appear to provide measurable benefits in LOS for this general population of HF patients. 


\section{References}

Abbott Laboratories (2014). Abbott nutrition for health care professionals. Retrieved from http://abbottnutrition.com/categories/therapeutic/therapeutic-nutrition-center

Agarwal, E., Ferguson, M., Banks, M., Batterham, M., Bauer, J., Capra, S., \& Isenring, E. (2013). Malnutrition and poor food intake are associated with prolonged hospital stay, frequent readmissions, and greater in-hospital mortality: results from the Nutrition Care Day Survey 2010. Clinical Nutrition (Edinburgh, Scotland), 32(5), 737-45. doi: 10.1016/j.clnu.2012.11.021

Agarwal, E., Ferguson, M., Banks, M., Bauer, J., Capra, S., \& Isenring, E. (2012). Nutritional status and dietary intake of acute care patients: results from the Nutrition Care Day Survey 2010. Clinical Nutrition (Edinburgh, Scotland), 31(1), 41-7. doi: 10.1016/j.clnu.2011.08.002

Arnaud-Battandier, F., Malvy, D., Jeandel, C., Schmitt, C., Aussage, P., Beaufrère, B., \& Cynober, L. (2004). Use of oral supplements in malnourished elderly patients living in the community: a pharmaco-economic study. Clinical Nutrition (Edinburgh, Scotland), 23(5), 1096-103. doi: 10.1016/j.clnu.2004.02.007

Aziz, E. F., Javed, F., Pratap, B., Musat, D., Nader, A., Pulimi, S., ... Kukin, M. L. (2011). Malnutrition as assessed by nutritional risk index is associated with worse outcome in patients admitted with acute decompensated heart failure: an ACAP-HF data analysis. Heart International, 6e2(1), 3-8. doi: 10.4081/hi.2011.e2

Barker, L. a, Gout, B. S., \& Crowe, T. C. (2011). Hospital malnutrition: prevalence, 
identification and impact on patients and the healthcare system. International Journal of Environmental Research and Public Health, 8(2), 514-27. doi:

10.3390/ijerph8020514

Botella-Carretero, J. I., Iglesias, B., Balsa, J. a, Arrieta, F., Zamarrón, I., \& Vázquez, C. (2010). Perioperative oral nutritional supplements in normally or mildly undernourished geriatric patients submitted to surgery for hip fracture: a randomized clinical trial. Clinical Nutrition (Edinburgh, Scotland), 29(5), 574-9. doi: 10.1016/j.clnu.2010.01.012

Botella-Carretero, J. I., Iglesias, B., Balsa, J. a, Zamarrón, I., Arrieta, F., \& Vázquez, C. (2008). Effects of oral nutritional supplements in normally nourished or mildly undernourished geriatric patients after surgery for hip fracture: a randomized clinical trial. JPEN. Journal of Parenteral and Enteral Nutrition, 32(2), 120-8. doi: $10.1177 / 0148607108314760$

Bourdel-Marchasson, I., Barateau, M., Rondeau, V., Dequae-merchadou, L., Sallesmontaudon, N., Emeriau, J., ... Segalen, V. (2000). A multi-center trial of the effects of oral nutritional supplementation in critically ill older inpatients. Nutrition, 16(1), 1-5. doi: 10.1016/S0899-9007(99)00227-0

Centers for Disease Control and Prevention. (2015). About adult BMI. Retrieved from http://www.cdc.gov/healthyweight/assessing/bmi/adult_bmi/index.html

Charlson, M. E., Charlson, R. E., Peterson, J. C., Marinopoulos, S. S., Briggs, W. M., \& Hollenberg, J. P. (2008). The Charlson comorbidity index is adapted to predict costs 
of chronic disease in primary care patients. Journal of Clinical Epidemiology, 61(12), 1234-1240. doi: 10.1016/j.jclinepi.2008.01.006

Charlson, M. E., Pompei, P., Ales, K. L., \& MacKenzie, R. (1987). A new method of classifying prognostic in longitudinal studies: development and validation. Journal of Chronic Diseases. doi: 0021-9681/87

Chima, C., Barco, K., Dewitt, M., Maeda, M., Teran, J., \& Mullen, K., Chima, C. S., Barco, K., Dewitt, M. L. A., Maeda, M., Carlos Teran, J., \& Mullen, K. D. (1997). Relationship of nutritional status to length of stay, hospital costs, and discharge status of patients hospitalized in the medicine service. Journal of the American Dietetic Association, 97(9), 975-978. doi: doi: 10.1016/S0002-8223(97)00235-6

Correia, M. Isabel. T. D., W. D. L. (2003). The impact of malnutrition on morbidity, mortality, length of hospital stay and costs evaluated through a multivariate model analysis. Clinical Nutrition, 22(3), 235-239. http://doi.org/10.1016/S0261$5614(02) 00215-7$

Degroot, V., Beckerman, H., Lankhorst, G., \& Bouter, L. (2003). How to measure comorbiditya critical review of available methods. Journal of Clinical Epidemiology, 56(3), 221-229. http://doi.org/10.1016/S0895-4356(02)00585-1

Detsky, A. S., McLaughlin, J. R., Baker, J. P., Johnston, N., Whittaker, S., Mendelson, R. A., \& Jeejeebhoy, K. N. (1987). What is Subjective Global Assessment of Nutritional Status? Journal of Parenteral and Enteral Nutrition, 11(1), 8-13.

Deyo, R. A., Cherkin, D. C., \& Ciol, M. A. (1992). Adapting a Clinical Comorbidity 
Index for Use With ICD-9-CM Administrative Databases. Journal of Clinical Epidemiology, 45(6), 613-619.

Dhaliwal, A. S., Deswal, A., Pritchett, A., Aguilar, D., Kar, B., Souchek, J., \& Bozkurt, B. (2009). Reduction in BNP levels with treatment of decompensated heart failure and future clinical events. Journal of Cardiac Failure, 15(4), 293-9. http://doi.org/10.1016/j.cardfail.2008.11.007

Di Somma, S., Magrini, L., Pittoni, V., Marino, R., Mastrantuono, A., Ferri, E., ... Clopton, P. (2010). In-hospital percentage BNP reduction is highly predictive for adverse events in patients admitted for acute heart failure: the Italian RED Study. Critical Care (London, England), 14(3), R116. http://doi.org/10.1186/cc9067

Faggiano, P., Valle, R., Aspromonte, N., D’Aloia, A., Di Tano, G., Barro, S., ... Dei Cas, L. (2010). How often we need to measure brain natriuretic peptide (BNP) blood levels in patients admitted to the hospital for acute severe heart failure? Role of serial measurements to improve short-term prognostic stratification. International Journal of Cardiology, 140(1), 88-94. http://doi.org/10.1016/j.ijcard.2008.11.020

Farley, J. F., Harley, C. R., \& Devine, J. W. (2006). A Comparison of Comorbidity Measurements. The American Journal of Managed Care, (February), 110-117.

Ferguson, M., Capra, S., Bauer, J., \& Banks, M. (1999). Development of a valid and reliable malnutrition screening tool for adult acute hospital patients. Nutrition (Burbank, Los Angeles County, Calif.), 15(6), 458-64. Retrieved from http://www.ncbi.nlm.nih.gov/pubmed/10378201 
Gariballa S, Forster S, Walters S, Powers, H. (2007). Oral nutritional supplements during acute illness and recovery reduced non-elective hospital readmissions in older patients. Evidence-Based Nursing, 10(3), 81. http://doi.org/10.1136/ebn.10.3.81

Gariballa, S., Forster, S., Walters, S., \& Powers, H. (2006). A randomized, double-blind, placebo-controlled trial of nutritional supplementation during acute illness. The American Journal of Medicine, 119(8), 693-9.

http://doi.org/10.1016/j.amjmed.2005.12.006

Halfon, P., Eggli, Y., Van Melle, G., Chevalier, J., Wasserfallen, J. B., \& Burnand, B. (2002). Measuring potentially avoidable hospital readmissions. Journal of Clinical Epidemiology, 55(6), 573-587. http://doi.org/10.1016/S0895-4356(01)00521-2

Hannan, E. L. (2008). Randomized clinical trials and observational studies: guidelines for assessing respective strengths and limitations. JACC. Cardiovascular Interventions, 1(3), 211-7. http://doi.org/10.1016/j.jcin.2008.01.008

Heyman, H., Van De Louverbosch, D. E. J., Meijer, E. P., \& Schols, J. M. G. A. (2008). Benefits of an oral nutritional supplement on pressure ulcer healing in long-term care residents. Journal of Wound Care, 17(11), 476-480.

Hiesmayr, M., Schindler, K., Pernicka, E., Schuh, C., Schoeniger-Hekele, A., Bauer, P., ... Team, T. N. A. (2009). Decreased food intake is a risk factor for mortality in hospitalised patients: The NutritionDay survey 2006. Clinical Nutrition, 28(5), 484 91. http://doi.org/10.1016/j.clnu.2009.05.013

Hoekstra, J. C., Goosen, J. H. M., de Wolf, G. S., \& Verheyen, C. C. P. M. (2011). 
Effectiveness of multidisciplinary nutritional care on nutritional intake, nutritional status and quality of life in patients with hip fractures: a controlled prospective cohort study. Clinical Nutrition (Edinburgh, Scotland), 30(4), 455-61. http://doi.org/10.1016/j.clnu.2011.01.011

Houwing, R. (2003). A randomised, double-blind assessment of the effect of nutritional supplementation on the prevention of pressure ulcers in hip-fracture patients. Clinical Nutrition, 22(4), 401-405. http://doi.org/10.1016/S0261-5614(03)00039-6

Hubbard, G. P., Elia, M., Holdoway, A., \& Stratton, R. J. (2012). A systematic review of compliance to oral nutritional supplements. Clinical Nutrition (Edinburgh, Scotland), 31(3), 293-312. doi: 10.1016/j.clnu.2011.11.020

Johns Hopkins Bloomberg School of Public Health. (2008). Epidemiologic investigation. Retrieved from http://ocw.jhsph.edu/courses/fundepi/pdfs/lecture2.pdf

Joshi, A. V., D’Souza, A. O., \& Madhavanevision, S. S. (2004). Differences in Hospital Length-of-Stay, Charges, and Mortality in Congestive Heart Failure Patients. Congestive Heart Failure, 10(2), 76-84. doi: 10.1111/j.1527-5299.2004.02008.x

Kociol, R. D., Liang, L., Hernandez, A. F., Curtis, L. H., Heidenreich, P. a, Yancy, C. W., ... Peterson, E. D. (2013). Are we targeting the right metric for heart failure? Comparison of hospital 30-day readmission rates and total episode of care inpatient days. American Heart Journal, 165(6), 987-994.e1. doi: org/10.1016/j.ahj.2013.02.006

Lawson, R. M., Dishi, M. K., Barton, J. R., \& Cobden, I. (2003). The effect of unselected 
post-operative nutritional supplementation on nutritional status and clinical outcome of orthopaedic patients. Clinical Nutrition, 22(1), 39-46. doi:

10.1054/clnu.2002.0588

Lim, S. L., Ong, K. C. B., Chan, Y. H., Loke, W. C., Ferguson, M., \& Daniels, L. (2012). Malnutrition and its impact on cost of hospitalization, length of stay, readmission and 3-year mortality. Clinical Nutrition (Edinburgh, Scotland), 31(3), 345-50. doi: 10.1016/j.clnu.2011.11.001

Miller, M. D., Crotty, M., Whitehead, C., Bannerman, E., \& Daniels, L. a. (2006). Nutritional supplementation and resistance training in nutritionally at risk older adults following lower limb fracture: a randomized controlled trial. Clinical Rehabilitation, 20(4), 311-23. doi: 10.1191/0269215506cr942oa

Milne, A. C., Avenell, A., \& Potter, J. (2006). Meta-analysis: protein and energy supplementation in older people. Annals of Internal Medicine, 144(1), 37-48. doi:10.7326/0003-4819-144-1-200601030-00008

Neelemaat, F., Bosmans, J. E., Thijs, A., Seidell, J. C., \& van Bokhorst-de van der Schueren, M. a E. (2012). Oral nutritional support in malnourished elderly decreases functional limitations with no extra costs. Clinical Nutrition (Edinburgh, Scotland), 31(2), 183-90. doi: 10.1016/j.clnu.2011.10.009

Park, L., Andrade, D., Mastey, A., Sun, J., \& Hicks, L. (2014). Institution specific risk factors for 30 day readmission at a community hospital: a retrospective observational study. BMC Health Services Research, 14(1), 40. doi: 10.1186/1472- 
6963-14-40

Philipson, T. J., Snider, J. T., Lakdawalla, D. N., Stryckman, B., \& Goldman, D. P. (2013). Impact of oral nutritional supplementation on hospital outcomes. The American Journal of Managed Care, 19(2), 121-8. Retrieved from http://www.ncbi.nlm.nih.gov/pubmed/23448109

Porta, M. (2008). A dictionary of epidemiology ( $5^{\text {th }}$ ed.). Oxford University Press, USA.

Potter, J., Langhorne, P., \& Roberts, M. (1998). Routine protein energy supplementation in adults : systematic review, British Medical Journal, 317:495. doi: 10.1136/bmj.317.7157.495

Potter, J. M., Roberts, M. A., McColl, J. H., \& Reilly, J. J. (2001). Protein energy supplements in unwell elderly patients--a randomized controlled trail. Journal of Parenteral and Enteral Nutrition, 25(6), 323-329. doi:

$10.1177 / 0148607101025006323$

Quan, H., Sundararajan, V., Halfon, P., Fong, A., Burnand, B., Luthi, J.-C., ... Ghali, W. A. (2005). Coding algorithms for defining comorbidities in ICD-9-CM and ICD-10 administrative data. Medical Care, 43(11), 1130-1139. doi:

10.1097/01.mlr.0000182534.19832.83

Rasheed, S., \& Woods, R. T. (2013). Predictive validity of "Malnutrition Universal Screening Tool" ("MUST") and Short Form Mini Nutritional Assessment (MNASF) in terms of survival and length of hospital stay. E-SPEN Journal, 8(2), e44-e50. doi: 10.1016/j.clnme.2013.01.001 
Rohrer, J. E., Adamson, S. C., Barnes, D., \& Herman, R. (2008). Obesity and General Pain in Patients Utilizing Family Medicine: Should Pain Standards Call for Referral of Obese Patients to Weight Management Programs?, 17(3), 204-209. doi: 10.1097/01.qmh.0000326724.47837.f5

Rohrer, J. E., Rasmussen, N., \& Adamson, S. A. (2008). Illness severity and total visits in family medicine. Journal of Evaluation in Clinical Practice, 14, 65-69.

Rozentryt, P., von Haehling, S., Lainscak, M., Nowak, J. U., Kalantar-Zadeh, K., Polonski, L., \& Anker, S. D. (2010). The effects of a high-caloric protein-rich oral nutritional supplement in patients with chronic heart failure and cachexia on quality of life, body composition, and inflammation markers: a randomized, double-blind pilot study. Journal of Cachexia, Sarcopenia and Muscle, 1(1), 35-42. doi: $10.1007 / \mathrm{s} 13539-010-0008-0$

Schneider, M. (2006). Introduction to public health ( $2^{\text {nd }}$ Ed). Sudbury, MA: Jones and Bartlett Publishers.

Serum albumin test. (n.d.). In U. S. National Library of Medicine. Retrieved from http://www.ncbi.nlm.nih.gov/pubmedhealth/PMH0003951/

Singh, H., Watt, K., Veitch, R., Cantor, M., \& Duerksen, D. R. (2006). Malnutrition is prevalent in hospitalized medical patients: are housestaff identifying the malnourished patient? Nutrition (Burbank, Los Angeles County, Calif.), 22(4), 3504. doi: 10.1016/j.nut.2005.08.009

Somanchi, M., Tao, X., \& Mullin, G. E. (2011). The facilitated early enteral and dietary 
management effectiveness trial in hospitalized patients with malnutrition. JPEN. Journal of Parenteral and Enteral Nutrition, 35(2), 209-16. doi:

$10.1177 / 0148607110392234$

Sundararajan, V., Henderson, T., Perry, C., Muggivan, A., Quan, H., \& Ghali, W.A. (2004). New ICD-10 version of the Charlson comorbidity index predicted inhospital mortality. Journal of Clinical Epidemiology, 57(12), 1288-94. doi: 10.1016/j.jclinepi.2004.03.012

Tappenden, K. A., Quatrara, B., Parkhurst, M. L., Malone, A. M., Fanjiang, G., \& Ziegler, T. R. (2013). Critical role of nutrition in improving quality of care: an interdisciplinary call to action to address adult hospital malnutrition. JPEN. Journal of Parenteral and Enteral Nutrition, 37(4), 482-97. doi:

$10.1177 / 0148607113484066$

The Joint Commission. (2012). Provision of Care, Treatment, and Services (CAMH / Hospitals). Standards FAQ details. Retrieved from http://www.jointcommission.org/mobile/standards_information/jcfaqdetails.aspx?St andardsFAQId=471\&StandardsFAQChapterId=78

Yancy, C. W., Jessup, M., Bozkurt, B., Butler, J., Casey, D. E., Drazner, M. H., ... Wilkoff, B. L. (2013). 2013 ACCF/AHA guideline for the management of heart failure: a report of the American College of Cardiology Foundation/American Heart Association Task Force on Practice Guidelines. Journal of the American College of Cardiology, 62(16), e147-239. doi: 10.1016/j.jacc.2013.05.019 
Young, A. M., Kidston, S., Banks, M. D., Mudge, A. M., \& Isenring, E. A. (2013). Malnutrition screening tools: comparison against two validated nutrition assessment methods in older medical inpatients. Nutrition, 29(1), 101-6. doi:

10.1016/j.nut.2012.04.007 
Appendix

Nutrition Screening - Adult Admission and Shift Assessment Nutrition Screen (screen shot from EMR)

\begin{tabular}{|c|c|}
\hline Wutrition Screen & 8 \\
\hline Diet Reswictions: & D Clear All \\
\hline Comments & DWh \\
\hline Cuthurat Screen & 빌 $<18$ \\
\hline ICultural Screen & [D "Braden scale \&18 and 2 or less Nutrtion score \\
\hline | practices, custr & [C. "Cancer headhed: wichemolrad tx \\
\hline Ipinbual Practices & [Diagnosis of mainubiacntailure to thave \\
\hline itual Restrictions & "Hiperemesis Graidanum \\
\hline iritust Communit: & [D "Patient NPOFClear Liquid Diet >5 days \\
\hline & [) "PO intake $<50 \%$ for 3 consecutrve meals \\
\hline 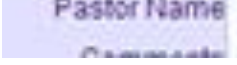 & [ "Poot intake $>3$ dajs \\
\hline Mutrition Screen & (8) \\
\hline Diet Restrictions: & [1] "Cancer headhect, wichemolrad to \\
\hline Comments & [C] "Diagnosis of mainutisontabure to theive \\
\hline Cultural Screen & D. Hyperemesis Grasidanum \\
\hline practices custs & 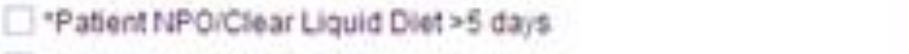 \\
\hline pracsices, cusat & D. "PO intaine $<50 \%$ for 3 consecubve meals \\
\hline pinoual Practices & (1) "Poor intake $>3$ dajs \\
\hline tual Restrictions & "Stage IFAV pressure sore, non-hesking wound. deep tissue injury \\
\hline itual Community & L "Tube feeding THATTRN \\
\hline Paster Rame & $\begin{array}{l}\text { "Unplanned weighn loss >10 los in } 3 \text { montons } \\
\text { "Unable so assess }\end{array}$ \\
\hline ramments & \\
\hline
\end{tabular}

